\title{
Call for an Integrative and Multi-Disciplinary Approach to Traumatic Brain Injury (TBI)
}

\author{
Alfred Mansour ${ }^{1,2}$, Renee Lajiness-0'Neill² \\ ${ }^{1}$ Origami Brain Injury Rehabilitation Center, Mason, MI, USA \\ ${ }^{2}$ Department of Psychology, Eastern Michigan University, Ypsilanti, MI, USA \\ Email: Alfred.Mansour@Origamirehab.org, rlajiness@emich.edu
}

Received 12 February 2015; accepted 2 March 2015; published 6 March 2015

Copyright (C) 2015 by authors and Scientific Research Publishing Inc.

This work is licensed under the Creative Commons Attribution International License (CC BY). http://creativecommons.org/licenses/by/4.0/

(c) (7) Open Access

\begin{abstract}
Much has been gained in our understanding of the psychopathology, assessment, and treatment of TBI. Still lacking is the breadth and depth that an integrative and multi-disciplinary approach to TBI portends. While there is a greater awareness of a need for such a systems-based approach as evidenced by the number of professional organizations and government agencies recently advocating a need for standardization in the collection data in TBI, the application of multi-dimensional approach, and the development novel strategies to deliver prevention, assessment and treatment to large, diverse populations, we are still in the early stages in making this important shift. In the nearer term, there are clinical assessment and interventional programs that can be developed and empirically validated to bring us closer to this integrative, multi-disciplinary ideal. The following review calls for a universal diagnostic classification system for TBI, integration of pathophysiology and pharmacological and rehabilitative therapies, development of treatments addressing disorders comorbid with TBI, and the delivery of assessment and treatment services to large underserved populations.
\end{abstract}

\section{Keywords}

TBI, Traumatic Brain Injury, Neuropsychological Assessment, Cognitive Rehabilitation

\section{Introduction}

Traumatic brain injury (TBI) is a major health concern causing a wide range of cognitive and behavioral impairments (Levin, 1995; Lezak \& O’Brian, 1988; Millis et al., 2001; Ponsford, Oliver, \& Curran, 1995) that of- 
ten lead to decades of disability, reduced independence, unemployment and poor social and familial relations (Machamer, Temkin, Fraser, Doctor, \& Dikmen, 2005; Sherer et al., 2002). The societal impact of such injuries is alarming. The Center for Disease Control and Prevention estimates that 5.3 million Americans have a longterm or lifelong need for help to perform activities of daily living because a brain injury (Rutland-Brown, Langlois, Thomas, \& Lily, 2006). Direct medical and indirect costs for TBI are estimated at $\$ 60$ billion in the United States in 2000 (Corso, Finkelstein, Miller, Fiebelkorn, \& Zaloshnja, 2006) and projected to increase in the years ahead with advances in intensive care, trauma medicine and rehabilitation that have dramatically improved survival rates post TBI in the last 25 years (Ghajar, 2000).

The following review documents the psychopathological, assessment, and treatment literature of TBI and demonstrates the gains achieved in our understanding of the disorder. However, for these gains to translate into improved patient functioning and a reduced overall burden to the healthcare system, there needs to be a paradigm shift. Psychopathology, assessment, and treatment are reciprocally interactive and it is the synthesis of data across these domains that should drive research and clinical decision-making. Application of the basic and clinical sciences to TBI will require a substantial shift in the classification, diagnosis, and delivery of assessment and treatment services. Proposed is an integrative, multi-disciplinary approach to TBI and suggestions for future studies.

\section{Psychopathology}

\subsection{Definition of TBI}

A traumatic brain injury (TBI) is defined by the Centers for Disease Control as "a blow or jolt to the head or a penetrating head injury that disrupts the function of the brain" (www.cdc.gov/traumaticbraininjury). The severity of such brain injury may range from "mild", where there may be a brief change in mental status or consciousness to "severe", involving an extended period of coma, unconsciousness or amnesia after the injury.

While TBI is thought to be a neurological and neurosurgical disorder, it produces a predictable cognitive and neurobehavioral clinical syndrome. Postconcussional Disorder (PCD) is, in fact, defined by the Diagnostic and Statistical Manual, $4^{\text {th }}$ Edition (DSM-IV-TR; American Psychiatric Association, 2000) as a syndrome following significant cerebral concussion resulting in quantifiable deficits in memory (learning or recalling information) or attention (concentrating, shifting focus of attention, performing simultaneous cognitive tasks) based on neuropsychological testing, and the onset, or substantial post-injury worsening of any three or more of the following symptoms: tiring easily, disordered sleep, headaches, vertigo/dizziness, irritability, anxiety/depression/affective lability, changes in personality, or apathy. The disturbances resulting from these symptoms must either have their onset following the head trauma or represent a worsening of preexisting symptoms, result in a significant decline in social or occupational functioning, and should not be better accounted for by other diagnostic categories. With more severe TBI, people may experience changes in personality, and lack self-awareness or have difficulty adjusting to their post-injury outcomes even decades after the event (Hoofien, Gilboa, Vakil, \& Donovick, 2001). While there may be residual cognitive changes following brain injury, it is the emotional, behavioral and psychosocial disturbances that form the greatest barrier to community integration and hinder the maintenance of social and family interactions, return to work, and re-establishment of quality of life (Lezak, 1987).

\subsection{Epidemiology}

1) Incidence of TBI in the United States and globally. In the United States, more than 1.7 million people sustain a TBI each year. Approximately 52,000 will likely die, 275,000 are hospitalized, and 1.365 million are treated and released from an emergency department (Rutland-Brown et al., 2006). The statistics are likely underestimations; unknown are the number of people with TBI who fail to report the event and not seen in an Emergency Department (Delaney, Abuzeyad, Correa, \& Foxford, 2005). Rates of TBI among military personnel are far higher and it is estimated that $12 \%-23 \%$ of combat veterans meet criteria of mild TBI on post deployment screening (McCrea et al., 2008; Schneiderman, Braver, \& Kang, 2008; Terrio et al., 2009).

Globally, an estimated 10 million people are affected by TBI annually (Hyder, Wunderlich, Puvanachandra, Gururaj, \& Kobusingye, 2007) and according to the World Health Organization (WHO) it will surpass many diseases as the major cause of death and disability by the year 2020. TBI is especially prominent in low and middle-income countries where there is a higher preponderance of risk factors and inadequate healthcare sys- 
tems. In developed westernized societies, the rates of TBI are increasing, especially in those over 60 years old (Dhruva \& Redberg, 2008). Further altering the epidemiological and clinical pattern of TBI is the increasing burden of military conflict and exposure of civilians in combat zones (Risdall \& Menon, 2011). Internationally, TBI has devastating effects on patients, their families, and pose high socioeconomic costs to us all.

2) Leading causes of TBI. In the United States, the leading causes of TBI are falls (35.2\%), motor vehicle-traffic crashes (17.3\%), struck by/against events (16.5\%), assaults (10\%), and those due to unknown causes (21\%). Within the war zone military population, blasts from explosive devices are the leading cause of TBI and the pathophysiology of these injuries may differ substantially from those produced by motor vehicle accidents and falls (Cernak \& Noble-Haeusslein, 2010). In the civilian population, risk will vary with age, gender and racial group. A higher proportion of African Americans, for example, experience brain injuries from assaults (Arango-Lasprilla et al., 2007; Burnett Silver, Kolakowsky-Hayner, \& Cifu, 2000; Hart, Whyte, Polansky, Kersey-Matusiak, \& Fidler-Sheppard, 2005; Sherer et al., 2003), while individuals above the age of 65 or below the age of 4 experience a disproportionate number of TBIs caused by falls (Sosin, Sniezek, \& Thurman, 1996).

3) TBI risk factors. In the civilian population, males are 1.5 times as likely as females to sustain a TBI (Guerrero, Thurman, \& Sniezek, 2000; Sosin et al., 1996). The age groups at highest risk for TBI are 0 - 4 years old, 15 - 24 years old and those over the age of 65 (Ghajar, 2000; Kraus \& Chu, 2005; Sosin et al., 1996). As a racial group, African Americans are more likely to experience a TBI and have the highest death rate from such trauma (Cooper et al., 1983). Alcohol consumption is a specific risk factor, with alcohol blood levels positively correlated with TBI risk (Smith \& Kraus, 1988). A prior history of traumatic brain injury also increases risk of a subsequent TBI: increasing it 2-fold with one prior TBI and 8-fold with two or more prior brain injuries (Gualtieri \& Cox, 1991; Salcido \& Costich, 1992). Genetic factors influence outcome, with individuals with the APOE E4 gene, as well as, polymorphisms in the Interleukin-1 (IL-1) system are at significantly increased the risk of poorer neurological outcomes (Hadjigeorgiou et al., 2005; Isoniemi, Tenovuo, Portin, Himanen, \& Kairisto, 2006; Teasdale, Nicoll, Murray, \& Fiddes, 1997).

\subsection{Classification Schemes of TBI}

Historically, the classification of TBI is based on the severity of the injury as measured by the Glasgow Coma Scale (GCS), whether there is a loss of consciousness (LOC) or the length of posttraumatic amnesia (PTA). Originally described by Teasdale and Jennett (1974), the GCS differentiates mild (15 - 13), moderate (12 - 9) and severe (8 - 3) TBI and while it has proved to be extremely useful in the clinical management of TBI, it does not provide specific information concerning the pathophysiological and neuropsychological deficits associated with the injury. More recently, clinicians have further differentiated mild TBI into those with positive signs on computerized tomography (CT) or magnetic resonance imaging (MRI) scans versus those with negative brain imagining results. Mild TBI with positive brain imaging results are referred to as complicated mild TBI and behaviorally and functionally more closely resemble moderate TBI (Borgaro, Prigatano, Kwasnica, \& Rexer, 2003; Kashluba, Hanks, Casey, \& Millis, 2008; Kurca, Sivak, \& Kucera, 2006; Lange, Iverson, \& Franzen, 2009), while those with negative brain imaging scans are referred to as uncomplicated mild TBI. Based on the Marshall scoring system (Maas, Hukkelhoven, Marshall, \& Steyerberg, 2005), similar distinctions are made in moderate and severe TBI.

Despite efforts for greater diagnostic precision, the vast majority of clinical studies continue to differentiate TBI patients as mild, moderate or severe based on the GCS, PTA or LOC. Such scales and measures fail, however, to account for the heterogeneity of deficits and the variable outcomes seen with TBI that depend not only on the severity of the trauma, but the specific neuronal systems that are compromised, pre-morbid functioning, and the quality and intensity of post-injury support and rehabilitative care. Moderating factors affecting the severity of TBI include advancing age that is associated with increased mortality, especially after age 65 (Gomez et al., 2000; Susman et al., 2002), cognitive vulnerabilities and past history of depression and anxiety (Goldstein, Levin, Goldman, Clark, \& Attonen, 2001), and environmental factors such as, marital or employment status prior to the injury (Whiteneck, Gerhart, \& Cusick, 2004). Repeated traumatic brain injuries, even when mild, leave an individual neurobiologically compromised and vulnerable to a subsequent brain trauma (Gronwall \& Wrightson, 1975; Salcido \& Costich, 1992). Pre-injury alcohol use, which has a potentiating effect on the injury, is also associated with poorer neuropsychological performance and outcomes, even when demographic and event severity are controlled (Baguley et al., 1997; Cunningham, Maio, Hill, \& Zink, 2002). Cognitive and neu- 
robehavioral deficits generally associated with different severities of injury are presented below to illustrate the richness of clinical presentation seen in TBI.

1) Mild TBI. Mild TBI comprises 70\% - 80\% of all the brain injury cases in the Emergency Department (Udekwu, Kromhout-Schiro, Vaslef, Baker, \& Oller, 2004). Immediately following a mild TBI or a concussion, individuals can experience a wide variety of symptoms that can include headaches, sensitivity to light and sound, dizziness, disorientation, fatigue, disturbed sleep and emotional lability. Commonly, people will report difficulty concentrating, thinking, focusing, excessive tiredness, memory problems and being irritable. Meta analyses suggest that these symptoms typically resolve within three months of the trauma (Frencham, Fox, \& Mayberry, 2005; Larrabee et al., 1997; Schretlen \& Shapiro, 2003), but a significant minority of mild TBI patients (7\% to 33\%) have residual deficits in the speed of processing information, memory, and attention (Bernstein, 2002; Bigler, 2008; Mathias, Beall, \& Bigler, 2004). Individuals with complicated mild TBI fare worse and have deficits at 3 months and a year following TBI (Borgaro et al., 2003; Goldstein \& Levin, 2001; Kashluba et al., 2008; Kurca et al., 2006) and have a higher risk of developing epilepsy (Diaz-Arrastia et al., 2009), further complicating the clinical presentation.

If the symptoms of mild TBI persist for more than 3 months, the term that is used is persistent post-concussive syndrome or PPCS (Begaz, Kyriacou, Segal, \& Bazarian, 2006; Iverson, 2006; McCauley, Boake, Levin, Contant, \& Song, 2001). Clinically, individuals with PPCS will have symptoms of impaired attention, memory, and executive function along with difficulties in emotional regulation, depression and anxiety (Lundin, de Boussard, Edman, \& Borg, 2006). While there is a relationship between trauma severity and the subsequent development of PPCS, severity itself is a poor predictor of who develops PPCS (Ponsford et al., 2000; Guskiewicz et al., 2004) and the appearance of PPCS may be more related to pre-morbid psychopathology and coping behaviors.

2) Moderate TBI. Comprising 15\% - 25\% of all TBIs, impairments associated with moderate TBI are not well understood due to the great deal of overlap at one end of the spectrum with mild TBI, and on the other, with severe TBI. Patients with moderate TBI will recover in the months following the trauma, with the vast majority of the improvement occurring within the first year of the injury (Dikmen, Ross, Machamer, \& Temkin, 1995). While most can lead independent lives, moderate TBI patients tend to have pervasive, long-standing cognitive deficits, are emotionally dysregulated, and experience significant anxiety and depression (Hiott \& Labbate, 2002; Robinson \& Jorge, 2002). Return to work is more variable, with many moderate TBI patients unable to achieve sustained employment or become fully integrated into their community (Machamer et al., 2005; Sherer et al., 2002). Other factors such as lower levels of education, increased distractibility, and higher levels of neuroticism at time of injury are also associated with decreased likelihood of employment, marriage and having a driver's license following a brain injury (Schretlen, 2000).

3) Severe TBI. Whereas the total number of severe TBI is comparatively small, estimated at $5 \%-10 \%$ of all brain injuries, they disproportionately affect the health care system due the intensive, life-long medical, psychological and rehabilitative care that individuals sustaining such injuries will require. While there may be some recovery of functioning in the first year following injury, severe TBI patients will continue to have cognitive deficits with impairments in attention, processing speed, working memory, executive function, visuo-spatial skills, prospective, short term and long term memory and the ability to encode and learn new information (Azouvi, Vallat-Azouvi, \& Belmont, 2009; Bate, Mathias, \& Crawford, 2001; Dikmen et al., 1995; Ponsford \& Kinsella, 1992; Ruff, Evans, \& Marshall, 1986). The greatest obstacles to vocational reintegration are executive in nature and include problems in initiating, planning, decision-making, flexibility, organization and self-control, making it difficult to find and maintain employment (Brooks, Mckinlay, Symington, Beattie, \& Campsie, 1987).

\subsection{Post-Acute TBI}

1) Psychological deficits. Moderate and severe TBI patients are at particular risk of developing mental heath disorders with the symptoms of depression, anxiety, emotional withdrawal, anger/aggression and apathy typically worsening in the first 6 months post the traumatic event (Dunlop et al., 1991; Iverson, 2006; Levine, Dawson, Boutet, Schwartz, \& Stuss, 2000; Temkin, Corrigan, Dikmen, \& Machamer, 2009). Combined with impaired judgment, poor insight, self-awareness and self-monitoring (Flashman \& McAllister, 2002; Hart, Seignourel, \& Sherer, 2009), increased impulsivity, and memory and social skills deficits, it is not surprising that TBI patients may have psychosocial and interpersonal problems and poorly integrate into their communities and 
families without a comprehensive program of rehabilitation. Pre-morbid emotional and personality characteristics may become exaggerated or muted, while in others there may be a dramatic change in personality (Prigatano, 1992; Warriner \& Velikonja, 2006). Paranoia and schizophrenia-like symptoms may appear after moderate and severe TBI and characterized by negative symptoms such as, heightened suspiciousness and social withdrawal, rather than delusions and hallucinations (Guerreiro, Navarro, Silva, Carvalho, \& Gois, 2009; Zhang \& Sachdev, 2003).

2) Family dysregulation. The impact of TBI is not limited to the person who has experienced the injury, but has profound effects on the family (Camplair, Butler, \& Lezak, 2003; Florian, Katz, \& Lahav, 1989; Kaitaro, Koskinen, \& Kaipo, 1995; Marsh, Kersel, Havill, \& Sleigh, 2002). Most distressing to family members of patients with moderate to severe TBI are the increased aggression, irritability and temper outbursts, social withdrawal and emotional lability. Physical impairments add to the burden, and families become socially isolated, exacerbating feelings of life dissatisfaction, depression and hopelessness (Camplair et al., 2003; Harris, Godfrey, Partridge, \& Knight, 2001). Psychotherapeutic treatments focused solely on the TBI patient are clearly insufficient and a biosocial systems approach that includes the patient's family and social group are necessary.

\subsection{Comorbidities with TBI}

Several psychiatric comorbidities, particularly mood and anxiety disorders and substance abuse, have been associated with TBI (Fann, Katon, Uomoto, \& Esselman, 1995; Iverson, 2006; Levine et al., 2000; Rogers \& Read, 2007; van Reekum, Cohen, \& Wong, 2000). The appearance of these behavioral symptoms and disorders is dependent on the physical, cognitive and emotional deficits following TBI, pre-morbid personality traits and the psychosocial environmental factors (Deb, Lyons, Koutzoukis, Ali, \& McCarthy, 1999; Rao \& Lyketsos, 2002).

1) Mood disorders. Rates (18.5\% to 61\%) of comorbid Major Depression and TBI vary widely (Kim et al., 2007) and influenced by both pre-morbid factors and lesion location (Simpson \& Tate, 2007; Teasdale \& Engberg, 2001). The onset of symptoms following TBI is also variable, with some patients meeting criteria for Major Depression at discharge, while others not meeting criteria for months or years later (Dikmen, Bombardier, Machamer, Fann, \& Temkin, 2004; Kreutzer, Seel, \& Gourley, 2001; Seel et al., 2003). The risk and severity of developing Major Depression is particularly high in the first 3 - 12 months following a traumatic brain injury (Jorge et al., 2004) and deceases with time from injury in the first 6 years post-injury (Ashman, Gordon, Cantor, \& Hibbard, 2006; Dikmen et al., 2004). Other risk factors associated with TBI and comorbid depression include socioeconomic factors, minority status, unemployment and low income, history of psychiatric disorders and alcohol abuse, and less than 12 years of education (Ashman et al., 2006; Jorge et al., 2004). In general, patients receiving a dual diagnosis of both TBI and Major Depression have much poorer outcomes relative to those diagnosed with TBI alone (Levin et al., 2001; Mooney \& Speed, 2001).

2) Anxiety disorders. TBI patients also have higher rates (24.5\% - 44\%) of Generalized Anxiety Disorder (GAD) (Fann et al., 1995; Hoofien et al., 2001) and Post-Traumatic Stress Disorder (PTSD; 17\% - 33\%) and a dual psychiatric diagnosis of TBI and GAD or PTSD is associated with poorer outcomes and course of recovery. The risk of a comorbid PTSD diagnosis is highest with mild and moderate injury, when there may be a minimum of posttraumatic amnesia (Bryant et al., 2009; Harvey \& Bryant, 2000). Pre-morbid factors associated with an increased risk of developing PTSD with TBI include lower socioeconomic status (Brewin, Andrews, \& Valentine, 2000), use of avoidance coping strategies (Ehlers, Mayou, \& Bryant, 1998), prior history of trauma or psychiatric problems (Friedman, Schnurr, \& McDonagh-Coyle, 1994), and limited social support (Brewin et al., 2000). As seen more generally in treating TBI, social support is the dominant moderating factor, such that increased social support is associated with decreased symptoms of psychiatric disorders, and improvement in long-term survival and community integration (Douglas \& Spellacy, 2000; Lezak, 1987; Oddy, Coughlan, Tyerman, \& Jenkins, 1985). The high rates of comorbidity of TBI, chronic pain and PTSD in military veterans (42\%), particularly those who served in Afghanistan and Iraq, highlight the fundamental need for an interdisplinary approach to treat this population and address their unique needs (Otis, McGlinchey, Vasterling, \& Kerns, 2011).

3) Impulse control and substance abuse disorders. TBI may also result in some individuals developing impulsive behaviors or Impulse Control Disorders (Rochat et al., 2010). This is particularly true when the damage has been to the frontal cortical areas of the brain (Jentsch \& Taylor, 1999) and has been associated with high rates of substance abuse and risk taking behaviors (van Reekum et al., 2000). Thirty-six to fifty-one percent of people 
experiencing a TBI will be intoxicated at time of injury (Corrigan, 1995; Parry-Jones, Vaughan, \& Cox, 2006). A disproportionate number of those intoxicated will be younger, will be men, will be injured in a motor vehicle accident and assaults, and have a history of alcohol abuse (55\% - 66\%). Those TBIs with positive blood alcohol levels will have more medical complications such as longer stays on a ventilator (Chatham-Showalter et al., 1996), longer acute hospital stays, show poorer neuropsychological test performance (Bombardier \& Thurber, 1998; Tate, Freed, Bombardier, Harter, \& Brinkman, 1999), and significantly poorer functional outcomes (Corrigan, 1995; Parry-Jones et al., 2006). Rates of substance abuse post-injury are inversely related to functional status, with higher rates in individuals with fewer residual deficits (Bombardier, Temkin, Machamer, \& Dikmen, 2003; Kreutzer, Witol, \& Marwitz, 1996).

\subsection{Pathophysiology of TBI}

1) Physics of TBI. The physics of brain injury are complex and involve interplay of focal damage occurring when an object hits the skull or when the brain is jolted against the interior surface of the skull, and diffuse damage, which results from the rapid acceleration, deceleration and rotation of the brain (Bandak, 1995). With acceleration/deceleration injuries, particularly when there is some rotation force (Zhang, Yoganandan, Pintar, \& Gennarelli, 2006), there is a high risk of developing diffuse axonal injury (DAI), which results in microscopic tears and hemorrhages being formed throughout the brain (Marshall, 2000). Shearing effects are greatest at the boundaries between white and gray matter and most frequently occurs in the frontal and temporal lobe regions (Bigler, 1996; Kurth, Bigler, \& Blatter, 1994). Particularly vulnerable to DAI are the cerebral commissures that are important for inter- and intrahemispheric communication, as the anterior commissure, internal capsule and corpus callosum, as well as, other major fiber tracts as, the fornix, and ascending and descending fiber tracts of the brainstem (Bigler, 2001; Gale, Johnson, Bigler, \& Blatter, 1995; Tomaiuolo et al., 2005; Li, Zhang, Yoganandan, Pintar, \& Gennarelli, 2007). Damage to these major fiber systems have been observed even with mild brain injury (Niogi et al., 2008a, b) and likely associated with the cognitive losses in processing efficiency, attention and memory, as well as, the neurobehavioral changes seen with TBI. Common brain regions and white matter pathways identified to be altered both with TBI and Major Depression include the frontotemporal lobes, corpus callosum, and structures within the basal ganglia, suggestive that damage to these brain areas may be important, at least in part, for the etiology of the depressive symptoms following TBI (Maller et al., 2010).

In addition to interrupting intra- and interhemsipheric communication, the biomechanics of the injury put the brain in direct, forceful contact with the boney fossa of the cranium, resulting in a focal injury of the upper brainstem, pituitary-hypothalamic area, medial temporal lobe, prefrontal lobe and basal forebrain, likely contributing to the broad array of autonomic, hormonal, emotional, cognitive and neurobehavioral and neurotransmitter system changes seen with TBI (Bigler, 2007, 2008). Depending on the severity of the TBI, other secondary complications/injuries, such as the development of a subdural hematoma, edema, increased intracranial pressure, ischemia and hypoxia, can occur in the acute stages of injury, complicating the clinical presentation (Zink, 1996) and contributing to an increased mortality and morbidity.

2) Cellular response to TBI. At a cellular level, neuronal injury results in breaks being formed in the axonal membrane, initiating a series of excitotoxic, inflammatory and metabolic cascades that evolve over minutes to daybes post-injury (Novack, Dillon, \& Jackson, 1996). Excessive glutamate and aspartate rush into the cells, depolarizing them, and increasing the permeability of calcium and potassium. Calcium activates lipid peroxidases, proteases and phospholipases that in turn increase intracellular free fatty acids and free radicals. Left unchecked, the cells fire uncontrollably until all ATP reserves are depleted and the cells enter into a state of oxidative stress, and ultimately, apoptosis or cell death (Siesj, 1993). One can visualize the cellular damage by following inflammatory markers and biomarker of cell injury at time of brain injury. For example, inflammatory reactions and hemosiderin deposits occur in the perivascular space in response to injury and are associated with white matter damage (Bigler, 2003; Konsman, Drukarch, \& Van Dam, 2007). With time, as the cells die and neuronal fibers degenerate, evidence of atrophy and cellular and axonal loss can be measured in the chronic phase of TBI using structural imaging methods as, MRI and diffusion tensor imaging (DTI). The period of degeneration varies with individual patient characteristics, course of treatment and severity of injury, but generally is complete by 3 - 6 months post-injury in mild to moderate TBI (Bigler, Kurth, Blatter, \& Abildskov, 1992).

3) Anatomical studies

a) Structural imaging studies. Particularly with moderate and severe TBI, quantitative MRI studies have consistently shown a reduction in the size of the corpus callosum, a direct measure of white matter loss, and the ex- 
pansion of the ventricular space, an indirect measure of gray and white matter loss (Gale, Burr, Bigler, \& Blatter, 1993; Gale et al., 1995). Both of these morphometric results correlate with TBI severity, with the greatest changes in these measures indicative of white matter loss and cellular atrophy, lower GCS values, and poorer neuropsychological testing results (Anderson \& Bigler, 1994; Levine et al., 2006; Mathias et al., 2004). Similarly, dilation of the temporal horn of the ventricular system, which is reflective of degeneration of amygdalahippocampal-fornix formation, is associated with greater neuropsychological impairment (Gale et al., 1993, 1995).

Among specific neuronal systems, the frontal lobes, particularly the orbitofrontal, the temporal lobes, midbrain and hypothalamic-pituitary axis are especially vulnerable to damage from TBI (Bigler, 1996). Within the mesial temporal lobe, the hippocampal formation appears to be particularly sensitive to damage, as cellular losses and atrophy of the hippocampus is present regardless of the point of injury and likely accounts for the memory deficits associated with TBI. Loss of fibers in the fornix, a major fiber tract carrying information from the hippocampus, correlates with TBI severity, suggesting that the damage with TBI is continuous with severity and that hippocampal dysregulation is present even in mild forms of the disorder (Bigler, 2008; Blumbergs et al., 1995). Despite the recovery seen in the majority of mild TBI patients, the injury often produces long-lastly, perhaps permanent effects on the brain as evidenced by the pathophysiological findings presented above and the observation that subsequent brain injury invariably produces more severe effects than would be expected with denovo trauma (Gronwall \& Wrightson, 1975; Salcido \& Costich, 1992). Central midline structures, including pontine tegmentum, periaqueductal gray, substantia nigra and thalamus, are also vulnerable to TBI. These brain areas are critical in neuroregulatory functions and in maintaining the sleep-arousal cycle. Dysfunction in these brain regions may account for some of the disruption of attention and concentration seen with TBI.

b) Functional imaging studies. Functional imaging techniques as, positron emission tomography (PET), single photon emission tomography (SPECT), and functional MRI (fMRI) permit a more direct comparison of brain activity and cognitive and behavioral functioning. Several studies suggest that TBI is associated with a hypometabolism or decreased resting blood flow, most prominently, in the frontal cortex (Abdel-Dayem et al., 1998; Fontaine, Azouvi, Remy, Bussel, \& Samson, 1999; Gross, Kling, Henry, Herndon, \& Lavretsky, 1996; Langfitt et al., 1986; Ruff et al., 1994). While such changes in metabolic activity and blood utilization may be indicative of possible pathology, these findings are not specific and observed in number of neurological and psychiatric disorders (Dunn et al., 2002; Ketter et al., 2001). Activation paradigms, that link brain activity to specific behaviors, address this issue and attempt to identify unique, behaviorally driven brain imaging activation patterns. For example, Ricker, Hillary, and DeLuca (2001) demonstrated a decrease in left frontal lobe oxygen utilization with PET imaging in moderate to severe TBI patients during a free retrieval verbal memory task when compared to controls, but an increased utilization in more posterior brain regions during both free and cued recall. While there are multiple explanations for these results, the increased oxygen utilization in the posterior regions of the brain in conjunction with a decreased activation in left frontal lobe suggests a possible reallocation of cognitive processes to more primitive brain areas.

Functional MRI studies using working and episodic memory paradigms have similarly shown that there may be a reallocation of cognitive processing following TBI. On working memory tasks, when compared to controls, moderate to severe TBI patients show a reduced right dorsolateral prefrontal, left inferior frontal, and left parietal activation with increases in working memory load (Perlstein et al., 2004). Using a similar n-back working memory task, McAllister and colleagues (2001) examined the effects of memory load or difficulty in mild TBI and non-injured controls. The investigators found a main effect of working memory load across groups, with activation seen in the left and right middle frontal gyri, bilateral medial parietal cortex, right parietal cortex and the left superior parietal lobe. Mild TBI patients show less activation than controls in the 0-back and the 1-back comparisons, but show a more extensive activation as working memory load increases from 1-back to 2-back, when compared to the non-injured controls, suggestive of less efficient allocation and processing of memory information. Similar differences in functional activation and imaging have been also been reported in concussed athletes who experienced persistent symptoms following a mild TBI (Chen et al., 2004).

Injury severity is major factor in assessing functional activation following TBI. Using a stimulus response compatibility task and fMRI at 3 months post-injury, Scheibel and colleagues (2009) demonstrated that patients with GCS of 8 or less showed increased, diffuse activation that included structures thought to mediate visual attention and cognitive control. The cingulate gyrus and thalamus were among the brain areas showing the greatest increases, consistent with increased vulnerability of these midline structures with severe, diffuse TBI. There 
were differences in the over activation pattern that varied with TBI severity, including a greater reliance on left lateralized brain structures in the patients with the most severe injuries and better task performance associated with higher levels of activation, suggestive that over activation in TBI, while inefficient, may be partially effective in improving performance and have a compensatory function.

4) Neurotransmitter systems and TBI

a) Dysregulation of glutamatergic, dopaminergic, and cholinergic systems. Given the frontal-temporal pathophysiology of TBI, with particular vulnerability of the basal ganglia, amygdala-hippocampal-fornix formation, and hypothalamic-pituitary axis, as well as, central midline structures, including pontine tegmentum, periaqueductal gray, substantia nigra and thalamus, it is not surprising that dysregulation in the glutamatergic, dopaminergic, and cholinergic systems have been implicated with TBI (Griffin, van Reekum, \& Masanic, 2003; Wheaton, Mathias, \& Vink, 2009; Writer \& Schillerstein, 2009). Traditionally, research in recovery of function after TBI has focused on preventing cellular events related to brain trauma, including blocking glutamate induced excitotoxicity, inhibiting apoptosis and reducing oxidative stress, with the premise that sparing neuronal cell death and axonal damage would result in improved functional outcome. Despite the preponderance of evidence from animal studies showing the neuroprotective effects of glutamatergic blockade with NMDA antagonists (Jennings, Gerber, \& Vallano, 2008), the results have not translated well in the clinic.

Clinical evidence that dopamine systems are altered following TBI is based on the consistent findings that catecholaminergic stimulants, as methylphenidate, and dopaminergic agonists, amantadine and bromocriptine, attenuate the cognitive deficits in attention, information processing speed, working memory, and executive functioning associated with TBI (Warden et al., 2006; Wheaton et al., 2009) and SPECT imaging data showing a decrease in dopamine transporters in the striatum of severe TBI patients 4 - 5 months post-injury (Donnemiller et al., 2000). Deficiencies in dopaminergic transmission may underlie, at least in part, the chronic affective, motivational and emotional changes with TBI.

Cholinergic systems have also been implicated, as evidence suggests that there is an initial period of hypercholinergic activity in the brain following TBI that is followed by a more chronic state of hypocholinergic activity (McIntosh, Juhler, \& Wieloch, 1998) and reduced cholinergic levels in the basal forebrain, hippocampus and temporal, cingulate and parietal cortical areas on post-mortem examination (Dewar \& Graham, 1996; Murdoch, Perry, Court, Graham, \& Dewar, 1998). These long-term deficits in cholinergic neuronal transmission may account for the memory and attention impairments, social interactive and cognitive deficits, and increased risk of Alzheimer's dementia with TBI (Deb, Lyons, \& Koutzoukis, 1998). Consistent with these findings, cholinesterase inhibitors, as donepezil, that increase the available levels of acetylcholine in the brain, have been shown to improve attention and memory in moderate to severe TBI at 2 - 24 months post-injury (Zhang, Plotkin, Wang, Sandel, \& Lee, 2004).

\section{Assessment of TBI}

\subsection{Acute, Subacute and Chronic TBI}

Assessment strategies vary with the phase of TBI, with some measures and protocols relevant to a specific phase, while others are used at multiple phases of recovery. In the acute phase (immediately after the injury and mintutes to days post), levels of consciousness and gross motor, visual and cognitive responsiveness provide indices of possible brain injury. Depending on the nature of the trauma and the behavioral presentation, brain scans (CT or MRI) are ordered to assess possible, skull fracture, edema or hemorrhage that would require immediate medical treatment. Once PTA has resolved and the patient is medically stable (subacute phase), formal neuropsychological testing may begin, with follow-up evaluations performed at 6 to 12 months intervals to monitor recovery (Sherer \& Novack, 2003). While not standard of care, advanced neuroimaging methods, as DTI and MRS, and prognostic biological markers can be used at all three phases acute, subacute and chronic TBI to follow neuroplastic and degenerative changes. Functional outcome measures as, quality of life measures, employment status and productivity, and community integration, are used in the chronic phase, which begins 3 - 12 months post-injury, depending on the severity of the brain injury.

\subsection{Assessment of the Level of Consciousness}

TBI severity is assessed by the Glasgow Coma Scale (GCS), loss of consciousness (LOC; 30 minutes or less is 
mild TBI), or posttraumatic amnesia (PTA). The GCS is a 15-point scale that divides patients into mild (13 - 15), moderate $(9-12)$ and severe $(3-8)$ TBI based on that measures eye opening, verbal responses and motor movements and reflexes. Duration of PTA is prospectively defined by serial assessments of a person's degree of disorientation using the Galveston Orientation and Amnesia Test (GOAT; Levin, O'Donnell, \& Grossman, 1979). TBI patients with less than 1 hour of PTA are classified as mild, 1 - 24 hours of PTA as moderate, 1 - 7 days of PTA as severe (Russell \& Smith, 1961). While GCS scores and duration of PTA are correlated with one another (Levin, Benton, \& Grossman, 1982), length of PTA is more accurate than GCS and LOC in predicting cognitive status at two years post-injury and eventual return to work (Brooks, Aughton, Bond, Jones, \& Rizvi, 1980; Cattelani, Tanzi, Lombardi, \& Mazzucchi, 2002). To gain a finer grade of functional assessment in the acute phase of TBI, the Rancho Los Amigos Scale (RLAS; Zafonte et al., 1996) was developed that is a 10-level scale, with Level I, for example, corresponding to no response, Level V is confused, inappropriate, nonagitated, and Level X corresponding to purposeful, appropriate and independent. While the RLAS provides more information regarding cognitive and emotional functioning, it suffers from the same problems as the GCS, LOC and PTA, in that, it provides little or more data regarding the pathophysiology of the injury, resulting in a great deal of variability at each of the RLAS levels.

\subsection{Brain Imaging as an Assessment Measure of TBI}

With the introduction of advanced structural and functional brain imaging techniques, new tools are now available to assess underlying brain systems associated with traumatic brain injury (McAllister, Sparling, Flashman, \& Saykin, 2001; Belanger, Vanderploeg, Curtiss, \& Warden, 2007). Computer Tomography (CT) and Magnetic Resonance Imaging (MRI) are the primary structural imaging technologies used in acute clinical diagnosis and management of TBI, while fMRI, PET, SPECT, and Magnetoencepahology (MEG) are functional imaging technologies that are not currently standard of care, but show promise in aiding in the assessment and monitoring of recovery of TBI.

CT scans are cost-effective in detecting gross anomalies, as brain hemorrhage, edema and skull fracture (Stein, Burnett, \& Glick, 2006), but lack the spatial resolution that is possible with MRI to detect more subtle neuronal injury (Jenkins, Teasdale, Hadley, Macpherson, \& Rowan, 1986). While superior in assessing permanent pathological changes associated with moderate and severe TBI and well correlated with TBI severity (Levin et al., 1987), volumetric MRI results only modestly relate to rehabilitative potential and functional performance post-injury. The physiological and functional integrity of the brain is far more extensively disrupted than would be implied by traditional volumetric MRI, making this method of neuroimaging comparatively insensitive in predicting functional outcome and guiding treatment. In fact, $43 \%$ to $68 \%$ of mild TBI patients have normal clinical scans on MRI (Hughes et al., 2004). This discrepancy between structure and functional imaging is particular evident when the two modalities are compared in the same TBI patients. In such a comparison, perfusion SPECT and PET imaging show far broader neuronal dysfunction than with quantitative MRI (Abdel-Dayem et al., 1998; Kesler, Adams, \& Bigler, 2000). Further, 75\% of a group of mild TBI patients with persistent postconcussional symptoms had normal MRI scans at time of injury, yet later displayed frontal and temporal lobe abnormalities on PET and SPECT (Umile, Sandel Alavi, Terry, \& Plotkin, 2002).

Magnetic Resonance Spectroscopy (MRS), a form of magnetic resonance imaging, is used to measure specific metabolites and neurotransmitters in the living brain. For a specified imaging voxel, MRS allows the noninvasive measurement of specific neurotransmitters or other chemicals in an anatomical context (Sanders, 1995). MRS measurement of N-aceytl-L-aspartate (NAA), a marker of neuronal integrity, is of particular interest, as NAA levels are reduced with acute TBI and associated with neuropsychological outcome (Friedman et al., 1999; Holshouser et al., 2006). Other metabolites measured by MRS are choline that is a marker of inflammation (Brenner et al., 1993), myo-inositol, a glial marker (Bitsch et al., 1999), lactate, an indirect indicator of ischemia and hypoxia (Nakai, Rhine, Enzmann, Stevensom, \& Spielman, 1996), and creatine and phosphocreatine, which are indices of energy metabolism (Anderson et al., 1990). Each of these MRS metabolic markers has been used with varying degrees of success in assessing the changes with TBI (Belanger et al., 2007). Support for MRS as a promising assessment modality comes from studies as those of Babikian and colleagues (2006) that demonstrated that regional measures of ratios of NAA/choline and NAA/creatine obtained after 1 - 2 weeks after TBI in children accounted for $40 \%$ of the variance in cognitive functioning 1 - 4 years post-injury.

Diffusion Tensor Imaging (DTI), which measures the integrity of white matter pathways (Pierpaoli, Jezzard, 
Basser, Barnett, \& Di Chiro, 1996), has been used to quantify the degree of diffuse axonal injury (DAI) associated with TBI. In several brain regions including, the anterior corona radiata, uncinate fasciculus, the genu of the corpus callosum, inferior longitudinal fasciculus and cingulum bundle, DAI at 1-month post mild TBI was significantly correlated with slower reaction times (Niogi et al., 2008a, b) and at a 12-month follow-up, TBI patients with good overall outcomes showed recovery of white matter functioning (Sidaros et al., 2008).

With the future development of normative standards and procedures, fMRI and PET have the potential to yield rich clinical data and provide a stronger link between the neural changes associated with TBI and behavioral and treatment outcomes. In fMRI, brain activation is inferred based on the MR characteristics of oxy- and deoxyhemoglobin (Lewine \& Orrison, 1995). Neuronal activity is associated with increased utilization of oxygen, resulting in a high ratio of deoxy- to oxyhemoglobin. In PET imaging, cerebral blood flow or the utilization of either oxygen or glucose is measured within a precise anatomical context and high temporal fidelity to provide an index of neuron activity (Yamamoto, Thompson, Meyer, Robertson, \& Feindel, 1977). As review above with fMRI, PET imaging studies demonstrate persistent altered neuronal activity with TBI that are task and cognitive load dependent and reflective of inefficient, possibly compensatory changes with brain injury (Ricker et al., 2001; Perlstein et al., 2004; McAllister et al., 2001; Levine et al., 2002; Scheibel et al., 2009).

\subsection{Prognostic Biological Markers}

Advances in neurotrauma neuroproteomics have identified several candidates that may serve as TBI specific biomarkers (Ottens et al., 2006). The clinical relevance of these biomarkers is currently under investigation and although there is no consensus, the ones that are generating the most interest include lactate dehydrogenase (LDH), glial fibrillary acid protein (GFAP), neuron specific enolase (NSE), and S-100 $\beta$ (Begaz et al., 2006). Damage of neurons and glia causes the leakage of certain proteins into the extracellular matrix and cerebrospinal fluid. As the blood-brain barrier is compromise with TBI, these proteins gain access to the peripheral circulation where they can be sampled. S-100, a calcium binding protein involved in intracellular growth and transport is synthesized in astroglia and Schwann cells in the CNS and is not detectable in serum under non-neurodegenerative or non-neurotrauma conditions. The beta sub-chain, $S-100 \beta$, has been the most widely studied biomarker for TBI, and while there are methodological differences in the literature, a S- $100 \beta$ cutoff of $.5 \mathrm{mcg} / \mathrm{liter}$ is the most consistent acute stage predictor of post-concussion symptoms and the diagnosis of a TBI (Savola \& Hillbom, 2003; Stranjalis et al., 2004). Higher concentrations of serum protein S-100 $\beta$ obtained within the first 12 hours of severe TBI are associated with severity of the injury based on GCS and PTA and poorer performance across neuropsychological cognitive domains (Watt, Shores, Baguley, Dorsch, \& Feamside, 2006). The initial rise in serum S-100 $\beta$ is followed by a significant decrease over the next 24 hours, falling to undetectable levels at 7 days post-injury.

\subsection{Comprehensive Neuropsychological Assessment}

Given the broad range of deficits seen with TBI, a neuropsychological evaluation will need to be comprehensive and assess all the cognitive domains, as well as, psychiatric, interpersonal, and emotional functioning to be able to make accurate assessment and develop a rehabilitative treatment plan (Podell, Gifford, Bougakov, \& Goldbrg, 2010). While the use of the term cognitive domain implies a sharp separation of skills and functions, there is far more blurring of the boundaries between domains, particularly between attention, working memory and executive function and the neuropsychological tests designed to test them. Neuropsychological batteries may be "fixed" as the Halstead-Reitan Battery (Reitan \& Wolfson, 1985) or a more flexible set of neuropsychological tests that are designed assess the specific deficits and strengths of the patient (Larrabee, Millis, \& Meyers, 2008). In practice, most clinicians employ a fixed group of neuropsychological tests and modify the protocol depending of the individual needs of the TBI patient, their age and pre-morbid functioning, the clinical history and interview, time post-injury and the referral question. A prototypical neuropsychological assessment battery for TBI that may be modified to meet the needs of the patient and testing setting is presented in Table 1.

The assessment of attention is essential, as other cognitive abilities as, memory and learning, build on it. Attention impairments, the most common deficits observed with TBI, include deficits in arousal, particularly acutely, attention span, focused attention or the ability to attend to a target and ignore irrelevant stimuli, and divided attention, or the ability to attend to more than one stimulus at a time (Mathias \& Wheaton, 2007). Mild TBI patients often complain of impaired "memory", but these are usually a product of attention problems (re- 
Table 1. Neuropsychological assessment measures relevant to traumatic brain injury. (a) Assessment of attention; (b) Assessment of memory; (c) Assessment of executive function; (d) Assessment of language; (e) Assessment of visuospatial and visuomotor function; (f) Assessment of motor function; (g) Assessment of affect and personality; (h) Assessment of effort.

(a) ASSESSMENT OF ATTENTION

\begin{tabular}{|c|c|c|c|}
\hline Instrument & General description & Reliability data & Validity data \\
\hline $\begin{array}{l}\text { Digit Span (Wechsler } \\
\text { Adult Intelligence } \\
\text { Scale-IV; Wechsler, } \\
\text { 2008) }\end{array}$ & $\begin{array}{l}\text { A core Working Memory subtest of } \\
\text { the WAIS-IV that has three distinct } \\
\text { tasks that require repeating a series of } \\
\text { digits forward, backward, and in } \\
\text { ascending order. }\end{array}$ & $\begin{array}{l}\text { Reliability coefficients at or } \\
\text { above } .89 \text { for each age group } \\
\text { (range } .89 \text { to } .94) \text {. Moderate } \\
\text { correlation with FSIQ }(\mathrm{r}=.72)^{\mathrm{b}}\end{array}$ & $\begin{array}{l}\text { Convergent validity, with correlation } \\
\text { coefficient of Digit Span to } \\
\text { Number-Letter Switching of the } \\
\text { DKEFS being . } 63 \text { for TBI patients }{ }^{b}\end{array}$ \\
\hline $\begin{array}{l}\text { Letter-Number } \\
\text { Sequencing (Wechsler } \\
\text { Adult Intelligence } \\
\text { Scale-IV; Wechsler, } \\
\text { 2008) }\end{array}$ & $\begin{array}{l}\text { A supplemental Working Memory } \\
\text { subtest requires the individual to } \\
\text { listen to a series of random numbers } \\
\text { and letters that are presented orally } \\
\text { and then has to sequentially order the } \\
\text { numbers in ascending order and the } \\
\text { letters alphabetically. }\end{array}$ & $\begin{array}{l}\text { Reliability coefficients at or } \\
\text { above } .85 \text { for each age group } \\
\text { (range } .85 \text { to } .91 \text { ). Moderate } \\
\text { correlation with FSIQ }(r=.64)^{b}\end{array}$ & $\begin{array}{l}\text { Convergent validity, with correlation } \\
\text { coefficient of Letter-Number } \\
\text { Sequencing to Number-Letter } \\
\text { Switching of the DKEFS being .71 } \\
\text { for TBI patients }{ }^{\text {b }}\end{array}$ \\
\hline $\begin{array}{l}\text { Spatial Addition } \\
\text { (Wechsler Memory } \\
\text { Scale-IV; Wechsler, } \\
\text { 2009) }\end{array}$ & $\begin{array}{l}\text { Assesses visual-spatial working } \\
\text { memory using a visual addition task. } \\
\text { Subject is shown sequentially, two } \\
\text { grids with blue and red circles and } \\
\text { asked to add or subtract the locations } \\
\text { of the circles based on a set of rules. }\end{array}$ & $\begin{array}{l}\text { Reliability coefficient of .89 } \\
\text { to } .91 \text { in ages } 16-69 \text { and } .98 \text { in } \\
\text { population of TBI patients. } \\
\text { Test-retest reliability } .77\end{array}$ & $\begin{array}{l}\text { Convergent validity with correlation } \\
\text { coefficient of } r=.6 \text { of Spatial } \\
\text { Addition and Symbol Span tests in } \\
\text { TBI patients. }\end{array}$ \\
\hline $\begin{array}{l}\text { Symbol Digit } \\
\text { Modalities Test } \\
\text { (SDMT) Ponsford \& } \\
\text { Kinsella, 1992) }\end{array}$ & $\begin{array}{l}\text { A test of divided attention that } \\
\text { requires a person scan a set of } 9 \text { key } \\
\text { symbols and write down or orally say } \\
\text { the number corresponding to each } \\
\text { symbol as rapidly as possible. }\end{array}$ & $\begin{array}{l}\text { Test-retest reliability was .80 for } \\
\text { the written SDMT and .76 for the } \\
\text { oral version (Smith, 1991) } \text { (a,c }^{\text {a }}\end{array}$ & $\begin{array}{l}\text { Criterion validity of SDMT and } \\
\text { Symbol/Coding subtest of the } \\
\text { WAIS-IV range from } r=.62 \text { to } r \\
=.91 \text {, depending on population }{ }^{\mathrm{a}, \mathrm{c}}\end{array}$ \\
\hline $\begin{array}{l}\text { Conners' Continuous } \\
\text { Performance Test II } \\
\text { (CPT-II) (Conners, } \\
\text { 1997) }\end{array}$ & $\begin{array}{l}\text { Computerized vigilance task that } \\
\text { requires a person to maintain } \\
\text { attention over long intervals to detect } \\
\text { infrequently occurring targets. }\end{array}$ & $\begin{array}{l}\text { Internal reliability coefficients for } \\
\text { Hit Reaction Time (.95), } \\
\text { Omissions (.94), Commissions } \\
\text { (.83), Standard Error }(.87)^{\mathrm{a}, \mathrm{c}}\end{array}$ & $\begin{array}{l}\text { Convergent validity } \\
\text { demonstrated-CPT Commissions was } \\
\text { moderately correlated to Posner } \\
\text { Visual Orienting Task }(\mathrm{r}=.62) \text { and } \\
\text { Signal-Stop Task }(\mathrm{r}=.43)(\text { Epstein, } \\
\text { Johnson, Varia, \& Conners, 2001) }{ }^{\mathrm{a}, \mathrm{c}}\end{array}$ \\
\hline $\begin{array}{l}\text { Stroop Interference } \\
\text { Test (Stroop, 1935) }\end{array}$ & $\begin{array}{l}\text { A selective attention and cognitive } \\
\text { flexibility test. There are several } \\
\text { versions, but each version tests the } \\
\text { ability of a person to inhibit their } \\
\text { response in naming a color when } \\
\text { presented as a mismatch (i.e., word } \\
\text { "blue” printed in yellow ink). }\end{array}$ & $\begin{array}{l}\text { For Victoria Stroop Test, } \\
\text { Reliability Coefficients } \\
\text { were } .90, .83 \text { and } .91 \text { for the three } \\
\text { parts of the test of Color, Word, } \\
\text { Color/Word }{ }^{\text {a,c }}\end{array}$ & $\begin{array}{l}\text { Convergent validity with moderate } \\
\text { correlation with other attention } \\
\text { measures as Omission Errors on } \\
\text { CPT-II ( } \mathrm{r}=.31 \text { ) (Weinstein, } \\
\text { Silverstein, Nader, \& Turnbull, 1999) } \\
\text { and Stop-Signal Task ( } \mathrm{r}=.56 \text { ) (May } \\
\text { \& Hasher, 1998) })^{\mathrm{a}, \mathrm{c}}\end{array}$ \\
\hline $\begin{array}{l}\text { Trail Making Tests } \\
\text { (Reitan, 1955) }\end{array}$ & $\begin{array}{l}\text { Requires connecting of } 25 \text { encircled } \\
\text { numbers randomly arranged on a } \\
\text { page in proper order (Trails A) and } \\
25 \text { encircled numbers and letters in } \\
\text { alternating order (Trails B). }\end{array}$ & $\begin{array}{l}\text { Test-retest Reliability } \\
\text { Coefficients were .79 for Trails A } \\
\text { and .89 for Trails B (Dikmen, } \\
\text { Heaton, Grant, Temkin, 1999). } \\
\text { Interrater reliability of .94 for } \\
\text { Trails A and .90 for Trails B } \\
\text { (Fals-Stewart, 1992), }^{\text {a,c }}\end{array}$ & $\begin{array}{l}\text { Convergent validity for visual search, } \\
\text { object finding and hidden pattern } \\
\text { tests, with correlations from .36 to .93 } \\
\text { (Ehrenstein, Heister, \& Cohen, 1982). } \\
\text { Trails B moderately correlated with } \\
\text { SDMT and PASAT (Royan, } \\
\text { Tombaugh, Rees, \& Francis, 2004) }\end{array}$ \\
\hline
\end{tabular}

(b) ASSESSMENT OF MEMORY

\begin{tabular}{|c|c|c|c|}
\hline Instrument & General description & Reliability data & Validity data \\
\hline $\begin{array}{l}\text { Wechsler Memory } \\
\text { Scale-IV (WMS-IV; } \\
\text { The Psychological } \\
\text { Corporation, 2009) }\end{array}$ & $\begin{array}{l}\text { Individually administered test battery } \\
\text { designed to assess verbal (story, paired } \\
\text { associates), visual-spatial (geometric shapes, } \\
\text { designs and locations) and visual working } \\
\text { memory. Scaled scores of immediate and } \\
\text { delayed story memory (Logical Memory I, II) } \\
\text { and Verbal Paired Associates form the } \\
\text { Auditory Memory Index. Scaled scores of } \\
\text { immediate and delayed Visual Reproduction } \\
\text { and Designs form the Visual Memory Index. }\end{array}$ & $\begin{array}{l}\text { Reliability coefficient of .94 to } .97 \\
\text { in ages } 16 \text { - } 69 \text { and } .97 \text { in } \\
\text { population of TBI patients for the } \\
\text { Auditory Memory Index. } \\
\text { Reliability coefficient of } .95 \text { to } .97 \\
\text { in ages } 16 \text { - } 69 \text { and } .99 \text { in } \\
\text { population of TBI patients for the } \\
\text { Visual Memory Index. Test-retest } \\
\text { reliability are; Auditory Memory } \\
\text { Index }(.83) \text { and Visual Memory } \\
\text { Index }(.81)^{\mathrm{a}, \mathrm{c}}\end{array}$ & $\begin{array}{l}\text { Convergent validity of } \\
\text { Auditory Memory Index, } \\
\text { correlation coefficient of .63 } \\
\text { to CVLT-II Trials } 1 \text { - } 5 \\
\text { correct. Construct validity of } \\
\text { Visual Memory Index, } \\
\text { correlation coefficient of .70 } \\
\text { to RBANS Total Scale } \\
\text { score }^{\text {a,c }}\end{array}$ \\
\hline
\end{tabular}




\section{Continued}

California Verbal Learning Test-II (CVLT-II; Delis, Kramer, Kaplan, \& Ober, 2000)

Rey-Osterrieth Complex Figure Tes (Developed by Rey (1941) and translated by into English by Corwin and Bylsma, 1993)

Rey

Auditory-Verbal Learning Test (RAVLT; Lezak, Howieson, \& Loring, 2004)
CVLT-II assesses both recall and recognition of two word lists over immediate and delayed memory trials. In first 5 trials, person recalls words from List A immediately after presentation. List A consists of 16 words, four from each of four semantic categories. List B, a 16-word interference list, is presented once, followed by a short delay free recall and short delay cued recall of List A. A 20-minute delay is introduced, followed by a long delay free recall and long delay cued recall and recognition of List $A$.

Permitsassessment of a variety of cognitive processes, including planning, organization skills, and problem solving strategies, as well as perceptual, motor, and episodic memory functions. Consists of a copy, immediate and delayed recall, and recognition of the Rey Complex Figure.

List learning and memory task. List A consists of 15 nouns that are read aloud for 5 consecutive trials, each trial is followed by a free recall test. List B, an interference list, is then presented followed by free recall of that list. Trial 6 is the delayed recall of List A. After a 20-minute delay, Trial 7, a free recall test of List A is performed, followed by recognition test of List $\mathrm{A}$. Used as an alternate for CVLT-II.
Internal reliability coefficients are high and range from .79 to .96 for 5 immediate recall trials of CVLT-II. Test-retest reliability coefficients are high for overall measures as,

Trials 1 - 5, Short- and Long-Delay II coefficients with Paired Word Test was moderate $(.76)^{\mathrm{a}, \mathrm{c}}$

High interrater and intrarater reliability coefficients for total scores (Berry, Allen, \& Schmitt, 1991; Delaney, Prevey, Cramer, Mattson, \& VA

EpilepsyCooperativeStudy 264 Research Group, 1992) $)^{\text {a,c }}$

Data from correlation and factor analysis support the validity of the Rey Complex Figure Test as a measure of visual-constructional ability based on copy portion of test and memory based on recall and recognition portions (Meyers \& Meyers, 1995),

Internal reliability coefficient of total score was .90 (van den Burg \& Kingma, 1999). Test-retest reliability for Trial 5 and delayed recall were .60 to .70 (Mitrushina, Satz, Chervinsky, \& D’Elia 1991) ${ }^{\mathrm{a}, \mathrm{c}}$

RAVLT correlates moderately well with other measures of learning and memory as, the WMS-III Logical Memory Test and CVLT-II (Johnstone, Vieth, Johnson, \& Shaw, 2000; Crossen \& Wiens, 1994) ${ }^{\mathrm{a}, \mathrm{c}}$

\section{(c) ASSESSMENT OF EXECUTIVE FUNCTION}

\begin{tabular}{cc}
\hline Instrument & General description \\
\hline & Assess the ability to conceptualize qualities
\end{tabular}

such as size, shape, number, position, and color. Consists of 7 sets of items, totally 208, and each is organized based on a different principle. Subjects must use feedback they

Booklet Category Test (DeFilippis, McCampbell, \& Rogers, 1979)

Wisconsin Card Sorting Test (WCST; Berg, 1948; Grant \& Berg, 1948) receive from the correct and incorrect guesses in each series to infer the underlying principle. Requires the deduction of principles based on response-contingent feedback and then be able to abandon it when it is no longer effective.

Assesses abstraction ability and the ability to shift cognitive strategies in response to changing environmental contingencies. It requires strategic planning, organization and the ability to use feedback to shift cognitive set. Goal-orienting behavior and the ability to modulate impulsive responding are also measured. The test consists of presenting 4 stimulus cards to the subject. The subject receives 128 response cards that vary in color, form and number. The subject is told to match the response cards to the stimulus cards and given feedback each time on the correctness of the response. No warning is given that the sorting rule changed. Indices include preservative responses, failure to maintain set, and number of categories achieved.

High internal reliability coefficients for the total score of $>.95$ (Lopez, Charter, \& Newman, 2000). However, reliabilities for Subtest I (.46) and Subtest II (.65) are unacceptable for clinical purposes. Test-retest reliabilities range from .60 to .85 (Dikmen et al., 1999; Bornstein, Baker, \& Douglas, $1987)^{\mathrm{a}, \mathrm{c}}$

\section{Validity data}

While the Category Test is sensitive to variety of brain disturbances (Choca,

Laatsch, Wetzel, \& Agresti, 1997), it is a complex measure. Convergent validity coefficients suggest that it is correlated with spatial-analytical skills (Perrine, 1993) a,c $^{\mathrm{a}}$

Test-retest reliability difficult to measure in normal individuals. On retesting, it is no longer measuring problem solving abilities in the same manner as the subject are now aware of the category sorts and shifting principle (Paolo, Axelrod, \& Troster, 1996) ${ }^{\mathrm{a}, \mathrm{c}}$
Convergent validity as a measure of executive function was demonstrated by regression analysis, with perseverative errors on the WCST loading on to a factor defined by the measure of Piagetian formal operations (Shute \& Huertas, 1990). Construct validity demonstrated in normal elderly and Parkinson patients (Paolo, Troster, Axelrod, \& Koller, 1995) $)^{\text {a,c }}$ 


\section{Continued}

Rey-Osterrieth

Complex Figure

Test (Developed by

Rey (1941) and

translated by into

English by Corwin

and Bylsma, 1993)

Trail Making Tests

(Reitan, 1955)

Stroop Interference

Test (Stroop, 1935)

Verbal Fluency as measured by

phonemic and

semantic tests (i.e.

Controlled Oral

Word Association

Test COWAT;

Benton \& Hamsher, 1989)

Delis-Kaplan

Executive Function System (DKEFS; Delis, Kaplan, \& Kramer, 2001)
Same as indicated above

Same as indicated above

Same as indicated above

With phonemic fluency tests, subjects must produce orally as many words as possible beginning with a specified letter (e.g. FAS) during a fixed period, usually 1 minute. With semantic fluency tests, subjects must produce orally as many words as possible in common categories as, animals, vegetables, boys or girl names, during a fixed period, usually 1 minute.

Designed to detect forms of executive dysfunction and includes 9 tests that derive from existing experimental and clinical findings: Trail Making Test, Verbal Fluency Test, Design Fluency Test, Color-Word Interference Test, Sorting Test, Twenty Questions Test, Word Context Test, Tower Test, and Proverbs Test. It is a flexible battery and tests may be administered individually or in combination with other DKEFS tests.
Same as indicated above

Same as indicated above

Same as indicated above

Same as indicated above

Same as indicated above

Factor analysis studies suggest that phonemic and

Internal reliability coefficients for FAS and CFL phonemic fluency is .83 (Ruff, Light, Parker, \& Levin, 1996). Test retest reliability coefficients are typically above .70 for both phonemic and semantic fluency (Dikmen et al., 1999) (a,c $^{\mathrm{a}}$

Internal reliability coefficients range from inadequate or less than .60 for Trial Making

Conditions 1 - 4, Verbal Fluency Category Switching, and Twenty Questions to as high as .80 to.90 for FAS Verbal Fluency. Test retest reliability coefficients also range from inadequate or less than .60 for Design Fluency, Sorting Test, Twenty Questions and Tower Test to adequate (.70 to .79) for Color-Word, Word Context, and Proverbs Test ${ }^{\mathrm{a}, \mathrm{c}}$ semantic fluency tests load on attention control/working memory functions. Subjects who perform well on working memory tasks also achieve high scores on semantic and phonemic fluency tasks (Rosen \& Engle, 1997) $)^{\mathrm{a}, \mathrm{c}}$

Convergent validity of the DKEFS with the WCST, with correlations in the moderate range $(.31$ - .59) between the Number of Categories Completed on the WCST and various measures from the nine tests of the DKEFS $^{\mathrm{a}, \mathrm{c}}$

(d) ASSESSMENT OF LANGUAGE

\begin{tabular}{|c|c|c|c|}
\hline Instrument & General description & Reliability data & validity data \\
\hline $\begin{array}{l}\text { Boston Diagnostic } \\
\text { Aphasia Examination } \\
\text { (Goodglass, Kaplan, } \\
\text { \& Barresi, 2000) }\end{array}$ & $\begin{array}{l}\text { Boston Diagnostic Aphasia Examination, } \\
\text { Third Edition is composed } 50 \text { subtests that } \\
\text { allow both a qualitative and quantitative } \\
\text { evaluation of language including speech } \\
\text { melody, fluency, anomia, and syntactic } \\
\text { organization and paraphasia types. }\end{array}$ & $\begin{array}{l}\text { Internal reliability } \\
\text { coefficients range from } \\
\text { acceptable to high across } \\
\text { subtests; alpha coefficients } \\
\text { for Sentence Repetition } \\
\text { and Boston Naming are } \\
\text { greater than } .95 \text {, while } \\
\text { Word-Picture Matching is } \\
\text { less than } .65^{\text {a,c }}\end{array}$ & $\begin{array}{l}\text { Convergent validity varies with } \\
\text { subtest, with correlations of .86 } \\
\text { and .93, for the auditory } \\
\text { comprehensive measure with } \\
\text { the Token Test and with Porch } \\
\text { Index of Communicative } \\
\text { Ability (Divenyi \& Robinson, } \\
\text { 1989)a,c }\end{array}$ \\
\hline $\begin{array}{l}\text { Reitan-Indiana } \\
\text { Aphasia Screening } \\
\text { Test (Reitan \& } \\
\text { Wolfson, 1993) }\end{array}$ & $\begin{array}{l}\text { Assesses symbolic-language related deficits } \\
\text { such as, difficulties in reading, writing, } \\
\text { naming, arithmetic, and repeating words and } \\
\text { phrases. The test asks the patient to perform } \\
\text { a series of tasks such as naming common } \\
\text { objects, spelling simple words, identifying } \\
\text { individual numbers and letters, reading } \\
\text { writing/enunciating/understanding spoken } \\
\text { language, identifying body parts, calculating } \\
\text { simple arithmetic problems, differentiating } \\
\text { between right and left, and copying simple } \\
\text { shapes. }\end{array}$ & $\begin{array}{l}\text { Review of the studies of } \\
\text { Halstead-Reitan Battery } \\
\text { suggest that the available } \\
\text { data indicate adequate } \\
\text { internal and test-retest } \\
\text { reliability (Bornstein et al., } \\
1987)^{\text {a,c }}\end{array}$ & $\begin{array}{l}\text { Discriminant function analyses } \\
\text { of the Aphasia and } \\
\text { Sensory-perceptual } \\
\text { Examination which permitted } \\
\text { classification of subjects into } \\
\text { their appropriate groups with } \\
\text { the same degree of accuracy as } \\
\text { achieved using the rest of the } \\
\text { Halstead-Reitan Battery } \\
\text { (Reitan \& Wolson, 1993) }^{\text {a,c }}\end{array}$ \\
\hline
\end{tabular}


(e) ASSESSMENT OF VISUOPSATIAL AND VISUOMOTOR FUNCTION

\begin{tabular}{|c|c|c|c|}
\hline Instrument & General description & Reliability data & Validity data \\
\hline $\begin{array}{l}\text { Judgment of the Line } \\
\text { Orientation Test (JLO; } \\
\text { Benton, Sivan, \& } \\
\text { Hamsher, 1994) }\end{array}$ & $\begin{array}{l}\text { Measure of spatial perception and orientation. } \\
\text { Items are presented in an ascending order of } \\
\text { difficulty. Test material are presented in } \\
\text { spiral-bound booklet, with } 35 \text { stimuli individually } \\
\text { presented in the upper page and } 11 \text { line choices in } \\
\text { an array are presented in the lower part. Subject } \\
\text { required to identify the two lines from the array } \\
\text { that match the direction of the stimulus lines. }\end{array}$ & $\begin{array}{l}\text { Internal reliability } \\
\text { coefficients were } .84 \\
\text { to } .91 \text { in adults (Benton } \\
\text { et al., 1994). Test retest } \\
\text { reliability coefficient } \\
\text { of .90 (Benton et al., } \\
1994 \text { ), }\end{array}$ & $\begin{array}{l}\text { Convergent validity with } \\
\text { loading of the JLO on the } \\
\text { Performance subtests of the } \\
\text { WAIS. The test measures } \\
\text { abilities separate from } \\
\text { facial recognition } \\
\text { (Larrabee, 2000) } \text { (a, }^{\text {a }}\end{array}$ \\
\hline $\begin{array}{l}\text { Hooper Visual } \\
\text { Organization Test } \\
\text { (HVOT; Hooper, 1983) }\end{array}$ & $\begin{array}{l}\text { Consists of } 30 \text { drawings of common objects on } \\
4 \times 4 \text { inch cards in a ring binder. Each object is cut } \\
\text { into } 2 \text { or more parts and randomly arranged. The } \\
\text { task is to visually integrate the parts and name the } \\
\text { object. }\end{array}$ & $\begin{array}{l}\text { Internal reliability } \\
\text { coefficients were }>.80 \\
\text { in adults (Lopez, Lazar, } \\
\text { \& Oh, 2003). Test retest } \\
\text { reliability coefficient } \\
\text { of .86 (Lezak et al., } \\
2004)^{\mathrm{a}, \mathrm{c}}\end{array}$ & $\begin{array}{l}\text { Convergent validity with } \\
\text { loading of the HVOT on } \\
\text { visual-spatial intelligence } \\
\text { factor and had its highest } \\
\text { correlation with the } \\
\text { Performance IQ (Johnstone } \\
\text { \& Wilhelm, 1997) })^{\text {a,c }}\end{array}$ \\
\hline $\begin{array}{l}\text { Rey-Osterrieth } \\
\text { Complex Figure Test } \\
\text { (Developed by Rey } \\
\text { (1941) and translated by } \\
\text { into English by Corwin } \\
\text { and Bylsma, 1993) }\end{array}$ & Same as indicated above & $\begin{array}{l}\text { Same as indicated } \\
\text { above }\end{array}$ & Same as indicated above \\
\hline
\end{tabular}

(f) ASSESSMENT OF MOTOR FUNCTION

\begin{tabular}{|c|c|c|c|}
\hline Instrument & General description & Reliability data & Validity data \\
\hline $\begin{array}{l}\text { Finger Tapping Test } \\
\text { (Reitan, 1969) }\end{array}$ & $\begin{array}{l}\text { Using a specially adapted tapper and counter, a } \\
\text { person is instructed to tap as rapidly as possible } \\
\text { using the index finger of the dominant and } \\
\text { non-dominant hand. Procedure call for five } \\
\text { consecutive trials within a 5-point range with } \\
\text { each hand (Reitan \& Wolfson, 1985). }\end{array}$ & $\begin{array}{l}\text { Reliability coefficients } \\
\text { range from } .58 \text { to } .93 \text { in } \\
\text { normal and patient } \\
\text { populations (Bornstein et } \\
\text { al., 1987; Dikmen et al., } \\
\text { 1999), }\end{array}$ & $\begin{array}{l}\text { Convergent validity; finger } \\
\text { tapping correlates highly ( } \mathrm{r} \\
=.78 \text { ) with Purdue peg } \\
\text { placement (Triggs, } \\
\text { Calvanio, Levine, Heaton, } \\
\text { \& Heilman, 2000), }\end{array}$ \\
\hline $\begin{array}{l}\text { Grip Strength (Reitan \& } \\
\text { Wolfson, 1985) }\end{array}$ & $\begin{array}{l}\text { Hand strength is measured by asking a person } \\
\text { to squeeze a dynamometer in the palm of their } \\
\text { hand. }\end{array}$ & $\begin{array}{l}\text { Internal consistency, } \\
\text { Chrombach’s alpha } \\
\text { was .82 (Christensen, } \\
\text { Mackinnon, Korten, \& } \\
\text { Jorn, 2001). Reliability } \\
\text { coefficient }>.70 \text { (Dikmen } \\
\text { et al., 1999), }\end{array}$ & $\begin{array}{l}\text { Ecological validity; poor } \\
\text { performance predictive of } \\
\text { cognitive decline } \\
\text { (MacDonald, Dixon, } \\
\text { Cohen, \& Hazlitt, 2004) } \\
\text { and mortality in older } \\
\text { adults (Anstey, Luszcz, } \\
\text { Giles, \& Andrews, 2001) }\end{array}$ \\
\hline $\begin{array}{l}\text { Grooved Pegboard Test } \\
\text { (Matthews \& Klove, } \\
\text { 1964) }\end{array}$ & $\begin{array}{l}\text { Test of fine motor skills. Person inserts metal } \\
\text { pegs as quickly as possible into } 25 \text { randomly } \\
\text { positioned slots on a small metal board, first } \\
\text { with the dominant and then the non-dominant } \\
\text { hand. }\end{array}$ & $\begin{array}{l}\text { Reliability coefficients } \\
\text { range from .67 to .86 } \\
\text { (Dikmen et al., 1999; } \\
\text { Levine, Miller, Becker, } \\
\text { Selnes, \& Cohen, 2004) } \text { a,c }^{\text {a }}\end{array}$ & $\begin{array}{l}\text { Ecological validity; } \\
\text { pegboard performance } \\
\text { associated activities of } \\
\text { daily living in TBI (Farmer } \\
\text { \& Eakman, 1995) }{ }^{\mathrm{a}, \mathrm{c}}\end{array}$ \\
\hline
\end{tabular}

(g) ASSESSMENT OF PERSONALITY

\begin{tabular}{|c|c|c|c|}
\hline Instrument & General description & Reliability data & Validity data \\
\hline $\begin{array}{l}\text { Minnesota Multiphasic } \\
\text { Personality Assessment-II } \\
\text { (MMPI; Graham, 2000) }\end{array}$ & $\begin{array}{l}\text { Self-report test that consists of } 567 \\
\text { true/false questions. The responses are } \\
\text { scored and interpreted based on a series of } \\
\text { clinical (Hypochondria, Depression, } \\
\text { Hysteria, Psychopathic Deviate, } \\
\text { Masculinity-Feminity, Paranoia, } \\
\text { Psychasthenia, Schizophrenia, Hypomania, } \\
\text { Social Introversion) and validity scales } \\
\text { (VRIN, TRIN, L, F, and K, S). }\end{array}$ & $\begin{array}{l}\text { Internal reliability coefficients } \\
\text { of clinical scales are variable } \\
\text { and range from .34 (Paranoia) } \\
\text { to } .85 \text { (Psychasthenia, } \\
\text { Schizophrenia). Test-retest } \\
\text { reliabilities coefficients range } \\
\text { from } .67 \text { (Psychasthenia) } \\
\text { to } .93 \text { (Social Introversion) }\end{array}$ & $\begin{array}{l}\text { Factor analysis of MMPI-II } \\
\text { performed in a normative } \\
\text { sample suggests the clinical } \\
\text { scales load on two factors. One } \\
\text { factor is general maladjustment } \\
\text { and psychotic mentation with } \\
\text { the second factor being neurotic } \\
\text { tendencies (Graham, 2000; } \\
\text { Nichols, 2001) }\end{array}$ \\
\hline
\end{tabular}




\section{Continued}

Beck Depression Inventory-II

(Beck, Steer, \& Brown, 1996)

Beck Anxiety Inventory (BAI; Beck, Epstein, Brown \& Steer, 1988) 21-item self report for measuring the presence and severity of depression. 21-item self report for measuring the presence and severity of anxiety.
Internal reliability coefficients for the BDI-II range from .83 to .93 (Schulenberg \& Yutrzenka, 2001; Whisman, Perez, \& Ramel, 2000). Test retest reliability coefficients range from .75 (Al-Musawi, 2001) to .96 (Sprinkle et al., 2002) $)^{\mathrm{a}, \mathrm{c}}$

Internal reliability was high (Cronbach's ALPHA = .94) and test retest reliability coefficient was .67 (Fydrich, Dowdall, \& Chambless, 1992) ${ }^{\mathrm{a}}$

Self-report multiple-scale inventory that consists of 344 items that constitute 4 sets of nonoverlapping scales: 4 validity scales, 11 clinical scales covering major categories of psychopathology based on the DSM nosology, 5 treatment scales measuring constructs relevant to treatment, and 2 interpersonal scales.
Internal reliabilities of the clinical scales are high, with median alphas for the full Test retest reliability coefficients of clinical scales ranged from .68 to .92 (Morey, 1991) ${ }^{\mathrm{a}, \mathrm{c}}$ scales between .81 and .86 .

Convergent validity; correlation coefficients of $r=.83$ for the SCID-1 (Sprinkle et al., 2002) and $r=.84$ for the Reynolds Adolescent Depression Scale (Krefetz, Steer, Gulab, \& Beck, 2002) $)^{\mathrm{a}, \mathrm{c}}$

Convergent validity; correlation between the BAI and Diary Anxiety being significantly higher than that between BAI and Diary Depression, and, compared to Trait Anxiety, the BAI was significantly less confounded with depression as measured by the BDI (Fydrich, Dowdall, \& Chambless, 1992)

Convergent and discriminate validity of the PAI was acceptable based on evaluations of mean profiles of relevant clinical groups (Morey, 1991) and correlations with other behavioral inventories (Costa \& McCrae, 1992) a,c

(h) ASSESSMENT OF EFFORT

\begin{tabular}{lll}
\hline Instrument & General description & Reliability data
\end{tabular}

Tests of Memory Malingering (TOMM) (Tombaugh, 1996)

Rey Fifteen-Item Test (FIT) (Rey, 1964; Lezak, 1983)

Victoria Symptom Validity Test (Hiscock \& Hiscock, 1989)

Consists of 2 learning trials and a retention trial. On each learning trial, the subject is shown 50 line drawings of common objects for 3 seconds at 1 -second intervals. Subject then is shown 50 recognition panels one at a time. Each panel has a previously presented target and the subject is required to select the previous target, and explicit feedback on correctness of choice is given. Performance significantly below norms suggest malingering.

Consists of 15 items arranged in 3 columns by 5 rows. Because of item redundancy, the FIT is easy and only requires immediate recall of 3 or 4 ideas to recall most of the 15 items. Malingerers misjudge the difficulty of the task and perform poorer than severely intellectually impaired individuals perform.

5-digit number is presented on a card for 5 seconds. Following a brief delay, another card with the correct choice and a foil is presented and subjects are asked to indicate the correct sequence they saw earlier. The correct answers can always be distinguished from foils by recognizing the first or last digit. Person is cued that this is a difficult task for those with memory problems. Malingerers perform poorer than expected based on norms.

Using a criterion cutoff score of 45 on Trial 2, TOMM had specificity rates of greater than $90 \%$ (Rees, Tombaugh, Gansler, \& Moczynski, 1998; Tombaugh, $1996)^{\mathrm{a}, \mathrm{c}}$

$=95$, Retention $=.94)^{\mathrm{a}, \mathrm{c}}$

Interrater reliability showed 95\% agreement for item correct and 97\% agreement for rows correct scores (Goldberg \& Miller, 1986) $)^{\mathrm{a}, \mathrm{c}}$

Test-retest reliability for selected measures of the VSVT for compensation seekers ranged from .56 to .84 (Slick, Hopp, Strauss, \& Thompson, 1996) $)^{\mathrm{a}, \mathrm{c}}$
Convergent validity with other measures of effort as, TOMM and Dot counting was moderate (.78) (McCaffrey, O'Bryant, Ashendorf, \& Fisher, 2003; Nelson et al., 2003) $)^{\mathrm{a}, \mathrm{c}}$

VSVT showed superior classification accuracy compared to other procedures as, Rey 15-Item Test, 21-Item Test and the Portland Digit Recognition Test (Vickery, Berry, Inman, Harris, \& Orey, 2001) $)^{\text {a,c }}$

Note: Additional resources used for psychometric data include ${ }^{\mathrm{a}}$ Lezak, Howieson, \& Loring, 2004; 'battler \& Ryan, 2009; 'Strauss, Sherman, \& Spreen, 2006. Validity, for the purpose of this table is restricted to convergent or criterion validity. 
duced span and distractibility) and verbal retrieval deficits (Howieson \& Lezak, 2002). Ponsford and Kinsella (1992) reported that the oral version of the Symbol Digit Modality Test (SDMT) was the single best indicator of information processing and divided attention impairments in TBI, compared with other tasks as, Stroop Interference Test and the Paced Auditory Serial Addition Test (PASAT). In addition to differentiating TBI patients from controls, performance on the SDMT test differentiated between early versus late recovery (Bate et al., 2001) and was sensitive to the effects of diffuse axonal injury (Felmingham, Baguley, \& Green, 2004), and predicted changes in the daily functioning 5 years after TBI (Hammond, Hart, Bushnik, Corrigan, \& Sasser, 2004). TBI patients have slower completion times on the subtests of the Stroop, although they do not consistently show disproportionate difficulty with the interference condition (Ponsford \& Kinsella, 1992; Felmingham et al., 2004) and some have questioned the sensitivity of the Stroop Interference test as a diagnostic tool in mild TBI (Cicerone \& Azulay, 2002). Measures of auditory attention span, as the Digits Forward test, tend to be more sensitive to left versus right hemisphere damage and performance on this test correlates with the number of concussions or brain injuries (Matser, Kessels, Lezak, Jordan, \& Troost, 1999).

With Trail Making tests that require complex attention and cognitive flexibility, completion times increase with increasing severity of head injury (Dikmen et al., 1995) and are associated with diffuse axonal injury (Felmingham et al., 2004), but they may not be sufficiently sensitive measure in mild brain injury (Cicerone \& Azulay, 2002). Scores from both Trails A and Trails B contributed to the prediction of degree of independent living of moderate and severe TBI patients, with shorter completion times associated with greater likelihood of independent living (Acker \& Davis, 1989). Performance on other working memory tasks, as the Arithmetic test, Digits Backwards, and the Letter-Number Sequencing test of the Wechsler Adult Scales of Intelligence, is similarly vulnerable to the effects of moderate and severe TBI, but not mild TBI (Donders, Tulsky, \& Zhu, 2001).

Memory refers to the ability to learn, retain, recall and recognize new information. TBI patients may have difficulties in their ability to encode, retrieve and consolidate information, significantly influencing their psychosocial interactions and functioning (Prigatano et al., 1984; Hoofien et al., 2001). Neuropsychological tests of memory asses the ability to encode new information and report it back immediately or following a 20 - 30 minutes delay, using free recall or recognition conditions. Information can be presented verbally in the form of story memory, list learning and word-paired associate learning, as with the Wechsler Memory Scale-IV (WMS-IV; Wechsler, 2009) and California Verbal Learning Test-II (CVLT-II; Delis, Kramer, Kaplan, \& Ober, 2000), or spatially, with the recall and recognition of figures and designs, as the Rey-Osterrieth Complex Figure Test (Corwin \& Bylsma, 1993) and the WMS-IV. Patients with frontal lobe damage show poorer overall recall, an increased tendency to make intrusion errors, reduced use of semantic clustering, but perform in the normal range on forced choice recognition on list learning tasks (Baldo, Delis, Kramer, \& Shimamura, 2002). Free and cued recall performance on paired-associate list tests, in fact, is negatively correlated (-.48 free recall, -.43 cued recall) with duration of coma and ventricular enlargement following TBI and indicative of injury severity (Vilkki, Holst, Ohman, Servo, \& Heiskanen, 1990). Even with mild brain injuries, deficits are seen in immediate and delayed story, paired associate list memory, and delayed visuo-spatial memory as measured by the Wechsler Memory Scale (Fisher, Ledbetter, Cohen, Mamor, \& Tulsky, 2000).

Executive function or control, a concept proposed by Luria (1966), refers to planning, deductive reasoning, organizing, problem solving, generativity and fluency, error monitoring, and set shifting abilities that are required in goal directed behaviors. Depending on the severity of injury, TBI patients show deficits on executive function tasks that can be assessed with questionnaires as, the Frontal System Behavior Scale (Grace \& Malloy, 2001) and the Behavior Rating Inventory of Executive Functions (BRIEF; Gioia, Isquith, Guy, \& Kenworthy, 2000), as well as, test batteries as assembled by Delis-Kaplan Executive Function System (D-KEFS; Delis et al., 2001). Given the complexity of functions subsumed under executive function, there is no single measure that adequately assesses this function. Among the commonly used tests of executive function are the family of Tower tests (Shallice, 1982; Goel \& Grafman, 1995; Saint-Cyr \& Taylor, 1992), Rey-Osterrieth Complex Figure Test (Corwin \& Bylsma, 1993), the Wisconsin Card Sorting Test (WCST; Grant \& Berg, 1948), Booklet Category Test (De Filippis et al., 1979), verbal fluency tests, as the Controlled Oral Word Association Test (COWAT; Benton \& Hamsher, 1989), and Stroop interference tests (Stroop, 1935).

Tower tests and the Rey-Osterrieth Complex Figure Tests are unique in that they measure the ability to plan and think ahead and have both qualitative and quantitative components. On the Tower of London test, for example, patients with focal damage make more moves, use a trial and error strategy and are slower to arrive at a solution compared to controls (Carlin et al., 2000). Similarly, patients with mild TBI show significant deficits on 
the Rey-Osterrieth Complex Figure Test within the first 21 months post-injury (Leininger, Gramling, Farrell, Kreutzer, \& Peck, 1990) and those with moderate TBI achieve higher 30 minutes delayed recall scores on the Rey-Osterrieth Complex figure Test than severe TBI patient 2 - 5 years post-injury (Bennett-Levy, 1984).

Following a TBI, patients often interpret information in a concrete or literal manner, are perseverative, and have difficulty inhibiting or changing activities. To assess these impairments, measures as the Booklet Category Test and the WCST, that assess mental flexibility, problem solving skills and the ability use feedback to shift cognitive sets are instructive in assessing these impairments. Of the tests of the Halstead-Reitan test battery, the Category Test is, in fact, the most sensitive to the presence of brain damage, with TBI patients making more errors than controls, and left hemispheric damage producing greater deficits than right hemisphere losses (Cullum \& Bigler, 1986; Goldstein \& Ruthven, 1983). TBI patients with diffuse and frontal lobe damage when tested with the WCST, similarly show deficits, with high levels of perseveration, a reduced ability to maintain cognitive set, and complete fewer categories (Segalowitz, Unsal, \& Dywan, 1992; Stuss et al., 2000; Martzke, Swan, \& Varney, 1991). The WCST test has predictive validity, as well, and performance is associated with brain-injured person’s capability to maintain independence outside a hospital setting (Heinrichs, 1990a, b).

Speech and language problems following TBI depend on the severity of the injury and the presence of focal damage in the hemisphere dominant for language (Iverson, Franzen, \& Lovell, 1999). More commonly, TBI patients experience anomia, or an inability to find words, which is a generative or executive function and can be assessed with verbal fluency and word finding tasks (Benton \& Hamsher, 1989). Performances on verbal and visuo-spatial fluency (design fluency) tasks can be compared to estimate the lateralization of executive function deficits following brain injury (Varney et al., 1996).

Visuo-spatial and construction skills may be compromised by brain injury and TBI patients often have difficulty understanding the spatial relationship between component parts or suffer a spatial neglect (Bigler, Rosa, Schultz, Hall, \& Harris, 1989). Motor, memory and executive components are intermixed in construction tasks as, the Rey-Osterrieth Complex Figure Test, making it difficult to differentiate the primary deficit(s). The Benton's Test of Spatial Orientation Test which requires a patient to match lines in an array (Benton et al., 1994), and the Hooper Visual Organization Test (Hooper, 1983) do not have as strong an executive function component, and allow the differential assessment of visuo-spatial from executive function deficits. Given that motor and sensory cerebral regions and the cerebellum may be injured, particularly with moderate and severe TBI, motor speed, dexterity and strength need to be assessed with tests such as, the Finger Tapping test (Reitan \& Wolfson, 1993), Grooved Pegboard test (Tiffin, 1968) and Grip Strength test (Reitan \& Wolfson, 1993), respectively. Finger tapping performance is moderately predictive of daily living skills in TBI patients (Prigatano, Altman, \& O’Brien, 1990) and employment status (Dikmen \& Morgan, 1980).

As long-term outcome following TBI is dependent personality variables, mood and affect, these variables need to be assessed in a neuropsychological evaluation. Typically, self-report inventories and questionnaires as, the Minnesota Multiphasic Personality Inventory (MMPI; Graham, 2000), Beck Depression Inventory (BDI; Beck, Steer, \& Brown, 1996), Beck Anxiety Inventory (BAI; Beck, Epstein, Brown, \& Steer, 1988) and behavioral checklists are used to assess emotional, personality, and psychiatric parameters of TBI. While certain of the clinical scales of the MMPI-II are typically elevated with TBI, such as Pd, D and Sc (Burke, Imhoff, \& Kerrigan, 1990; Leininger, Kreutzer, \& Hill, 1991), there is no systematic relation between severity of injury and personality profile (Bornstein, Miller, \& van Schoor, 1988). With severe TBI, Hy and Hs scales of the MMPI-II may, at times, be lower as compared to controls and indicative of a lack of awareness associated with the brain injury rather than a change in personality (Cripe, 1996). The Personality Assessment Inventory (Morey, 1991) has similar format to the MMPI-II, but has the advantage of being briefer (344 items) and TBI patients can more easily tolerate its administration. More focused inventories as the BDI-II and BAI have extensively been used in this population and in a sample of TBI patients administered the BDI-II, 59\% scored in the depressed range (>14), 34\% of which were moderately or severely depressed (Glenn, O’Neil-Pirozzi, Goldstein, Burke, \& Jacob, 2001).

No neuropsychological evaluation in TBI is complete without an assessment of effort and possible malingering. Several effort level measures have been cross-validation in TBI that include Computerized Assessment of Response Bias (Allen, Conder, Green, \& Cox, 1997), Rey Dot Counting Test (translated by Corwin \& Bylsma, 1993), Test of Memory Malingering (Tombaugh, 1996), Rey 15-Item Test (Rey, 1964), Victoria Symptom Validity Test (Slick, Hopp, Strauss, \& Spellacy, 1996), and Word Memory Test (Green, Allen, \& Astner, 1996) and it is recommended that at least two of these measures be used in assessing effort level (Lynch, 2004). 


\subsection{Functional Outcome Measures}

The Glasgow Outcome Scale (GOS), a 5-point scale $(1$ = dead, 2 = vegetative state, 3 = severely disabled, $4=$ moderately disabled, 5 = good recovery), is the standard measure of outcome following TBI (Jennett \& Bond, 1975). While easily administered and reliable (Woischneck \& Firsching, 1998), the GOS fails to measure the multidimensional qualities of functioning that include such measures as employment/productivity, community integration, life satisfaction, and quality of life. Complicating the use of these latter outcome measures is that they are highly interrelated as successful return to work, for example, is significantly related to an individual's social integration and satisfaction with life (O’Neill, Hubbard, Brown et al., 1998). Factors most consistently associated with employment outcome include pre-injury occupation status, functional status at discharge, global cognitive functioning, perceptual abilities, executive functioning, involvement in vocational rehabilitation services and emotional status (Ownsworth \& McKenna, 2004). Stability of employment, which differs from employment outcome, is related to pre-morbid characteristics, such as, being older and having a higher income before injury, and higher neuropsychological functioning at 1-month post-injury (Machamer et al., 2005). Assessment scales used by rehabilitation professions include the Disability Rating Scale (DRS), Functional Independence Measure (FIM), Community Integration Questionnaire (CIQ) and Functional Status Examination (FSE) (Rappaport, Hail, Hopkins, Belieza, \& Cope, 1982; Keith, Granger, Hamilton, \& Sherwin, 1987; Willer, Ottenbacher, \& Coad, 1994; Dikmen, Machamer, Miller, Doctor, \& Temkin, 2001). CIQ scores are related to premorbid factors, severity of injury, disability level (Fleming, Tooth, Hassell, \& Chan, 1999), as well as, to executive function and verbal memory (Hanks, Rapport, Millis, \& Deshpande, 1999) and levels of depression (Levin et al., 2001). Similar observations have made with the DRS, with scores at 6 months after rehabilitation strongly related to executive function and verbal memory (Hanks et al., 1999).

\subsection{Ethnic and Racial Disparities in Outcomes Following TBI}

Several studies demonstrate that minorities experience a higher incidence of TBI; African Americans at 278 injuries per 100,000 people and Hispanics at 262 per 100,000, compared to Whites at 209 per 100,000 (Cooper et al., 1983; Jager, Weiss, Coben, \& Pepe, 2000). Demographically, African Americans and Hispanics who experience a TBI are more likely to be younger, male, unemployed pre-injury, have lower levels of education, unmarried, have lower incomes pre-injury and less likely to have health insurance as compared to Whites (ArangoLasprilla et al., 2007; Burnett et al., 2000; Hart et al., 2005; Johnstone et al., 2003; Shafi et al., 2007a; Sherer et al., 2003). Acts of violence are also more prominent cause of injury, with African Americans and Hispanics being 3 - 4 times more likely sustain a TBI through acts of violence relative to Whites (Arango-Lasprilla et al., 2007; Burnett et al., 2000; Hart et al., 2005; Sherer et al., 2003).

Discrepant treatment of racial minorities and Whites with TBIs begins in the Emergency Department. African Americans, for example, are 3 times more likely to receive emergency room treatment from a resident, rather than a staff physician and Hispanics are 6 times more likely to receive a nasogastric tube in the emergency room compared to Whites (Bazarian, Pope, McClung, Cheng, \& Flesher, 2003). African American women are 21\% less likely to be hospitalized following a TBI than White women, even after controlling for injury severity, age and pre-exiting health problems (Selassie, Pickelsimer, Frazier, \& Ferguson, 2004). Not all studies have shown differences in the assessment and management of emergency patients based on minority status. In nationwide representative sample of emergency room visits, Shafi and Gentilello (2008) failed to find racial differences in assessment and management of emergent care, however, there was no control for trauma severity and the study did not exclusively focus on TBI.

In addition to differential treatment in the emergency room, racial minorities are less likely to be discharged to inpatient rehabilitation units or other intensive treatment facilities. Even with adjustments for injury severity, insurance status, and ownership of the hospital, African Americans and Hispanics with blunt TBI were 15\% less likely than White patients to be placed in inpatient rehabilitation units (Shafi et al., 2007b). In older patients, Chang, Ostir, Kuo, Granger, and Ottenbacher (2008) found that elderly Hispanics and African Americans with TBI were 2 times more likely to be discharged home, rather than an assisted living facility of other institution, compared to their White counterparts, even after controlling demographic, functional and medically related variables. When discharged to rehabilitative facilities, African Americans and Hispanics stayed in on average 3.4 fewer days than Whites and received less intense physical, occupational and speech therapy (Arango-Lasprilla \& Kreutzer, 2010). 
Given these findings, it is not surprising that functional outcome measures, as well as, psychosocial measures as, employment/productivity, martial status, community integration and life satisfaction, show marked disparities between African Americans who have experienced a brain injury as compared to Whites (Arango-Lasprilla \& Kreutzer, 2010; Hanks et al., 2003; Hart et al., 2005). African Americans were 2 times as likely to be unemployed or non-productive at one year post-injury compared to Whites, despite controlling for demographic, educational, employment and injury variables (Arango-Lasprilla et al., 2007, 2009; Kreutzer et al., 2003; Sherer et al., 2003).

Race independently predicts the ability of a person suffering from a TBI to return and integrate into their community. Despite controlling for demographic and injury severity variables, African Americans consistently score lower on the social integration sub-scale of the Community Integration Questionnaire (CIQ) compared to Whites at 1-year post-injury and longer (Hanks et al., 2003; Hart et al., 2005; Sander et al., 2009; Wagner, Hammond, Sasser, Wiercisiewski, \& Norton, 2000). African Americans participated less in recreational activities, had fewer contacts with friends and were likely to change their living situations at 1-year post-injury compared to Whites (Hart et al., 2005; Staudenmayer, Diaz-Arrastia, de Oliveira, Gentilello, \& Shafi, 2007). Regression analysis suggests that race is a predictive factor, with African Americans more likely to report depressive symptoms (Seel et al., 2003), to be diagnosed with Major Depression at 1-year post-injury and have lower social connection than Whites (Jorge, Robinson, Starkstein, \& Arndt, 1994). Similarly, African Americans experiencing a TBI reported markedly greater number and more severe PTSD symptoms of intrusions and avoidance compared to Whites at 6 and 12 months post-injury (Greenspan, Stringer, Phillips, Hammond, \& Goldstein, 2006).

\section{Treatment of TBI}

Depending on the nature and extent of the injury and impairments, TBI rehabilitation may include physical and occupational therapy, as well as, neuro-rehabilitative, pharmacological, social skills and behavioral therapies. These therapies can be administered individually or in a group setting and may be part of an acute, subacute and chronic rehabilitative program or a more integrative or community-based program (Mazaux \& Richer, 1998).

\subsection{Neuro-Rehabilitative Therapy}

As restoration of functional autonomy is highly dependent on resolution of cognitive deficits, development of effective neurocognitive rehabilitative paradigms are critical. There is substantial evidence to support cognitive rehabilitation following TBI, with an emphasis on compensatory strategies to improve attention, memory processes and executive function (Boelen, Spikman, \& Fasotti, 2011; Cernich, Kurtz, Mordecai, \& Ryan, 2010; Cicerone et al., 2005; Cicerone, Levin, Malec, Struss, \& Whyte, 2006). It is important to emphasize that these domains are by no means exclusive of one another and often in treating one domain, other cognitive abilities are brought into play and influence the therapeutic outcome.

Review of the literature by the special interest group of the American Congress of Rehabilitation Medicine suggests the effectiveness of attention training in TBI. In these studies there is an emphasis on developing strategies to compensate for the residual attention deficits, such as, dealing with informational overload and attention training, rather than directly addressing the impairment itself (Ylvisaker et al., 2007). The benefits of attention therapy seem to be greatest on complex attention tasks that require the self-regulation of attention and more similar to executive function, rather than those focused on vigilance, processing speed or reaction time which are difficult to rehabilitate.

As seen in addressing attention deficits, primarily compensatory strategies have been effective in treating the memory deficits associated with TBI. Internal strategies, as visual imagery training, are effective in improving interval and recall verbal memory in mild TBI (Kaschel et al., 2002), as well as, external compensatory devices as, notebooks, pagers, organizers and diaries, are similarly effective in moderate and severe TBI, particularly if they are several years post-injury (Ownsworth \& McFarland, 1999). When using external memory devices, it is beneficial to include self-management strategies or techniques to facilitate and maintain their use. Similarly, ease of use of the devices and relevance to the patient are vital for compliance.

Impairments in executive abilities can have wide-ranging effects on an individual's effective functioning in their environment that, in turn, influence their ability return to work and maintain job performance, integrate into their community, establish, and maintain interpersonal relationships. Remediation of executive dysfunction typically includes cognitive and behavioral strategies, which focus on planning, problem solving, and self-moni- 
toring skills (Cicerone et al., 2000; Cicerone et al., 2006; Kennedy et al., 2008; McDonald, Flashman, \& Saykin, 2002; von Cramon, Matthes-von Cramon, \& Mai, 1991). Interventions for problem solving, broadly defined as metacognition strategies of instruction (MSI), generally include training in problem orientation, problem definition and formulation, generation of alternatives, decision-making, and solution verification.

Levine and colleagues (2000) developed a formalized, staged problem-solving intervention, referred to goal management training (GMT) to remediate the executive deficits associated with TBI. GMT improves goal directed behavior through training in discrete stages of goal completion, including assessing the situation and directing attention toward specific goals and parsing them into subgoals, encoding and retaining these goals and subgoals, and monitoring outcomes. TBI patients who received GMT showed improved performance on paper and pencil tasks that corresponded to everyday problem-solving situations (Levine et al., 2000). Improvements in problem-solving abilities following TBI have been similarly been demonstrated with training strategies using such planning tasks, as the Tower of London task, that generalized beyond the training task (Cicerone \& Giacino, 1992), as well as, those focused on problem-solving strategies relevant to everyday life (Fox, Martella, \& Marchand-Martella, 1989).

\subsection{Social-Cognitive Skills Therapy}

Accumulating evidence suggests that TBI patients have a significantly impaired ability to perceive emotional information across sensory modalities and levels of abstraction from objects to faces and body postures (McDonald \& Saunders, 2005; Bornhofen \& McDonald, 2008). Perception of negative emotions appears to be more impaired than positive ones, but as a class, affect recognition tasks are effective indices of social cognition in this population. At the interface between affect recognition and social communication is the executive function of social problem solving which requires the ability to monitor, assess and integrate social cues and generate alternative solutions and engage in pragmatic language. Ratings of anxiety, self-concept, and interpersonal relationship ratings of TBI patients improve with the social skills training that include videotape feedback of the social interactions, modeling of specific skills, and practicing those skills during the treatment session (Helffenstein \& Wechsler 1982). Direct corrective feedback is also effective in reducing socially inappropriate comments and videotape feedback and social skills training has been effective in modifying social behavior and selfawareness (Brotherton, Thomas, Wisotzek, \& Milan, 1988; Lewis, Nelson, Nelson, \& Reusink, 1988). More recently, Dahlberg and colleagues (2007) have developed a program that targets social skills broadly and uses a group process approach, emphasizing self-assessment and individual goal setting, and encouraging generalization through homework and family or friend involvement. The social skills TBI group showed significant improvement in their participation in reciprocal conversation, social style, quantity and clarity of expression, and speech aesthetics, compared to their baseline scores that were not achieved by the control group and these treatment effects were maintained and at 3, 6, and 9 months follow-up (Dahlberg et al., 2007).

\subsection{Psychotherapeutic Approaches to the Treatment of TBI}

Providing psychotherapy to individuals suffering from a traumatic brain injury has its own set of challenges. Memory impairments can influence the therapeutic alliance and TBI patients may have difficulty recalling the contents and therapeutic interpretation provided in earlier sessions (Judd \& Wilson, 2005; Lewis, 1991). Increased distractibility reduced cognitive efficiency and fatigue can similarly compromise the therapeutic process (Pollack, 1994). Verbal fluency and word finding, particularly with left hemisphere damage, can make talk based therapies a greater challenge and require an innovative approach to therapy (Butler \& Satz, 1988; Leber \& Jenkins, 1996). Further complicating and hindering psychotherapy is the often-present lack of self-awareness with brain injury, particularly with more insight-based therapies. For psychotherapy to be successful, accommodations need to be made in relation the TBI patient's cognitive, emotional and neurobehavioral needs. The need for modifications of cognitive behavioral therapies to treat TBI is even more acute with individuals who have comorbid disorders as, PTSD or substance use, where outcomes are poorer and there are no empirically supported therapies to treat these comorbidities with TBI (Otis et al., 2011). The frequency and content of sessions may need to be adjusted to accommodate the patient's limited attention, memory or emotional needs (Pollack, 2005). Communication may need to be more directed, concrete and repetitive, amply supplemented with visual and mnemonic aids. Changes in their environment and new concepts will likely need to be introduced more gradually to reduce a TBI patient's feelings of being overwhelmed or their experiencing emotional flood- 
ing and catastrophizing (Pollack, 2005). Critical to therapeutic process after a brain injury is the re-establishment of a sense of self, acceptance of both their weakness and strengths, and the establishment of realistic goals of rehabilitation and therapy in the context of their familial and social environment.

1) Cognitive Behavioral Therapy (CBT). The vast majority of studies examining the effects of psychotherapy in the treatment of TBI have been case studies, with few controlled empirical studies addressing efficacy of treatment in this population (Coetzer, 2007). Using a manualized CBT approach in mild TBI, Mittenberg, Tremont, Zielinski, Fichera and Ravls (1996) demonstrated that brief cognitive therapy that consisted of psychoeducation around the symptoms and recovery from head injury, techniques for managing symptoms, and strategies for gradual resumption of activities could reduce the incidence of postconcussional syndrome following brain injury. In a controlled study, recovery of functioning was compared with TBI patients participating in a Neuro-behavioral Rehabilitation Program (NRP) that had a psychotherapeutic component to those who received standard rehabilitation without psychotherapy. Participants in NRP that included awareness and acceptance of injury, cognitive retraining, compensatory skills and better understanding of their emotional and motivational problems, showed improved neuropsychological test results, psychosocial adjustment, and patients were more likely to be employed as compared to controls (Prigatano et al., 1984). In a follow-up study, Prigatano and colleagues (1994) compared TBI patients treated in a neuropsychological oriented milieu therapy that included individual and group psychotherapy, physical, occupational therapy and speech and language therapy to historical controls. At a mean of 43 months post-injury, TBI patients who participated in the integrative cognitive rehabilitation program were more likely to be productively employed than historical controls. While no direct control group and formal outcome measures were used, a study by Delmonico, Hanley-Peterson and Englander (1998) suggested that group therapy of TBI patients with a dual diagnosis of substance abuse that emphasized frustration management through psychoeducation and cognitive-behavioral approaches involving modeling, coping strategies, rehearsal, self-monitoring and peer reinforcement within a rehabilitative center setting, was effective in reducing anger levels and substance abuse. Corrigan, Lamb Hart, and Rust (1995) have developed a similar, holistic rehabilitative and behavioral program to treat substance abuse following traumatic brain injury, but the empirical data regarding efficacy are limited.

2) Community and Integrative Therapies. Psychosocial impairments, some of the most disabling consequences of TBI, often do not emerge until after discharge from the hospital, when difficulties in family and community integration become evident (Ponsford et al., 1995; Caetano \& Christensen, 1999). A range of community-based TBI rehabilitation programs have been explored and include interdisplinary team rehabilitation (Ponsford et al., 2006; Ponsford, Oliver, \& Nelms, 2003; Powell, Heslin, \& Greenwood, 2002; Smith et al., 2006), home based behavioral management program (Carnevale, Anselmi, Busichio, \& Millis, 2002; Carnevale, Anselmi, Johnston, Busichio, \& Walsh, 2006), outdoor experiential education programs (Thomas, 2004; Walker, Onus, Doyle, Clare, \& McCarthy 2005), telephone counseling (Bell et al., 2005), client and caregiver educational training program (Sinnakaruppan, Downey, \& Morrison, 2005) and community-based peer support (Hibbard et al., 2002). While the efficacy of these programs depended on an interaction of program and participant characteristics, and the methods used to assess outcomes (Evans \& Brewis, 2008), the greatest treatment effects were seen in quality of life and functional independence measures and were associated with interdisplinary team rehabilitation programs as, telephone counseling, educational group training, and a group outward bound course. Overall, those programs that involved group interventions, demonstrated greater treatment effects than those involving individual therapy programs on measures of quality of life and functional independence (Evans \& Brewis, 2008).

\subsection{Pharmacological Treatment of Cognitive and Neurobehavioral Impairments}

Despite the broad use of pharmacotherapies to treat the cognitive and neurobehavioral sequelae of TBI, there are no FDA approved drugs to treat the behavioral consequences of TBI (Warden et al., 2006). The use of stimulants as, methylphenidate, has the most evidence to support their use in the treatment of sustained attention deficits, processing speed and more general cognitive functioning (Whyte et al., 1997, 2004). The psychostimulant, dextroamphetamine, may also have the added benefit of reducing the variability in performance in tasks of attention and working memory (Hornstein, Lennihan, Seliger, Lichtman, \& Schroeder, 1996), but the studies at this time are limited. Cholinesterase inhibitors, initially developed in treating dementia, as donepezil and physostigmine, have been useful in treating the memory deficits and improving attention following TBI (Cardenas et al., 1994; Griffin et al., 2003; Taverni, Seliger, \& Lichtman, 1998; Zhang et al., 2004). Other drugs in this 
pharmacological class as, rivastigmine and galantamine, as well as, other drugs used in treating dementia, as the NMDA antagonist, memantine, need to be more systematically studied in future studies. The dopamine receptor agonists, bromocriptine and amantadine, are the only drugs that have been shown to be effective in treating the executive functions as initiation and mental flexibility, but, again, the data are limited (Kraus \& Maki, 1997; McDowell, Whyte, \& D’Espoito, 1998).

Selective serotonin reuptake inhibitors (SSRI), as fluoxetine and sertraline, have been shown to be effective in treating depression following TBI, with $87 \%$ of patients reported as responders and $67 \%$ in remission on the Hamilton Depression Scale following 8 weeks of treatment with sertraline (Fann, Uomoto, \& Katan, 2000). SSRIs may also be effective in treating anxiety following TBI, but the data is limited to a few case studies with venlafaxine (Khouzam \& Donnelly, 1998). Similarly, limited data is available for the treatment of psychotic symptoms following TBI, however, case reports suggest that the atypical antipsychotic, olanzapine, is effective in reducing delusional ideation, persecutory voices and improved patient compliance (Butler, 2000; Umansky \& Geller, 2000).

\section{Research and Design}

\subsection{Frequently Used Research Designs in the Study of the Psychopathology of TBI}

The research designs used to study the psychopathology of traumatic brain injuries are numerous and range from population-based epidemiological studies to case presentations. While it is beyond the scope of this review to comprehensively evaluate this literature, representative research studies and findings are provided to exemplify the advantages and limitations of these designs.

1) Epidemiological studies. Epidemiological studies have been essential in estimating the rates of TBI, mortalities and morbidities that are associated with the disorder, populations that are risk and the moderating factors that influence outcomes at both the national and global levels (Coronado et al., 2011; Hyder et al., 2007; Tagliaferri, Compagnone, Korsic, Servadei, \& Kraus, 2006). Given the public health concern and the financial and emotional impact on the lives of those experiencing a TBI and their families, several epidemiological surveys have been performed in the Untied States, with the Center of Disease Control (National Center for Injury Prevention and Control) and the American College of Surgeons taking leading roles. During 1997-2007, for example, the CDC reported that while the overall death rates from TBI decreased 8.2\% from 19.3 to 17.8 per 100,000 , they increased in younger (5 - 19 years old) and older individuals ( $>75$ years old) and minority populations (Coronado et al., 2011). Internationally, based on finding from the Global Burden of Disease Survey, the major causes of TBI were traffic related accidents, falls, other unintentional injuries, violence and war, with the precise rates, risk factors, sequelae, financial cost, and social impact, varying by country (Hyder et al., 2007).

National databases as, the National Hospital Ambulatory Medical Care Survey (NHAMCS; McCaig \& McLemore, 1994) and National Hospital Discharge Survey (NHDS; Dennison \& Pokras, 2000) have been used to estimate Emergency Department (ED) visits and outcomes, with falls being the leading cause of ED visits (32\%), followed by motor vehicle accidents (19\%), struck by/against which includes sports related injuries (18\%), and assaults (10\%) (Rutland-Brown et al., 2006). Rates of sports concussions are likely grossly underestimated in such surveys (approximately 300,000/year; Thurman, Branche, \& Sniezek, 1998), as they include persons reporting a loss of consciousness (Langlois, Rutland-Brown, \& Wald, 2006), which represent only 8\% to $19.2 \%$ of sport related TBIs (Collins et al., 2003; Schultz et al., 2004). Taking this into consideration, a more accurate estimate of just sports related TBIs is 1.6 to 3.8 million in the United States annually, which may still be an underestimation, as many do not seek medical care (Langlois et al., 2006).

Based on the National Trauma Data Bank, investigators have used retrospective analyses to identify populations that are at risk, ED procedures, and variables affecting outcomes. For example, of a sample of 50,835 pediatric ED visits, males experienced $69 \%$ of the concussions, 33\% were sports-related, and $69 \%$ of those diagnosed with a concussion received a CT scan (Meehan \& Mannix, 2010). In a sample of 52,344 moderate and severe TBI patients, despite controlling for confounding variables, individuals with health insurance showed improved outcomes (lower mortality rates) than their uninsured counterparts (Alban et al., 2010). In a sample of 58,729 of hospitalized moderate and severe TBI, racial minorities were $15 \%$ less likely to be placed in rehabilitation settings following discharge (Shafi et al., 2007a, b) and suffered poorer functional outcomes based on the Functional Status Examination (Staudenmayer et al., 2007).

2) Longitudinal studies. Longitudinal studies, particularly prospectively designed ones, have been useful in 
identifying the recovery of cognitive and neurobehavioral functioning following traumatic brain injury and the efficacy of treatment. Long-term longitudinal studies agree that moderate to severe TBI results in cognitive impairments in processing speed, attention and memory in the first year (Dikmen et al., 1995; Bercaw et al., 2011) that can extend several years (Millis et al., 2001) to decades post-injury (Draper \& Ponsford, 2008; Himanen et al., 2005). Longitudinal studies suggest further that changes in performance from inpatient treatment to 1-year post-injury in word list learning and processing speed are sensitive, predictive indicators of second year postinjury ratings and functional status (Bercaw et al., 2011).

These latter findings should not imply that neuropsychological recovery after TBI is uniform across individuals and cognitive domains. For a subset of moderate and severe TBI patients, neuropsychological recovery may continue several years after injury with substantial recovery, while others have measurable deficits 5 years postinjury (Millis et al., 2001). Even a decade post-injury, neuropsychological measures of attention/processing, memory, and executive functioning (Burgess \& Shallice, 1997) differentiate TBI patients from controls, and injury severity correlates with neuropsychological performance (Draper \& Ponsford, 2008). One-year post moderate to severe TBI, there are also declines in community productivity, increases in depressive symptoms, and lower satisfaction with life (Hart et al., 2005). Impairments are not limited to the injured person and 2 and 5 years post severe TBI, poor family functioning, anxiety and depression in the relatives are predicted by behavioral and mood changes in the injured individual, suggesting reciprocity of functioning (Schönberger, Ponsford, Olver, \& Ponsford, 2010).

3) Cross-sectional observational studies. Cross-sectional studies may be retrospective or prospective and allow the analysis of specific cohorts of interest at a point in time. Such cross sectional study designs have been used to explore variables as gender and the number of sport concussions (Cantu, Guskiewicz, \& Register-Mihalik, 2010; Frommer et al., 2011; Matser et al., 1999), cognitive deficits in persistent postconcussive syndrome (e.g. Cicerone \& Azulay, 2002) and psychiatric comorbidities of PTSD and depression with moderate and severe TBI (Romesser et al., 2011; Zatzick et al., 2010). In comparing 812 sports concussions across nine competitive sports, male athletes were more likely to report symptoms of amnesia, confusion and disorientation, while female athletes reported more drowsiness and sensitivity to noise than did males (Frommer et al., 2011). In studies using formal neuropsychological testing, amateur soccer players that had 1 to 5 concussions were impaired on tests of planning (39\% vs. $13 \%$ ) and memory ( $27 \%$ vs. $7 \%$ ) compared to swimming and track athletic controls and the number of concussions incurred in soccer was inversely related to neuropsychological performance (Matser et al., 1999). In a multisite, prospective cohort study of 3047 combat veterans, severe and moderate TBI patients, but not those with mild TBI had a diminished risk of PTSD symptoms relative to patients without TBI (Zatzick et al., 2010).

Regardless of TBI severity, however, injured patients with PTSD demonstrate the greatest impairment based on self-report (Zatzick et al., 2010) and endorsed decreased ability to cope with the PTSD symptoms compared combat veterans without a TBI (Romesser et al., 2011). In a study directly comparing cohorts of TBI patients, those with a dual diagnosis of depression performed poorly on tests of frontotemporal functioning (Trail Making B, WCST), had lower choline/creatine and N-acetylaspartate/creatine ratios in right basal ganglia based on MRS, and lower regional brain volumes in the right frontal, left occipital and temporal lobes (Rao et al., 2010).

\subsection{Frequently Used Research Designs for the Assessment of TBI}

1) Threats to reliability and validation of neuropsychological assessment tests. The evaluation of the reliability and validity of neuropsychological testing instruments used to measure cognitive and neurobehavioral performance is an intensive area of research and essential in determining the clinical utility and generalizability of the results. As can be seen from Table 1, measures of test-retest, internal and inter-rater reliability, as well as, criterion and construct validity, vary considerably across assessment measures. Reliability coefficients should be interpreted with caution as they will vary with testing conditions and population, and only those of .80 or greater are considered acceptable. Table 1 includes measures of construct validity based on convergent correlation coefficients or factor analysis loading. While the validity values are generally acceptable, they should not be interpreted as measuring a pure or single construct, as there is overlap between cognitive domains, particularly those of attention, working memory and executive function.

The Traumatic Brain Injury Outcome Workshop, formed to address the need for a common set of outcome measures for TBI research across agencies and populations, proposed a 3-tier system in the selection of measures (Wilde et al., 2010). In the first tier, core measures included statistically valid, robust, and widely applicable 
outcome measures with proven utility in TBI from identified domains of global level of functioning (Glasgow Outcome Scale), neuropsychological impairment (RAVLT, Trail Making Test, Processing Speed Index of WAIS-IV), psychological status (Brief Symptom Inventory-18), TBI related symptoms (Rivermead Post Concussion Symptom Questionnaire) and physical functioning (FIM Cognitive Subscale), and social role participation (CHART-SF) and perceived quality of life (Satisfaction With Life Scale). Supplemental or 2-tier neuropsychological measures they recommended were the Brief Visual memory Test, Letter-Number Sequencing (WAIS-IV), Controlled Oral Word Association Test (COWAT), Stroop Color-Word Interference Test, Digit Span (WAIS), Word Reading of the WRAT-4, Grooved Pegboard Test, consistent with the model battery provided in Table 1 and the deficits documented with TBI. The Workgroup recognized the importance of assessing comorbidities with TBI and in the 2-tier measures of psychological status included the MMPI-II, Alcohol Use Disorder Identification Test, Alcohol, Smoking and Substance Use Involvement Test and the PTSD Check List.

2) Limitations in neuropsychological assessment. While immensely useful in detecting specific deficits, most neuropsychological assessment measures used to evaluate the consequences of a TBI have little ecological validity. Tests as, the Wisconsin Card Sorting Test, Category Test or Stoop Interference, require veridical, external reasoning and fail to measure more ecologically important internal, actor-centered reasoning (Goldberg \& Bougakov, 2005). With executive function tests that are vertical in nature, the patient's responses are either right or wrong, while actor-centered tests as, the Iowa Gambling Test (Bechara, 2007) and the Cognitive Bias Task (Goldberg, Podell, \& Lovell, 1994) depend on the patient's needs or the perception of those needs. Similar criticisms can be made of list learning tasks to assess memory that has little relevance to the kind of memory functioning needed to maintain an independent life. More ecologically valid tests of executive function, as the Iowa Gambling Test, which has reward contingencies and requires adaptive reasoning, and prospective memory, as assessed with the Rivermead Behavioral Memory Test, are rarely used in TBI (Lajiness-O’Neill, Erdodi, \& Bigler, 2010; Mathias \& Mansfield, 2005). Despite its limited adoption, poor performance on the Iowa Gambling Test has excellent predictive validity and is strongly associated with impaired decision-making and an inability to maintain employment (Bechara \& Van Der Linden, 2005).

Other limitations of neuropsychological assessment are as follows. First, several neuropsychiatric disorders, such as depression, posttraumatic stress disorder, and substance abuse share the symptoms of impaired attention, executive function, memory and psychomotor speed, seen with TBI, often making a differential diagnosis difficult (Iverson, 2006). Neuropsychological evaluations include objective measures of mood disturbances, PTSD and substance abuse to better ensure accurate diagnoses and prevent misdiagnosing of these disorders (Greiffenstein \& Baker, 2008), but there are diagnostic limits that need to be kept in mind. Second, the level of effort put forth by the patient and being able to operationally measure it, is critical in evaluating TBI. Effort, a clear mediator of neuropsychological performance, is difficult to control and accounts for more of the variance in performance that trauma severity (Green, Rohling, Lees-Haley, \& Allen, 2001). Discrepant performance within and between assessment measures need to be evaluated for possible signs of reduced effort and at least two tests of malingering need to be included in an evaluation (Lynch, 2004). Third, racial and cultural biases need to be considered in evaluating the results of neuropsychological testing. While there are only a few studies that have examined racial differences in neuropsychological testing in the context of TBI (Kennepohl, Shore, Nabors, \& Hanks, 2004), such biases have been broadly documented when testing different racial or ethnic groups (Baird, Ford, \& Podell, 2007; Pedraza \& Mungas, 2008; Wilkie et al., 2003). Fourth, ligation status of the patient needs to be considered, as it can often distort the clinical presentation, particularly in mild TBI (Larrabee, 1997, 2000). Lastly, premorbid functioning needs to be considered and estimated by convergent neuropsychological and achievement measures, in order to gain a more accurate measure of current functioning. Given these limitations, many have argued that physiological measures, as neuroimaging and the tracking biological markers, need to be integrated with neuropsychological testing to not only to aid in diagnosis of TBI, but also to monitor recovery and guide treatment (Maas et al., 2011).

3) Brain neuroimaging studies as assessment measures. Neuroimaging techniques that are particular promising in the early detection of brain damage and the changes with TBI are those that measure specific metabolites and neurotransmitters, as with MR Spectroscopy (MRS), or the integrity of white matter tracts with DTI (Haacke et al., 2010; Kou et al., 2010; Van Boven et al., 2009). MRS measurement of N-aceytl-L-aspartate (NAA), a marker of neuronal integrity, is of particular interest, as NAA values have been shown to be reduced with acute TBI and associated with neuropsychological outcome (Babikian et al., 2006; Brooks et al., 2000; Brooks, Friedman, \& Gasparovic, 2001; Friedman et al., 1999; Garnett, Blamire, Rajagopalan, Styles, \& Cadoux Hudson, 
2000; Holshouser et al., 2006; Shutter, Tong, Lee, \& Holshouser, 2006). The time course of changes in NAA/Cr ratios parallel the reported recovery of symptoms in sports-related concussions, declining at 3 days post-injury, partially recovered at 15 days post, and returned to control levels at 30 days post brain injury (Vagnozzi et al., 2008). Similarly, the integrity of white matter pathways as assessed with DTI (Pierpaoli et al., 1996) has been shown to be sensitive to the early detection of changes in the corpus callosum and anterior internal capsule within the first 24 hours of a mild TBI (Arfanakis et al., 2002). Changes in white matter integrity have been observed at 3 and 7 days post mild TBI (Wilde et al., 2008) and were correlated with the development of postconcussive symptoms, and visual motor speed and impulse control deficits (Bazarian et al., 2007). Altered axonal integrity has also been observed in the chronic phase of mild TBI and is correlated with complex attention, list learning, and memory performance (Hartikainen et al., 2010).

Despite the increased sensitivity and functional relevance of methods as MRS and DTI, the interpretation of these imaging results are often complicated by methodological considerations and lack standardization across studies of TBI (McAllister et al., 2001; Levine et al., 2006). There is no standardization of the time post-injury, imaging protocols, targeted neurotransmitters, or the metabolites and fiber systems studied across laboratories, severely limiting our understanding of the early pathophysiological sequelae of TBI. The establishment of common data element database for radiological imaging of TBI has recently been called for by a consortium of government and private agencies (Duhaime et al., 2010; Haacke et al., 2010). The development of such a database holds great promise in indentifying the cellular and neuroanatomical systems central to the assessment and treatment of TBI.

Also lacking in the literature are studies that combine structural and functional brain imaging strategies in individuals sustaining a TBI. The combination of structural MRI studies examining white matter and neuronal integrity (DTI and MRS-NAA), with the functional imaging methods as, PET and SPECT, to visualize specific neurotransmitter systems, holds the potential of opening new horizons in our understanding of TBI to rationally inform pharmacotherapy and behavioral treatment. One example of the successful marriage of functional and structural imaging techniques is the combination of MEG and DTI to characterize the anatomical deficits associated with TBI (Huang et al., 2009). Longitudinal studies using such integrative structural and functional imaging techniques that span the acute and chronic rehabilitative settings, in conjunction with neurocognitive assessment, are essential in furthering our understanding of the biology of brain injury and designing effective treatment protocols.

\subsection{Frequently Used Research Designs for Studying Treatments and Interventions of TBI}

There is broad range of research designs used to evaluate the efficacy and effectiveness of interventions in TBI. In randomized controlled trials (RCT), the gold standard of empirical research, subjects are randomly assigned to one of several treatment or control (placebo) groups. RCTs may have a crossover feature, where subjects receive multiple treatment or control conditions in a randomized order, allowing subjects to be used as their own controls. Crossover trial designs are limited to the chronic phase of TBI treatment, as this design requires a more stable clinical presentation. RCTs need to meet internal and external validity requirements and be statistically powered or have a sufficient number of participants to observe a predefined difference (percentage change) at a prospectively defined level of statistical certainty (Kazdin, 2003). Such a research design can be applied to the acute care setting, as the study that demonstrated that increasing rehabilitation intensity reduces length of hospital stay (Shiel et al., 2001) or in the chronic care setting, where structured, multidisciplinary rehabilitation in a community setting can improve social functioning (Powell et al., 2002). Using a RCT design, investigators have demonstrated that: direct patient involvement in neurorehabilitation goal setting resulted in a significant improvement in obtaining the goals from pre-test to post-test (Webb \& Glueckauf, 1994), that donepezil improved attention and short-term memory (Zhang et al., 2004), and social communication skill training improved communication skills (Dahlberg et al., 2007). While findings from a well-designed RCT are statistically the most the convincing, they have limitations that include the financial and resource requirements of conducting such trials, the ethical implications of including a placebo or control group, and the masking of individual treatment responses due to data aggregation and group reporting.

Study requirements may prevent the randomization of subjects to different conditions. Such nonrandomized research designs include prospective cohort studies, retrospective cohort or case-control studies, and multiple baseline studies that permit a direct comparison of treatment conditions. Investigators have used nonrandomized research designs to elegantly demonstrate that: both cognitive remediation and day treatment were associated 
with a decrease in depressed mood (Ruff \& Neimann, 1990), that internal strategies were an effective aid in improving recall (Goldstein, Levin, Boake, \& Lohrey, 1990), and that pragmatic language interventions including role-playing improved social communication skills, as well as, self-concept (Helffenstein \& Wechsler, 1982).

Another commonly used research design to study treatment effects in TBI is the single-subject single-group design that does not have a concurrent control, but uses the subject or the group, respectively, as their own pretreatment control. Investigators using such designs have demonstrated that: peer-group training of pragmatic language skills may benefit individuals with communication problems following TBI (Snow, Douglas, \& Ponsford, 1998), that mindfulness-based stress reduction program may be effective in treating depressed mood (Bedard et al., 2003), and that the anticonvulsant, carbamazepine, may decrease the incidence of aggressive behaviors (Azouvi et al., 1999). Each of the above research designs may be cross-sectional, examining the effects of treatment at a particular point in time, or longitudinal, where the emphasis is on the sustainability or durability of the treatment.

1) Threats to validation of treatment studies. There are several threats to reliability and validity that, while common in medical and psychological research, are particularly problematic in the study of inventions and treatments of TBI. First, is the choice of outcome measure, its clinical meaningfulness, and sensitivity mat be unclear. As an example of the complexity of this question, in a review of community-based TBI therapies, the authors reported that there were 41 standardized assessment tools, self-report measures and qualitative techniques used in the 11 studies reviewed for treatment effectiveness (Evans \& Brewis, 2008). Further complicating the question of which outcome measures may be appropriate is the range of sensitivities and specificities of each of these measures, which vary with sample population and research setting. The clinical meaningfulness of an outcome measure may also not be immediately obvious, as, it will vary not only with the magnitude of the effect, but also the individual measure. While a $10 \%$ change, for example, in mortality rates following TBI treatment is unquestionably clinically meaningful, the same level of statistical improvement on the Community Integration Questionnaire or in Trail Making, may not be. A common or standardized set of outcome measures for TBI that span institutions, researchers and populations that is statistically valid, robust, and widely applicable has been proposed (Wilde et al., 2010), but we have by no means achieved universal consensus, particularly, in the emerging fields of neuroproteomics and neuroimaging.

A second threat to the reliability and validity of research design as it relates to treatment is the lack of agreement as to what constitutes mild, moderate and severe TBI and whether these classifications are too broad, adding an unacceptable amount of variability to the treatment groups. Such broad categories make it difficult to evaluate differences seen across interventions, whether they are community based or individually administered psycho- or pharmacotherapies, as they may be due differences in the sample being tested, rather than the treatment paradigm or its implementation.

A third threat, particularly relevant to the research design of therapeutic studies in TBI, relates to sampling biases, inclusion and exclusion criteria that may be too narrow or broad, and the use of samples of convenience (Kazdin, 2003). Time post-injury to initiate treatment is also of great importance, as the nature and severity of the TBI deficits vary with recovery time and influence the study sample and the likelihood of observing a treatment effect. Use of double blind RCT designs, stratification strategies and multi-center study sites mitigates some of these selection biases, but such research designs add substantially to the costs and resources needed to implement.

2) Limitations in research and design of treatment studies

a) Lack of head-to-head treatment studies. The relative lack of direct treatment comparison studies makes it exceedingly difficult to make informed, empirically based decisions as to which intervention may be most effective for a given patient. One such study design compared the efficacy of 4 months of holistic, intensive neuropsychological rehabilitation to a standard rehabilitation program. While both treatment groups showed improvements in community integration, the holistic, intensive neuropsychological rehabilitation group was twice as likely to show clinical benefits in community integration, and showed significant improvement in overall neuropsychological functioning and perceived self-efficacy (Cicerone, Mott, Azulay, \& Friel, 2004). The interpretation of this study should be made cautiously, however, as there was a systematic selection bias in the assignment of treatment groups. Randomized controlled clinical trials directly comparing the effectiveness of treatment protocols and estimating cost-effectiveness of the treatments are critically needed.

b) Lack of an emphasis on prevention in clinical trials. Early diagnosis of a TBI is not only important in the medical management of the injury, but also vital in the prevention of the persistent symptoms and a lifetime of 
disability (Mittenberg et al., 1996; Ponsford et al., 2001). Half of individuals admitted to an ED with a head injury fail to be diagnosed with mild TBI, despite meeting diagnostic criteria, and discharged home without medical or psychological follow-up (Powell et al., 2008; Sharpe et al., 2012). With accurate and early assessment of TBI, intervention programs can be initiated to reduce the risk of postconcussive syndrome. Further, genetic screening for alleles that are known to be associated with poor outcomes following TBI (APOE4, BCL2, COMT, and DRD2) should be performed to identify those at greater risk and initiate prevention programs (Diaz-Arrastia \& Baxter, 2006; Jordan, 2007).

c) Lack of inclusion of racial and ethnic minorities. While it is difficult to know with certainty the root causes for the disparities in rehabilitative care and outcomes of racial and ethnic minorities who experience a TBI (Arango-Lasprilla et al., 2007; Burnett et al., 2000; Hart et al., 2005; Johnstone et al., 2003; Shafi et al., 2007a; Sherer et al., 2003), they are likely to involve at least three interacting sets of factors that relate to the patient and their trust of the medical system (Kahn, Mastroianni, \& Sugarman, 1998), the clinical providers and the institutions providing the care. At the institutional level, manipulation of such factors as increasing awareness of racial disparities, implementing and monitoring quality of care standards, and improving patient education may lead to an increased access to care and possibly reduce the gap in services and outcomes. Similarly, at the clinical provider level, implementing racial diversity and competency training that encourages a greater self-awareness of personal biases and attitudes towards others, may reduce the differential treatment experienced by diverse populations. Despite a clear need to improve treatment outcomes in racial and ethnic minorities, there are no clinical studies varying such institutional and clinical provider factors. Further, racial minorities are grossly under represented more broadly in clinical research (Kahn, Mastroianni, \& Sugarman, 1998; Corbie-Smith, Thomas, Williams, \& Moody-Ayers, 1999), and more specifically in TBI intervention trials (Arango-Lasprilla et al., 2007; Newgard et al., 2008), undermining the clinical validity and generalizability of the results.

\section{Future Studies and Recommendations}

As documented in the preceding review, much has been gained in our understanding of the psychopathology, assessment and treatment of TBI. Still lacking is the breadth and depth that an integrative and multi-disciplinary approach to TBI portends. While there is a greater awareness of a need for such a systems-based approach as evidenced by the number of professional organizations and government agencies recently advocating a need for standardization in the collection data in TBI, the application of multi-dimensional approach, and the development novel strategies to deliver prevention, assessment and treatment to large, diverse populations, we are still in the early stages in making this important shift (Jagoda et al., 2009; Maas et al., 2010, 2011; McCrea et al., 2007; Saatman et al., 2008; Vos et al., 2002; Wilde et al., 2010). In the nearer term, there are clinical assessment and interventional programs that can be developed and empirically validated to bring us closer to this integrative, multi-disciplinary ideal.

\subsection{Universal Diagnostic Classification System for TBI}

Central to our understanding of TBI is the need for a universal, reliable, validated classification system of traumatic brain injury that accounts for its varying clinical presentations. While measures of severity as, GCS, PTA, and LOC, are useful in the clinical management of TBI, they provide little or no information regarding the pathophysiological losses, the long-term functional or psychosocial outcomes, or guide the selection of targeted, efficacious interventions. Further, broad classification of mild, moderate or severe TBI is arbitrary and fails to capture the heterogeneity and continuum of deficits seen in each of these subclasses. As a simple example, within severe TBI subclass, outcomes are bimodally distributed, with $70 \%$ of patients falling in the good outcome group based on the Functional Independence Measure (FIM) or are dead (Bullock et al., 2002). Surveillance analysis data of 134,780 patients confirmed these findings, and while GCS scores were related to mortality, the relationship is nonlinear, casting doubt on its use as a continuous measure (Udekwu et al., 2004). Efforts have been made by the American Congress of Rehabilitation Medicine (Menon, Schwab, Wright, \& Maas, 2010), American Academy of Neurology (1997), American Psychiatric Association (2000), European Federation of Neurological Societies (Vos et al., 2002), World Health Organization Collaborative Task Force (Carroll et al., 2004), and the Center for Disease Control and Prevention (Rutland-Brown et al., 2006) to provide diagnostic criteria for mild TBI, but none of these diagnostic schemes relate the disorder to specific pathophysiological or neuropsychological findings. 
Ideally, a classification system should be iterative, incorporating diagnostic findings and measures from different areas of inquiry to derive pathophysiologically and prognostically distinct, normally distributed, nonoverlapping groups. Given the current tripartite classification system of TBI, failures to replicate study findings or differences between treatment groups become difficult to interpret, as they may be due to sampling differences, despite presumably controlling for injury severity. An interagency workshop on standardization of data collection in TBI and Psychological Health was organized in March 2009 (Thurmond et al., 2010) and as part of their analysis and recommendations stated, "We should recognize that the severity lies on a spectrum and that categorization into a limited number of categories leads to a loss of valuable information. Greatly different patterns of injury and pathology may be seen on structural imaging in patients with similar grades of clinical severity assessed by the GCS (Saatman et al., 2008). A more comprehensive and multidimensional approach to classification of TBI is advocated" (Maas et al., 2010). Despite such advocacy, we remain in our infancy in developing such a comprehensive, multidimensional approach to the classification of TBI.

\subsection{Integration of Pathophysiology and Pharmacological and Rehabilitative Therapies}

Presently, pharmacotherapy of TBI is a "hit or miss" process and largely based on acute symptom presentation. While there are pharmacological guidelines for the treatment of the cognitive and neurobehavioral sequelae of TBI (Warden et al., 2006), they are not based on the pathophysiological changes experienced by the patient. Pharmacotherapy and neurorehabilitative therapies decisions should be made in conjunction with serial brain imaging and microdyalisis studies (Timofeev et al., 2011) that identify specific neurochemical systems and neural circuits that may be altered with TBI.

\subsection{Development of Treatments Addressing Disorders Comorbid with TBI}

One area investigation that has clear clinical relevance, but inadequately addressed, is the high comorbidity of TBI and other disorders as, alcohol abuse, chronic pain and PTSD and the development of empirically supported, integrative therapies that take into consideration the unique set of deficits associated with brain trauma. For example, despite the intimate relationship between TBI and alcohol abuse and that two-thirds of patients admitted to brain injury rehabilitation units have a history of alcohol or illicit drug abuse (Corrigan, 1995; Parry-Jones et al., 2006), the vast majority of rehabilitative programs focus on cognitive, physical and occupational functioning in the context of physical medicine and rehabilitation and ignore issues of substance abuse.

Critically needed are holistic TBI programs that integrate cognitive, psychosocial and substance abuse intervention (Corrigan, Lamb Hart, \& Rust, 1995; Delmonico et al., 1998). At present, physical medicine physicians do not have the expertise treat the substance abuse problems of their patients, and psychologists who might be able to deal with the substance abuse issues, are unprepared for the cognitive and the rehabilitative challenges of the TBI patient. Moreover, failure to concurrently address the TBI patient's substance abuse problems puts them at high risk of compromising their rehabilitative gains (Graham \& Cardon, 2008). A standardized, group-based, empirically supported treatment program for individuals with TBI and substance abuse is clearly needed in the general population, if not more so, in the military, where there is a high concurrence of substance abuse and TBI (Jacobson et al., 2008; Richards, Goldberg, Rodin, \& Anderson, 1989). Similarly, despite the prevalence of PTSD and TBI among military personnel, there are few integrative, interdisplinary treatment programs and no RCTs investigating cognitive-behavioral therapies that meet the conflicting needs of these patients (Otis et al., 2011).

\subsection{Delivery of Assessment and Treatment Services}

1) Population delivery of assessment services. Even with conservative estimates of 1.7 million TBIs annually in the United States, a neuropsychological assessment battery will need to be delivered to a large, diverse population and spans the extremes of age. Further, while cognitive recovery post-injury follows a general pattern, there is a great deal of individual variability and physicians often underestimate the time needed for recovery and resumption of activities (Alexander, 1995). Early resumption of activities of TBI patients increases the risk of subsequent brain injury, exacerbates deficits, and increases the risk of developing Alzheimer's dementia and other dementias later in life, as well as, other neurological disorders (Anderson et al., 2009; Deb et al., 1998; Diaz-Arrastia, Agostini, Madden, \& Van Ness, 2009; Dobscha et al., 2009; Jellinger, Paulus, Wrocklage, \& Lit- 
van, 2001; Koponen et al., 2002; Lux, 2007). In diagnosing and treating a traumatic brain injury, the course of recovery is, therefore, critical and requires serial assessment.

Serial neuropsychological testing across levels of care, delivery of services to a large and diverse population, as well as, rapid data accessibility and transfer, requires a computerized testing system. Such assessment systems, as those developed for sports related concussions (Collie et al., 2003; Schatz, Pardini, Lovell, Collins, \& Podell, 2006), can be adapted to address the needs of the civilian and military populations (McCrea et al., 2008). The electronic platform should be highly portable (physically and electronically) and the testing protocols, while brief to administer, will need to meet psychometric rigors of reliability and validity (Randolph, McCrea, \& Barr, 2005) and show comparable sensitivity, specificity and predictive validity of tradition measures of attention, memory and executive function. Beyond the acute phase of TBI, the test protocol should include measures of response bias or effort, given motivational factors may confound clinical presentation. Ideally, alternate forms of the protocols will be developed to reduce possible practice effects with repeated administration. To take a further page from the sport concussion playbook, pre-deployment baseline can be established with military personnel to compare post-injury results and track recovery. Given the testing is performed at predetermined intervals, it can be terminated once pre-morbid estimates of functioning are achieved, treating only those patients who demonstrate persistent impairments.

For such a paradigm shift to occur in the assessment and treatment of TBI, outcome studies will need to be performed. Outcome measures would include measures of patient and provider satisfaction and the reduction of subsequent, more costly utilization of services. It is hypothesized that an objective and reliable measure of cognitive functioning at the time of injury would be welcomed by both patients and ED providers, as it would assist in managing care and in follow-up treatment, if any were necessary. As a leading risk factor for experiencing a TBI is a previous history of a traumatic brain injury, the early, accurate diagnosis and treatment of TBI, should produce a predictable, cost-offsetting, prevention of a subsequent, more impairing and costly TBI. Further, in the case of mild TBI, supportive psychological and psychoeducational interventions can effectively reduce the incidence of persistent postconcussional syndrome, which in turn improves functioning and reduces disability (Mittenberg et al., 1996; Ponsford et al., 2001). These interventions are most effective when introduced early in the course of the disorder, as in the acute and subacute phases (Borg et al., 2004). Despite these findings, under current standards of care, $56 \%$ of mild TBI fail to be diagnosed in the ED, as physicians tend to focus on physical injuries and making immediate medical decisions (Powell et al., 2008). Negative CT scan findings are given the greatest weight, followed by determination of LOC by ED physicians. Once a more severe brain injury is ruled out, findings of shorter lengths (i.e. $30 \mathrm{~min}$ ) of LOC or PTA do not necessarily lead to a written diagnosis of mild TBI. This seems to be especially true for those cases where there were other injuries to be addressed, even if the other injuries were relatively minor.

Independently, Sharpe and colleagues (2012) demonstrated in a random sample of children who were seen and discharged from a large metropolitan pediatric ED following a head injury that there were significant documentation deficiencies (below best practice guidelines) in identifying children with a potential brain injury, and as a result, $50 \%$ of the children that fulfilled the WHO diagnostic criteria of a mild TBI were not identified. In contrast, the documentation followed best practice guidelines in making a decision of whether a CT scan was required.

From a cost-effectiveness standpoint, one can model the costs of developing and administrating the proposed TBI neuropsychological testing and compare them to lost productivity costs, future rehabilitative and medical expenditures, and lifetime societal and interpersonal costs of a missed diagnosis. The savings are likely to be substantial, magnified if the brain injury occurs early in age and if one includes the impact of the TBI on the family and caregivers. A conceptually similar analysis was performed to determine the cost-effectiveness of adopting the existing Brain Trauma Foundation guidelines for acute care of severe TBI that suggested an annual savings in medical costs (\$262 million), rehabilitation costs (\$43 million), and lifetime societal costs of \$3.84 billion (Faul, Wald, Rutland-Brown, Sullivent, \& Sattin, 2007).

2) Population delivery of treatment services. As the unmet needs for effective treatments of TBI are so large, innovative delivery methods are needed. In addition to brief (4 - 6 sessions) cognitive behavioral group therapy to help patients gain acceptance of their injuries and psychoeducation to prevent future brain injury, internetbased therapies, bibliotherapy, educational programs, and the use of virtual reality should be systematically explored in randomized clinical trials, compared to other therapies, and empirically validated as possible treatment modalities. Currently, only limited data is available for the effectiveness of brief behavioral interventions (Nie- 
meier, Kreutzer, Marwitz, Gary, \& Ketchum, 2011) or alternate interventions, as educational programs, internet-based therapies, virtual reality-based therapies, in the treatment of TBI (Cernich et al., 2010; Echlin et al., 2010; Penn, Rose, \& Johnson, 2009; Rivara et al., 2011). For long-term therapy (>3 months), community-based rehabilitation programs are cost-effective and produce effect sizes on measures of quality of life and functional independence that are comparable to those of integrative rehabilitation programs (Evans \& Brewis, 2008). Of particular relevance to the issue of delivery of services, telephone counseling (30 - 45 minutes, bimonthly) lead to sustained improvements in quality of life, psychosocial functioning, and independence (Bell et al., 2005). With further experimental validation, telephone and video counseling may be used as stand-alone therapies or as adjunctive therapies, reducing the need of face-to-face interactions and costs of rehabilitation.

\section{Conclusion}

We have made tremendous advances in our understanding of the pathophysiology of traumatic brain injury and the cognitive, emotional, neurobehavioral, familial and social impact of these injuries since the landmark studies of Teasdale and Jennett (1974). Despite these advances in the basic sciences and technology, treatment of traumatic brain injuries has comparatively been lagged behind and will require coordinated, multi-disciplinary, systems-based approach and a standardized collection, analysis and interpretation of genetic, proteomic, neuroimaging, neuropsychological, and neurobehavioral variables, so that these findings can be translated in improved assessment and treatment algorithms, and ultimately, improved functional outcomes. Innovative, populationbased delivery of diagnostic and treatment services have been challenging, however, advances in computer and internet technologies hold great promise to profoundly alter the ability to evaluate and treat individuals, as well as, larger populations experiencing this disorder. Given the national and global financial, emotional, psychological impact of TBI, such population-based, cost-offsetting clinical studies are clearly warranted, critically needed, and should be a national and international priority.

\section{References}

Abdel-Dayem, H. M., Abu-Judeh, H., Kumar, M., Atay, S., Naddaf, S., El-Zeftawy, H. et al. (1998). SPECT Brain Perfusion Abnormalities in Mild or Moderate Traumatic Brain Injury. Clinical Nuclear Medicine, 23, 309-317. http://dx.doi.org/10.1097/00003072-199805000-00009

Acker, M. B., \& Davis, J. R. (1989). Psychology Test Scores Associated with Late Outcome in Head Injury. Neuropsychology, 3, 1-10.

Al-Musawi, N. M. (2001). Psychometric Properties of the Beck Depression Inventory-II with University Students in Bahrain. Journal of Personality Assessment, 77, 568-579. http://dx.doi.org/10.1207/S15327752JPA7703_13

Alban, R., Berry, C., Ley, E., Mirocha, J., Margulies, D., Tillou, A. et al. (2010). Does Health Care Insurance Affect Outcomes after Traumatic Brain Injury? Analysis of the National Trauma Databank. American Surgeon, 76, 1108-1111.

Alexander, M. P. (1995). Mild Traumatic Brain Injury: Pathophysiology, Natural History, and Clinical Management. Neurology, 45, 1253-1260. http://dx.doi.org/10.1212/WNL.45.7.1253

Allen, L. M., Conder, R. L., Green, P., \& Cox, D. R. (1997) CARB’97: Computerized Assessment of Response Bias. Manual. Durham, NC: CogniSyst.

American Psychiatric Association (2000). Diagnostic and Statistical Manual of Mental Disorders (4th ed. Text Revision). Washington DC: American Psychiatric Association.

Anderson, C. V., \& Bigler, E. D. (1994). The Role of Caudate Nucleus and Corpus Callosum Atrophy in Trauma-Induced Anterior Horn Dilation. Brain Injury, 8, 565-569. http://dx.doi.org/10.3109/02699059409151008

Anderson, G., Temkin, N., Dikmen, S., Diaz-Arrastia, R., Machamer, J., Farhrenbruch, C. et al. (2009). Haptoglobin Phenotype and Apolipoprotein E Polymorphism: Relationship to Posttraumatic Seizures and Neuropsychological Functioning after Traumatic Brain Injury. Epilepsy Behavior, 16, 501-506. http://dx.doi.org/10.1016/j.yebeh.2009.08.025

Anderson, M. L., Smith, D. S., Nioka, S., Subramanian, H., Garcia, J. H., Halsey, J. H. et al. (1990). Experimental Brain Ischaemia: Assessment of Injury by Magnetic Resonance Spectroscopy and Histology. Neurological Research, 12, 195204.

Anstey, K. J., Luszcz, M. A., Giles, L. C., \& Andrews, G. R. (2001). Demographic, Health, Cognitive, and Sensory Variables as Predictors of Mortality in Very Old Adults. Psychology and Aging, 16, 3-11. http://dx.doi.org/10.1037/0882-7974.16.1.3

Arango-Lasprilla, J., \& Kreutzer, J. (2010). Racial and Ethnic Disparities in Functional, Psychosocial, and Neurobehavioral 
Outcomes after Brain Injury. The Journal of Head Trauma Rehabilitation, 25, 128-136. http://dx.doi.org/10.1097/HTR.0b013e3181d36ca3

Arango-Lasprilla, J., Ketchum, J., Gary, K., Kreutzer, J., O’Neil-Pirozzi, T., Wehman, P. et al. (2009). The Influence of Minority Status on Job Stability after Traumatic Brain Injury. PM\&R, 1, 41-49. http://dx.doi.org/10.1016/j.pmrj.2008.07.001

Arango-Lasprilla, J., Rosenthal, M., Deluca, J., Komaroff, E., Sherer, M., Cifu, D. et al. (2007). Traumatic Brain Injury and Functional Outcomes: Does Minority Status Matter? Brain Injury, 21, 701-708. http://dx.doi.org/10.1080/02699050701481597

Arfanakis, K., Haughton, V., Carew, J., Rogers, B., Dempsey, R., \& Meyerand, M. E. (2002). Diffusion Tensor MR Imaging in Diffuse Axonal Injury. American Journal of Neuroradiology, 23, 794-802.

Azouvi, P., Jokic, C., Attal, N., Denys, P., Markabi, S., \& Bussel, B. (1999). Carbamazepine in Agitation and Aggressive Behaviour Following Severe Closed-Head Injury: Results of an Open Trial. Brain Injury, 13, 797-804. http://dx.doi.org/10.1080/026990599121188

Azouvi, P., Vallat-Azouvi, C., \& Belmont, A. (2009). Cognitive Deficits after Traumatic Coma. Progress in Brain Research, 177, 89-110. http://dx.doi.org/10.1016/S0079-6123(09)17708-7

Babikian, T., Freier, M. C., Ashwal, S., Riggs, M., Burley, T., \& Holshouser, B. (2006). MR Spectroscopy: Predicting Long-Term Neuropsychological Outcome Following Pediatric TBI. Journal of Magnetic Resonance Imaging, $24,801-811$. http://dx.doi.org/10.1002/jmri.20696

Baguley, I. J., Felmingham, K. L., Lahz, S., Gordan, E., Lazzaro, I., \& Schotte, D. E. (1997). Alcohol Abuse and Traumatic Brain Injury: Effect on Event-Related Potentials. Archives of Physical Medicine and Rehabilitation, 78, 1248-1253. http://dx.doi.org/10.1016/S0003-9993(97)90339-7

Baird, A., Ford, M., \& Podell, K. (2007). Ethnic Differences in Functional and Neuropsychological Test Performance in Older Adults. Archives of Clinical Neuropsychology, 22, 309-318. http://dx.doi.org/10.1016/j.acn.2007.01.005

Baldo, J., Delis, D., Kramer, J., \& Shimamura, A. (2002). Memory Performance on the California Verbal Learning Test-II: Findings from Patients with Focal Frontal Lesions. Journal of the International Neuropsychological Society, 8, 539-546. http://dx.doi.org/10.1017/S135561770281428X

Bandak, F. A. (1995). On the Mechanics of Impact Neurotrauma: A Review and Critical Synthesis. Journal of Neurotrauma, 12, 635-649. http://dx.doi.org/10.1089/neu.1995.12.635

Bate, A. J., Mathias, J. L., \& Crawford, J. R. (2001). Performance on the Test of Everyday Attention and Standard Tests of Attention Following Severe Traumatic Brain Injury. The Clinical Neuropsychologist, 15, 405-422. http://dx.doi.org/10.1076/clin.15.3.405.10279

Bazarian, J., Pope, C., McClung, J., Cheng, Y., \& Flesher, W. (2003). Ethnic and Racial Disparities in Emergency Department Care for Mild Traumatic Brain Injury. Academic Emergency Medicine, 10, 1209-1217. http://dx.doi.org/10.1111/j.1553-2712.2003.tb00605.x

Bazarian, J., Zhong, J., Blyth, B., Zhu, T., Kavcic, V., \& Peterson, D. (2007). Diffusion Tensor Imaging Detects Clinically Important Axonal Damage after Mild Traumatic Brain Injury: A Pilot Study. Journal of Neurotrauma, 24, 1447-1459. http://dx.doi.org/10.1089/neu.2007.0241

Bechara, A. (2007). Iowa Gambling Task Professional Manual. Lutz, FL: Psychological Assessment Resources, Inc.

Bechara, A., \& Van Der Linden, M. (2005). Decision-Making and Impulse Control after Frontal Lobe Injuries. Current Opinion in Neurology, 18, 734-739. http://dx.doi.org/10.1097/01.wco.0000194141.56429.3c

Beck, A. T., Epstein, N., Brown, G., \& Steer, R. A. (1988). An Inventory for Measuring Clinical Anxiety: Psychometric Properties. Journal of Consulting and Clinical Psychology, 56, 893-897. http://dx.doi.org/10.1037/0022-006X.56.6.893

Beck, A. T., Steer, R. A., \& Brown, G. K. (1996). Beck Depression Inventory (2nd ed.). San Antonio, TX: The Psychological Corporation.

Bedard, M., Felteau, M., Mazmanian, D., Fedyk, K., Klein, R., Richardson, J. et al. (2003). Pilot Evaluation of a Mindfulness-Based Intervention to Improve Quality of Life among Individuals Who Sustained Traumatic Brain Injuries. Disability and Rehabilitation, 25, 722-731. http://dx.doi.org/10.1080/0963828031000090489

Begaz, T., Kyriacou, D., Segal, J., \& Bazarian, J. (2006). Serum Biochemical Markers for Post-Concussion Syndrome in Patients with Mild Traumatic Brain Injury. Journal of Neurotrauma, 23, 1201-1210. http://dx.doi.org/10.1089/neu.2006.23.1201

Belanger, H., Vanderploeg, R., Curtiss, G., \& Warden, D. (2007). Recent Neuroimaging Techniques in Mild Traumatic Brain Injury. The Journal of Neuropsychiatry and Clinical Neurosciences, 19, 5-20. http://dx.doi.org/10.1176/jnp.2007.19.1.5

Bell, K., Temkin, N., Esselman, P., Doctor, J., Bombardier, C., Fraser, R. et al. (2005). The Effect of a Scheduled Telephone Intervention on Outcome after Moderate to Severe Traumatic Brain Injury: A Randomized Trial. Archives of Physical 
Medicine and Rehabilitation, 86, 851-856. http://dx.doi.org/10.1016/j.apmr.2004.09.015

Bennett-Levy, J. M. (1984). Long-Term Effects of Severe Closed Head Injury on Memory: Evidence from a Consecutive Series of Young Adults. Acta Neurologica Scandinavica, 70, 285-298. http://dx.doi.org/10.1111/j.1600-0404.1984.tb00826.x

Benton, A. I., \& Hamsher, K. (1989). Multilingual Aphasia Examination. Iowa City, IA: AJA Associates.

Benton, A. L., Sivan, A. B., \& Hamsher, K. (1994). Contributions to Neuropsychological Assessment. A Clinical Manual (2nd ed.). New York: Oxford University Press.

Bercaw, E., Hanks, R., Millis, S., \& Gola, T. (2011). Changes in Neuropsychological Performance after Traumatic Brain Injury from Inpatient Rehabilitation to 1-Year Follow-Up in Predicting 2-Year Functional Outcomes. The Clinical Neuropsychologist, 25, 72-89. http://dx.doi.org/10.1080/13854046.2010.532813

Berg, E. A. (1948). A Simple Objective Technique for Measuring Flexibility in Thinking. The Journal of General Psychology, 39, 15-22. http://dx.doi.org/10.1080/00221309.1948.9918159

Bernstein, D. (2002). Information Processing Difficulty Long after Self-Reported Concussion. Journal of the International Neuropsychological Society, 8, 673-682. http://dx.doi.org/10.1017/S1355617702801400

Berry, D. T., Allen, R. S., \& Schmidt, F. A. (1991). The Rey-Osterrieth Complex Figure: Psychometric Characteristics in a Geriatric Sample. The Clinical Neuropsychologist, 5, 143-153. http://dx.doi.org/10.1080/13854049108403298

Bigler, E. (2003). Neurobiology and Neuropathology Underlie the Neuropsychological Deficits Associated with Traumatic Brain Injury. Archives of Clinical Neuropsychology, 18, 595-621. http://dx.doi.org/10.1016/S0887-6177(02)00156-7

Bigler, E. (2007). Anterior and Middle Cranial Fossa in Traumatic Brain Injury: Relevant Neuroanatomy and Neuropathology in the Study of Neuropsychological Outcome. Neuropsychology, 21, 515-531. http://dx.doi.org/10.1037/0894-4105.21.5.515

Bigler, E. (2008). Neuropsychology and Clinical Neuroscience of Persistent Post-Concussive Syndrome. Journal of the International Neuropsychological Society, 14, 1-22. http://dx.doi.org/10.1017/S135561770808017X

Bigler, E. D. (1996). Brain Imaging and Behavioral Outcome in Traumatic Brain Injury. Journal of Learning Disabilities, 29, 515-530. http://dx.doi.org/10.1177/002221949602900507

Bigler, E. D. (2001). Quantitative Magnetic Resonance Imaging in Traumatic Brain Injury. The Journal of Head Trauma Rehabilitation, 16, 117-134. http://dx.doi.org/10.1097/00001199-200104000-00003

Bigler, E. D., Kurth, S. M., Blatter, D., \& Abildskov, T. J. (1992). Degenerative Changes in Traumatic Brain Injury: PostInjury Magnetic Resonance Identified Ventricular Expansion Compared to Pre-Injury Levels. Brain Research Bulletin, 28, 651-653. http://dx.doi.org/10.1016/0361-9230(92)90119-I

Bigler, E. D., Rosa, L., Schultz, F., Hall, S., \& Harris, J. (1989). Rey-Auditory Verbal Learning and Rey-Osterrieth Complex Figure Design Performance in Alzheimer's Disease and Closed Head Injury. Journal of Clinical Psychology, 45, $277-280$. http://dx.doi.org/10.1002/1097-4679(198903)45:2<277::AID-JCLP2270450216>3.0.CO;2-M

Bitsch, A., Bruhn, H., Vougioukas, V., Stringaris, A., Lassmann, H., Frahm, J. et al. (1999). Inflammatory CNS Demyelination: Histopathologic Correlation with in Vivo Quantitative Proton MR Spectroscopy. American Journal of Neuroradiology, 20, 1619-1627.

Blumbergs, P. C., Scott, G., Manavis, J., Wainwright, H., Simpson, D. A., \& McLean, A. J. (1995). Topography of Axonal Injury as Defined by Amyloid Precursor Protein and the Sector Scoring Method in Mild and Severe Closed Head Injury. Journal of Neurotrauma, 12, 565-572. http://dx.doi.org/10.1089/neu.1995.12.565

Boelen, D. H. E., Spikman, J. M., \& Fasotti, L. (2011). Rehabilitation of Executive Disorders after Brain Injury: Are Interventions Effective? Journal of Neuropsychology, 5, 73-113. http://dx.doi.org/10.1348/174866410X516434

Bombardier, C. H., \& Thurber, C. A. (1998). Blood Alcohol Level and Early Cognitive Status after Traumatic Brain Injury. Brain Injury, 12, 725-734. http://dx.doi.org/10.1080/026990598122124

Bombardier, C., Temkin, N., Machamer, J., \& Dikmen, S. (2003). The Natural History of Drinking and Alcohol-Related Problems after Traumatic Brain Injury. Archives of Physical Medicine and Rehabilitation, 84, 185-191. http://dx.doi.org/10.1053/apmr.2003.50002

Borg, J., Holm, L., Peloso, P., Cassidy, J. D., Carroll, L., von Holst, H. et al. (2004). Non-Surgical Intervention and Cost for Mild Traumatic Brain Injury: Results of the WHO Collaborating Centre Task Force on Mild Traumatic Brain Injury. Journal of Rehabilitation Medicine, 36, 76-83. http://dx.doi.org/10.1080/16501960410023840

Borgaro, S., Prigatano, G., Kwasnica, C., \& Rexer, J. (2003). Cognitive and Affective Sequelae in Complicated and Uncomplicated Mild Traumatic Brain Injury. Brain Injury, 17, 189-198. http://dx.doi.org/10.1080/0269905021000013183

Bornhofen, C., \& McDonald, S. (2008). Emotion Perception Deficits Following Traumatic Brain Injury: A Review of the Evidence and Rationale for Intervention. Journal of the International Neuropsychological Society, 14, 511-525.

http://dx.doi.org/10.1017/S1355617708080703 
Bornstein, R. A., Baker, G. B., \& Douglas, A. B. (1987). Short-Term Retest Reliability of the Halstead-Reitan Battery in a Normal Sample. Journal of Nervous and Mental Disease, 175, 229-232.

http://dx.doi.org/10.1097/00005053-198704000-00007

Bornstein, R. A., Miller, H. B., \& van Schoor, T. (1988). Emotional Adjustment in Compensated Head Injury Patients. Neurosurgery, 23, 622-627. http://dx.doi.org/10.1227/00006123-198811000-00013

Brenner, R. E., Munro, P. M., Williams, S. C., Bell, J. D., Barker, G. J., Hawkins, C. P. et al. (1993). The Proton NMR Spectrum in Acute EAE: The Significance of the Change in the Cho:Cr Ratio. Magnetic Resonance in Medicine, 29, 737745. http://dx.doi.org/10.1002/mrm.1910290605

Brewin, C. R., Andrews, B., \& Valentine, J. D. (2000). Meta-Analysis of Risk Factors for Posttraumatic Stress Disorder in Trauma-Exposed Adults. Journal of Consulting and Clinical Psychology, 68, 748-766. http://dx.doi.org/10.1037/0022-006X.68.5.748

Brooks, D. N., Aughton, M. E., Bond, M. R., Jones, P., \& Rizvi, S. (1980). Cognitive Sequelae in Relationship to Early Indices of Severity of Brain Damage after Severe Blunt Head Injury. Journal of Neurology, Neurosurgery and Psychiatry, 43, 529-534. http://dx.doi.org/10.1136/jnnp.43.6.529

Brooks, N., McKinlay, W., Symington, C., Beattie, A., \& Campsie, L. (1987). Return to Work within the First Seven Years of Severe Head Injury. Brain Injury, 1, 5-19. http://dx.doi.org/10.3109/02699058709034439

Brooks, W. M., Friedman, S. D., \& Gasparovic, C. (2001). Magnetic Resonance Spectroscopy in Traumatic Brain Injury. The Journal of Head Trauma Rehabilitation, 16, 149-164. http://dx.doi.org/10.1097/00001199-200104000-00005

Brooks, W. M., Stidley, C. A., Petropoulos, H., Jung, R. E., Weers, D. C., Friedman, S. D. et al. (2000). Metabolic and Cognitive Response to Human Traumatic Brain Injury: A Quantitative Proton Magnetic Resonance Study. Journal of Neurotrauma, 17, 629-640. http://dx.doi.org/10.1089/089771500415382

Brotherton, F. A., Thomas, L. L., Wisotzek, I. E., \& Milan, M. A. (1988). Social Skills Training in the Rehabilitation of Patients with Traumatic Closed Head Injury. Archives of Physical Medicine and Rehabilitation, 69, 827-832.

Bryant, R., Creamer, M., O’Donnell, M., Silove, D., Clark, C. R., \& McFarlane, A. (2009). Post-Traumatic Amnesia and the Nature of Post-Traumatic Stress Disorder after Mild Traumatic Brain Injury. Journal of the International Neuropsychological Society, 15, 862-867. http://dx.doi.org/10.1017/S1355617709990671

Bullock, M. R., Merchant, R., Choi, S., Gilman, C., Kreutzer, J., Marmarou, A. et al. (2002). Outcome Measures for Clinical Trials in Neurotrauma. Neurosurgical Focus, 13, 1-11. http://dx.doi.org/10.3171/foc.2002.13.1.6

Burgess, P. W., \& Shallice, T. (1997). The Hayling and Brixton Tests. Bury St Edmunds: Thames Valley Test Company.

Burke, J. M., Imhoff, C. L., \& Kerrigan, J. M. (1990). MMPI Correlates among Post-Acute TBI Patients. Brain Injury, 4, 223-231. http://dx.doi.org/10.3109/02699059009026171

Burnett, D. M., Silver, T. M., Kolakowsky-Hayner, S. A., \& Cifu, D. X. (2000). Functional Outcome for African Americans and Hispanics Treated at a Traumatic Brain Injury Model Systems Centre. Brain Injury, 14, 713-718. http://dx.doi.org/10.1080/026990500413731

Butler, P. V. (2000). Diurnal Variation in Cotard's Syndrome (Copresent with Capgras Delusion) Following Traumatic Brain Injury. Australian and New Zealand Journal of Psychiatry, 34, 684-687. http://dx.doi.org/10.1080/j.1440-1614.2000.00758.x

Butler, R. W., \& Satz, P. (1988). Individual Psychotherapy with Head-Injured Adults: Clinical Notes for the Practitioner. Professional Psychology Research and Practice, 19, 536-541. http://dx.doi.org/10.1037/0735-7028.19.5.536

Caetano, C., \& Christensen, A.-L. (1999). Outpatient/Day Patient Rehabilitation at the Centre for Rehabilitation of Brain Injury, Copenhagen, Denmark. Neuropsychological Rehabilitation, 9, 447-456. http://dx.doi.org/10.1080/096020199389509

Camplair, P. S., Butler, R. W., \& Lezak, M. D. (2003). Providing Psychological Services to Families of Brain-Injured Adults and Children in the Present Health-Care Environment. In G. P. Prigatano, \& N. H. Pliskin (Eds.), Clinical Neuropsychology and Cost Outcome Research: A Beginning (pp. 83-107). New York: Psychology Press.

Cantu, R., Guskiewicz, K., \& Register Mihalik, J. (2010). A Retrospective Clinical Analysis of Moderate to Severe Athletic Concussions. PM\&R, 2, 1088-1093. http://dx.doi.org/10.1016/j.pmrj.2010.07.483

Cardenas, D. D., McLean, A., Farrell Roberts, L., Baker, L., Brooke, M., \& Haselkorn, J. (1994). Oral Physostigmine and Impaired Memory in Adults with Brain Injury. Brain Injury, 8, 579-587. http://dx.doi.org/10.3109/02699059409151010

Carlin, D., Bonerba, J., Phipps, M., Alexander, G., Shapiro, M., \& Grafman, J. (2000). Planning Impairments in Frontal Lobe Dementia and Frontal Lobe Lesion Patients. Neuropsychologia, 38, 655-665. http://dx.doi.org/10.1016/S0028-3932(99)00102-5

Carnevale, G. J., Anselmi, V., Busichio, K., \& Millis, S. R. (2002). Changes in Ratings of Caregiver Burden Following a Community-Based Behavior Management Program for Persons with Traumatic Brain Injury. Journal of Head Trauma Rehabilitation, 17, 83-95. http://dx.doi.org/10.1097/00001199-200204000-00002 
Carnevale, G. J., Anselmi, V., Johnston, M. V., Busichio, K., \& Walsh, V. (2006). A Natural Setting Behavior Management Program for Persons with Acquired Brain Injury: A Randomized Controlled Trial. Archives of Physical Medicine and Rehabilitation, 87, 1289-1297. http://dx.doi.org/10.1016/j.apmr.2006.06.010

Carroll, L., Cassidy, J. D., Holm, L., Kraus, J., \& Coronado, V. (2004). Methodological Issues and Research Recommendations for Mild Traumatic Brain Injury: The WHO Collaborating Centre Task Force on Mild Traumatic Brain Injury. Journal of Rehabilitation Medicine, 36, 113-125. http://dx.doi.org/10.1080/16501960410023877

Cattelani, R., Tanzi, F., Lombardi, F., \& Mazzucchi, A. (2002). Competitive Re-Employment after Severe Traumatic Brain injury: Clinical, Cognitive and Behavioural Predictive Variables. Brain Injury, 16, 51-64. http://dx.doi.org/10.1080/02699050110088821

Cernich, A., Kurtz, S., Mordecai, K., \& Ryan, P. (2010). Cognitive Rehabilitation in Traumatic Brain Injury. Current Treatment Options in Neurology, 12, 412-423. http://dx.doi.org/10.1007/s11940-010-0085-6

Chang, P., Ostir, G., Kuo, Y., Granger, C., \& Ottenbacher, K. (2008). Ethnic Differences in Discharge Destination among Older Patients with Traumatic Brain Injury. Archives of Physical Medicine and Rehabilitation, 89, 231-236.

http://dx.doi.org/10.1016/j.apmr.2007.08.143

Chatham-Showalter, P. E., Dubov, W. E., Barr, M. C., Rhodes, M., Sun, J. M., \& Wasser, T. (1996). Alcohol Level at Head Injury and Subsequent Psychotropic Treatment during Trauma Critical Care. Psychosomatics, 37, 285-288. http://dx.doi.org/10.1016/S0033-3182(96)71567-0

Chen, J., Johnston, K. M., Frey, S., Petrides, M., Worsley, K., \& Ptito, A. (2004). Functional Abnormalities in Symptomatic Concussed Athletes: An fMRI Study. NeuroImage, 22, 68-82. http://dx.doi.org/10.1016/j.neuroimage.2003.12.032

Choca, J. P., Laatsch, L., Wetzel, L., \& Agresti, A. (1997). The Halstead Category Test: A Fifty Year Perspective. Neuropsychology Review, 7, 61-75. http://dx.doi.org/10.1023/B:NERV.0000005944.98635.16

Christensen, H., Mackinnon, A. J., Korten, A., \& Jorm, A. F. (2001). The “Common Cause Hypothesis” of Cognitive Aging: Evidence for Not Only a Common Factor but Also Specific Associations of Age with Vision and Grip Strength in a Cross-Sectional Analysis. Psychology and Aging, 16, 588-599. http://dx.doi.org/10.1037/0882-7974.16.4.588

Cicerone, K. D., \& Giacino, J. T. (1992). Remediation of Executive Function Deficits after Traumatic Brain Injury. NeuroRehabilitation, 2, 12-22.

Cicerone, K. D., Dahlberg, C., Kalmar, K., Langenbahn, D. M., Malec, J. F., Bergquist, T. F. et al. (2000). Evidence-Based Cognitive Rehabilitation: Recommendations for Clinical Practice. Archives of Physical Medicine and Rehabilitation, 81, 1596-1615. http://dx.doi.org/10.1053/apmr.2000.19240

Cicerone, K., \& Azulay, J. (2002). Diagnostic Utility of Attention Measures in Postconcussion Syndrome. The Clinical Neuropsychologist, 16, 280-289. http://dx.doi.org/10.1076/clin.16.3.280.13849

Cicerone, K., Dahlberg, C., Malec, J., Langenbahn, D., Felicetti, T., Kneipp, S. et al. (2005). Evidence-Based Cognitive Rehabilitation: Updated Review of the Literature from 1998 through 2002. Archives of Physical Medicine and Rehabilitation, 86, 1681-1692. http://dx.doi.org/10.1016/j.apmr.2005.03.024

Cicerone, K., Levin, H., Malec, J., Stuss, D., \& Whyte, J. (2006). Cognitive Rehabilitation Interventions for Executive Function: Moving from Bench to Bedside in Patients with Traumatic Brain Injury. Journal of Cognitive Neuroscience, 18, 1212-1222. http://dx.doi.org/10.1162/jocn.2006.18.7.1212

Cicerone, K., Mott, T., Azulay, J., \& Friel, J. (2004). Community Integration and Satisfaction with Functioning after Intensive Cognitive Rehabilitation for Traumatic Brain Injury. Archives of Physical Medicine and Rehabilitation, 85, 943-950. http://dx.doi.org/10.1016/j.apmr.2003.07.019

Coetzer, R. (2007). Psychotherapy Following Traumatic Brain Injury: Integrating Theory and Practice. The Journal of Head Trauma Rehabilitation, 22, 39-47. http://dx.doi.org/10.1097/00001199-200701000-00005

Collie, A., Maruff, P., Makdissi, M., McCrory, P., McStephen, M., \& Darby, D. (2003). CogSport: Reliability and Correlation with Conventional Cognitive Tests Used in Postconcussion Medical Evaluations. Clinical Journal of Sport Medicine, 13, 28-32. http://dx.doi.org/10.1097/00042752-200301000-00006

Collins, M., Iverson, G., Lovell, M., McKeag, D., Norwig, J., \& Maroon, J. (2003). On-Field Predictors of Neuropsychological and Symptom Deficit Following Sports-Related Concussion. Clinical Journal of Sport Medicine, 13, $222-229$. http://dx.doi.org/10.1097/00042752-200307000-00005

Conners, C. K. (1997). Conners' Continuous Performance Test Computer Program 3.0 User's Manual. Toronto, ON: MultiHealth System, Inc.

Cooper, K. D., Tabaddor, K., Hauser, W. A., Shulman, K., Feiner, C., \& Factor, P. R. (1983). The Epidemiology of Head Injury in the Bronx. Neuroepidemiology, 2, 70-88. http://dx.doi.org/10.1159/000110512

Corbie-Smith, G., Thomas, S. B., Williams, M. V., \& Moody-Ayers, S. (1999). Attitudes and Beliefs of African Americans toward Participation in Medical Research. Journal of General Internal Medicine, 14, 537-546.

http://dx.doi.org/10.1046/j.1525-1497.1999.07048.x 
Coronado, V., Xu, L., Basavaraju, S., McGuire, L., Wald, M., Faul, M. et al. (2011). Surveillance for Traumatic Brain InjuryRelated Deaths-United States, 1997-2007. MMWR Surveillance Summaries, 60, 1-32.

Corrigan, J. D. (1995). Substance Abuse as a Mediating Factor in Outcome from Traumatic Brain Injury. Archives of Physical Medicine and Rehabilitation, 76, 302-309. http://dx.doi.org/10.1016/S0003-9993(95)80654-7

Corrigan, J. D., Lamb Hart, G. L., \& Rust, E. (1995). A Programme of Intervention for Substance Abuse Following Traumatic Brain Injury. Brain Injury, 9, 221-236. http://dx.doi.org/10.3109/02699059509008195

Corso, P., Finkelstein, E., Miller, T., Fiebelkorn, I., \& Zaloshnja, E. (2006). Incidence and Lifetime Costs of Injuries in the United States. Injury Prevention, 12, 212-218. http://dx.doi.org/10.1136/ip.2005.010983

Corwin, J., \& Bylsma, F. W. (1993). Psychological Examination of Traumatic Encephalopathy. Clinical Neuropsychology, 7 , 3-21. http://dx.doi.org/10.1080/13854049308401883

Costa, P. T., \& McCrae, R. R. (1992). Normal Personality Assessment in Clinical Practice: The NEO Personality Inventory. Psychological Assessment, 4, 5-13. http://dx.doi.org/10.1037/1040-3590.4.1.5

Cripe, L. I. (1996). The MMPI in Neuropsychological Assessment: A Murky Measure. Neuropsychology, 3, 97-103.

Crossen, J. R., \& Wiens, A. N. (1994). Comparison of the Auditory-Verbal Learning Test (AVLT) and California Verbal Learning Test (CVLT) in a Sample of Normal Subjects. Neuropsychology, Development, and Cognition. Section A, Journal of Clinical and Experimental Neuropsychology, 16, 190-194. http://dx.doi.org/10.1080/01688639408402630

Cullum, C. M., \& Bigler, E. D. (1986). Ventricle Size, Cortical Atrophy and the Relationship with Neuropsychological Status in Closed Head Injury: A Quantitative Analysis. Neuropsychology, Development, and Cognition. Section A, Journal of Clinical and Experimental Neuropsychology, 8, 437-452. http://dx.doi.org/10.1080/01688638608401333

Cunningham, R., Maio, R., Hill, E., \& Zink, B. (2002). The Effects of Alcohol on Head Injury in the Motor Vehicle Crash Victim. Alcohol and Alcoholism, 37, 236-240. http://dx.doi.org/10.1093/alcalc/37.3.236

Dahlberg, C., Cusick, C., Hawley, L., Newman, J., Morey, C., Harrison Felix, C. et al. (2007). Treatment Efficacy of Social Communication Skills Training after Traumatic Brain Injury: A Randomized Treatment and Deferred Treatment Controlled Trial. Archives of Physical Medicine and Rehabilitation, 88, 1561-1573.

http://dx.doi.org/10.1016/j.apmr.2007.07.033

De Filippis, N. A., McCampbell, E., \& Rogers, P. (1979). Development of a Booklet Form of the Category Test: Normative and Validity Data. Journal of Clinical Neuropsychology, 1, 339-342. http://dx.doi.org/10.1080/01688637908401108

Deb, S., Lyons, I., \& Koutzoukis, C. (1998). Neuropsychiatric Sequelae One Year after a Minor Head Injury. Journal of Neurology, Neurosurgery and Psychiatry, 65, 899-902. http://dx.doi.org/10.1136/jnnp.65.6.899

Deb, S., Lyons, I., Koutzoukis, C., Ali, I., \& McCarthy, G. (1999). Rate of Psychiatric Illness 1 Year after Traumatic Brain Injury. The American Journal of Psychiatry, 156, 374-378.

Delaney, J. S., Abuzeyad, F., Correa, J., \& Foxford, R. (2005). Recognition and Characteristics of Concussions in the Emergency Department Population. The Journal of Emergency Medicine, 29, 189-197. http://dx.doi.org/10.1016/j.jemermed.2005.01.020

Delaney, R. C., Prevey, M. L., Cramer, J., \& Mattson, R. H. (1992). Test-Retest Comparability and Control Subject Data for the Rey-Auditory Verbal Learning Test and Rey-Osterrieth/Taylor Complex Figures. Archives of Clinical Neuropsychology, 7, 523-528.

Delis, D. C., Kaplan, E., \& Kramer, J. (2001). Delis-Kaplan Executive Function Scale. San Antonio, TX: Psychological Corporation.

Delis, D. C., Kramer, J. H., Kaplan, E., \& Ober, B. A. (2000). California Verbal Learning Test-Second Edition (CVLT-II). San Antonio, TX: Psychological Corporation.

Delmonico, R. L., Hanley Peterson, P., \& Englander, J. (1998). Group Psychotherapy for Persons with Traumatic Brain Injury: Management of Frustration and Substance Abuse. The Journal of Head Trauma Rehabilitation, 13, 10-22. http://dx.doi.org/10.1097/00001199-199812000-00004

Dennison, C., \& Pokras, R. (2000). Design and Operation of the National Hospital Discharge Survey: 1988 Redesign. Vital and Health Statistics. Series 1. Programs and Collection Procedures, No. 39, 1-42.

Dewar, D., \& Graham, D. I. (1996). Depletion of Choline Acetyltransferase Activity but Preservation of M1 and M2 Muscarinic Receptor Binding Sites in Temporal Cortex Following Head Injury: A Preliminary Human Postmortem Study. Journal of Neurotrauma, 13, 181-187.

Dhruva, S. S., \& Redberg, R. F. (2008) Variations between Clinical Trial Participants and Medicare Beneficiaries in Evidence Used for Medicare National Coverage Decisions. Archives of Internal Medicine, 168, 136-140.

http://dx.doi.org/10.1001/archinternmed.2007.56

Diaz-Arrastia, R., \& Baxter, V. (2006). Genetic Factors in Outcome after Traumatic Brain Injury: What the Human Genome Project Can Teach Us about Brain Trauma. The Journal of Head Trauma Rehabilitation, 21, 361-374. 
http://dx.doi.org/10.1097/00001199-200607000-00007

Diaz-Arrastia, R., Agostini, M., Madden, C., \& Van Ness, P. (2009). Posttraumatic Epilepsy: The Endophenotypes of a Human Model of Epileptogenesis. Epilepsia, 50, 14-20. http://dx.doi.org/10.1111/j.1528-1167.2008.02006.X

Dikmen, S. S., Heaton, R. K., Grant, I., \& Temkin, N. R. (1999). Test-Retest Reliability and Practice Effects of Expanded Halstead-Reitan Neuropsychological Test Battery. Journal of the International Neuropsychological Society, 5, 346-356. http://dx.doi.org/10.1017/S1355617799544056

Dikmen, S. S., Ross, B. L., Machamer, J. E., \& Temkin, N. R. (1995). One Year Psychosocial Outcome in Head Injury. Journal of the International Neuropsychological Society, 1, 67-77. http://dx.doi.org/10.1017/S1355617700000126

Dikmen, S., \& Morgan, S. F. (1980). Neuropsychological Factors Related to Employability and Occupational Status in Persons with Epilepsy. The Journal of Nervous and Mental Disease, 168, 236-240. http://dx.doi.org/10.1097/00005053-198004000-00008

Dikmen, S., Bombardier, C., Machamer, J., Fann, J., \& Temkin, N. (2004). Natural History of Depression in Traumatic Brain Injury. Archives of Physical Medicine and Rehabilitation, 85, 1457-1464.

http://dx.doi.org/10.1016/j.apmr.2003.12.041

Dikmen, S., Machamer, J., Miller, B., Doctor, J., \& Temkin, N. (2001). Functional Status Examination: A New Instrument for Assessing Outcome in Traumatic Brain Injury. Journal of Neurotrauma, 18, 127-140. http://dx.doi.org/10.1089/08977150150502578

Divenyi, P. L., \& Robinson, A. J. (1989). Nonlinguistic Auditory Capabilities in Aphasia. Brain and Language, 37, $290-326$. http://dx.doi.org/10.1016/0093-934X(89)90020-5

Dobscha, S., Clark, M., Morasco, B., Freeman, M., Campbell, R., \& Helfand, M. (2009). Systematic Review of the Literature on Pain in Patients with Polytrauma Including Traumatic Brain Injury. Pain Medicine, 10, 1200-1217. http://dx.doi.org/10.1111/j.1526-4637.2009.00721.x

Donders, J., Tulsky, D. S., \& Zhu, J. (2001). Criterion Validity of New WAIS-II Subtest Scores after Traumatic Brain Injury. Journal of the International Neuropsychological Society, 7, 892-898.

Donnemiller, E., Brenneis, C., Wissel, J., Scherfler, C., Poewe, W., Riccabona, G. et al. (2000). Impaired Dopaminergic Neurotransmission in Patients with Traumatic Brain Injury: A SPECT Study Using 123I-beta-CIT and 123I-IBZM. European Journal of Nuclear Medicine, 27, 1410-1414. http://dx.doi.org/10.1007/s002590000308

Douglas, J. M., \& Spellacy, F. J. (2000). Correlates of Depression in Adults with Severe Traumatic Brain Injury and Their Carers. Brain Injury, 14, 71-88. http://dx.doi.org/10.1080/026990500120943

Draper, K., \& Ponsford, J. (2008). Cognitive Functioning Ten Years Following Traumatic Brain Injury and Rehabilitation. Neuropsychology, 22, 618-625. http://dx.doi.org/10.1037/0894-4105.22.5.618

Duhaime, A., Gean, A., Haacke, E. M., Hicks, R., Wintermark, M., Mukherjee, P. et al. (2010). Common Data Elements in Radiologic Imaging of Traumatic Brain Injury. Archives of Physical Medicine and Rehabilitation, 91, 1661-1666. http://dx.doi.org/10.1016/j.apmr.2010.07.238

Dunlop, T. W., Udvarhelyi, G. B., Stedem, A. F., O’Connor, J. M., Isaacs, M. L., Puig, J. G. et al. (1991). Comparison of Patients with and without Emotional/Behavioral Deterioration during the First Year after Traumatic Brain Injury. The Journal of Neuropsychiatry and Clinical Neurosciences, 3, 150-156. http://dx.doi.org/10.1176/jnp.3.2.150

Dunn, R., Kimbrell, T., Ketter, T., Frye, M., Willis, M., Luckenbaugh, D. et al. (2002). Principal Components of the Beck Depression Inventory and Regional Cerebral Metabolism in Unipolar and Bipolar Depression. Biological Psychiatry, 51, 387-399. http://dx.doi.org/10.1016/S0006-3223(01)01244-6

Echlin, P., Johnson, A., Riverin, S., Tator, C., Cantu, R., Cusimano, M. et al. (2010). A Prospective Study of Concussion Education in 2 Junior Ice Hockey Teams: Implications for Sports Concussion Education. Neurosurgical Focus, 29 , E6. http://dx.doi.org/10.3171/2010.9.FOCUS10187

Ehlers, A., Mayou, R. A., \& Bryant, B. (1998). Psychological Predictors of Chronic Posttraumatic Stress Disorder after Motor Vehicle Accidents. Journal of Abnormal Psychology, 107, 508-519. http://dx.doi.org/10.1037/0021-843X.107.3.508

Ehrenstein, W. H., Heister, G., \& Cohen, R. (1982). Trail Making Test and Visual Search. Archiv für Psychiatrie und Nervenkrankheiten, 231, 333-338. http://dx.doi.org/10.1007/BF00345589

Epstein, J. N., Johnson, D. E., Varia, I. M., \& Conners, C. K. (2001). Neuropsychological Assessment of Response Inhibition in Adults with ADHD. Neuropsychology, Development, and Cognition. Section A, Journal of Clinical and Experimental Neuropsychology, 23, 362-371. http://dx.doi.org/10.1076/jcen.23.3.362.1186

Evans, L., \& Brewis, C. (2008). The Efficacy of Community-Based Rehabilitation Programes for Adults with TBI. International Journal of Therapy and Rehabilitation, 15, 446-458. http://dx.doi.org/10.12968/ijtr.2008.15.10.31213

Fals-Stewart, W. (1992). An Interrater Reliability Study of the Trail Making Test (Part A and B). Perceptual and Motor Skills, 74, 39-42. 
Fann, J. R., Katon, W. J., Uomoto, J. M., \& Esselman, P. C. (1995). Psychiatric Disorders and Functional Disability in Outpatients with Traumatic Brain Injuries. The American Journal of Psychiatry, 152, 1493-1499. http://dx.doi.org/10.1176/ajp.152.10.1493

Fann, J. R., Uomoto, J. M., \& Katon, W. J. (2000). Sertraline in the Treatment of Major Depression Following Mild Traumatic Brain Injury. The Journal of Neuropsychiatry and Clinical Neurosciences, 12, 226-232. http://dx.doi.org/10.1176/jnp.12.2.226

Farmer, J. E., \& Eakman, A. M. (1995). The Relationship between Neuropsychological Functioning and Instrumental Activities of Daily Living Following Acquired Brain Injury. Applied Neuropsychology, 2, 107-115. http://dx.doi.org/10.1080/09084282.1995.9645347

Faul, M., Wald, M., Rutland-Brown, W., Sullivent, E., \& Sattin, R. (2007). Using a Cost-Benefit Analysis to Estimate Outcomes of a Clinical Treatment Guideline: Testing the Brain Trauma Foundation Guidelines for the Treatment of Severe Traumatic Brain Injury. The Journal of Trauma, 63, 1271-1278. http://dx.doi.org/10.1097/TA.0b013e3181493080

Felmingham, K., Baguley, I., \& Green, A. (2004). Effects of Diffuse Axonal Injury on Speed of Information Processing Following Severe Traumatic Brain Injury. Neuropsychology, 18, 564-571. http://dx.doi.org/10.1037/0894-4105.18.3.564

Fisher, D. C., Ledbetter, M. F., Cohen, N. J., Marmor, D., \& Tulsky, D. S. (2000). WAIS-III and WMS-III Profiles of Mildly to Severely Brain-Injured Patients. Applied Neuropsychology, 7, 126-132. http://dx.doi.org/10.1207/S15324826AN0703_2

Flashman, L., \& McAllister, T. (2002). Lack of Awareness and Its Impact in Traumatic Brain Injury. NeuroRehabilitation, 17, 285-296.

Fleming, J., Tooth, L., Hassell, M., \& Chan, W. (1999). Prediction of Community Integration and Vocational Outcome 2 - 5 Years after Traumatic Brain Injury Rehabilitation in Australia. Brain Injury, 13, 417-431. http://dx.doi.org/10.1080/026990599121476

Florian, V., Katz, S., \& Lahav, V. (1989). Impact of Traumatic Brain Damage on Family Dynamics and Functioning: A Review. Brain Injury, 3, 219-233. http://dx.doi.org/10.3109/02699058909029637

Fontaine, A., Azouvi, P., Remy, P., Bussel, B., \& Samson, Y. (1999). Functional Anatomy of Neuropsychological Deficits after Severe Traumatic Brain Injury. Neurology, 53, 1963-1968. http://dx.doi.org/10.1212/WNL.53.9.1963

Fox, R. M., Martella, R. C., \& Marchand-Martella, N. E. (1989). The Acquisition, Maintenance and Generalization of Problem-Solving Skills by Closed Head Injured Adults. Behavioral Therapy, 20, 61-76. http://dx.doi.org/10.1016/S0005-7894(89)80118-2

Frencham, K. A. R., Fox, A., \& Maybery, M. (2005). Neuropsychological Studies of Mild Traumatic Brain Injury: A Meta-Analytic Review of Research since 1995. Neuropsychology, Development, and Cognition. Section A, Journal of Clinical and Experimental Neuropsychology, 27, 334-351. http://dx.doi.org/10.1080/13803390490520328

Friedman, M. J., Schnurr, P. P., \& McDonagh Coyle, A. (1994). Post-Traumatic Stress Disorder in the Military Veteran. Psychiatric Clinics of North America, 17, 265-277.

Friedman, S. D., Brooks, W. M., Jung, R. E., Chiulli, S. J., Sloan, J. H., Montoya, B. T. et al. (1999). Quantitative Proton MRS Predicts Outcome after Traumatic Brain Injury. Neurology, 52, 1384-1391. http://dx.doi.org/10.1212/WNL.52.7.1384

Frommer, L., Gurka, K., Cross, K., Ingersoll, C., Comstock, R. D., \& Saliba, S. (2011). Sex Differences in Concussion Symptoms of High School Athletes. Journal of Athletic Training, 46, 76-84. http://dx.doi.org/10.4085/1062-6050-46.1.76

Fydrich, T., Dowdall, D., \& Chambless, D. L. (1992). Reliability and Validity of the Beck Anxiety Inventory. Journal of Anxiety Disorders, 6, 55-61. http://dx.doi.org/10.1016/0887-6185(92)90026-4

Gale, S. D., Burr, R. B., Bigler, E. D., \& Blatter, D. (1993). Fornix Degeneration and Memory in Traumatic Brain Injury. Brain Research Bulletin, 32, 345-349. http://dx.doi.org/10.1016/0361-9230(93)90198-K

Gale, S. D., Johnson, S. C., Bigler, E. D., \& Blatter, D. D. (1995). Trauma-Induced Degenerative Changes in Brain Injury: A Morphometric Analysis of Three Patients with Preinjury and Postinjury MR Scans. Journal of Neurotrauma, 12, $151-158$. http://dx.doi.org/10.1089/neu.1995.12.151

Garnett, M. R., Blamire, A. M., Rajagopalan, B., Styles, P., \& Cadoux Hudson, T. A. (2000). Evidence for Cellular Damage in Normal-Appearing White Matter Correlates with Injury Severity in Patients Following Traumatic Brain Injury: A Magnetic Resonance Spectroscopy Study. Brain, 123, 1403-1409. http://dx.doi.org/10.1093/brain/123.7.1403

Ghajar, J. (2000). Traumatic Brain Injury. The Lancet, 356, 923-929. http://dx.doi.org/10.1016/S0140-6736(00)02689-1

Gioia, G. A., Isquith, P. K., Guy, S. C., \& Kenworthy, L. (2000). Behavior Rating Inventory of Executive Function. Neuropsychology, Development, and Cognition. Section C, Child Neuropsychology, 6, 235-238. http://dx.doi.org/10.1076/chin.6.3.235.3152

Glenn, M. B., O’Neil Pirozzi, T., Goldstein, R., Burke, D., \& Jacob, L. (2001). Depression amongst Outpatients with Traumatic Brain Injury. Brain Injury, 15, 811-818. http://dx.doi.org/10.1080/02699050010025777 
Goel, V., \& Grafman, J. (1995). Are the Frontal Lobes Implicated in "Planning” Functions? Interpreting Data from the Tower of Hanoi. Neuropsychologia, 33, 623-642. http://dx.doi.org/10.1016/0028-3932(95)90866-P

Goldberg, E., \& Bougakov, D. (2005). Neuropsychologic Assessment of Frontal Lobe Dysfunction. Psychiatric Clinics of North America, 28, 567-580. http://dx.doi.org/10.1016/j.psc.2005.05.005

Goldberg, E., Podell, K., \& Lovell, M. (1994). Lateralization of Frontal Lobe Functions and Cognitive Novelty. The Journal of Neuropsychiatry and Clinical Neurosciences, 6, 371-378. http://dx.doi.org/10.1176/jnp.6.4.371

Goldberg, J. O., \& Miller, H. R. (1986). Performance of Psychiatric Inpatients and Intellectually Deficient Individuals on a Task That Assesses the Validity of Memory Complaints. Journal of Clinical Psychology, 42, 792-795. http://dx.doi.org/10.1002/1097-4679(198609)42:5<792::AID-JCLP2270420519>3.0.CO;2-8

Goldstein, F. C., \& Levin, H. S. (2001). Cognitive Outcome after Mild and Moderate Traumatic Brain Injury in Older Adults. Neuropsychology, Development, and Cognition. Section A, Journal of Clinical and Experimental Neuropsychology, 23, 739-753. http://dx.doi.org/10.1076/jcen.23.6.739.1028

Goldstein, F. C., Levin, H. S., Boake, C., \& Lohrey, J. H. (1990). Facilitation of Memory Performance through Induced Semantic Processing in Survivors of Severe Closed-Head Injury. Neuropsychology, Development, and Cognition. Section A, Journal of Clinical and Experimental Neuropsychology, 12, 286-300. http://dx.doi.org/10.1080/01688639008400975

Goldstein, F. C., Levin, H. S., Goldman, W. P., Clark, A. N., \& Altonen, T. K. (2001). Cognitive and Neurobehavioral Functioning after Mild versus Moderate Traumatic Brain Injury in Older Adults. Journal of the International Neuropsychological Society, 7, 373-383. http://dx.doi.org/10.1017/S1355617701733115

Goldstein, G., \& Ruthven, I. (1983). Rehabilitation of Brain-Damaged Adults. New York: Plenum Press. http://dx.doi.org/10.1007/978-1-4613-3132-2

Gomez, P. A., Lobato, R. D., Boto, G. R., De la Lama, A., Gonzlez, P. J., \& de la Cruz, J. (2000). Age and Outcome after Severe Head Injury. Acta Neurochirurgica, 142, 373-380. http://dx.doi.org/10.1007/s007010050445

Goodglass, H., Kaplan, E., \& Barresi, B. (2000). The Boston Diagnostic Aphasia Examination. Philadelphia, PA: Lippincott.

Grace, J., \& Malloy, P.F. (2001). Frontal Systems Behavior Scale (FrSBe): Professional Manua. Lutz, FL: Psychological Assessment Resources.

Graham, D., \& Cardon, A. (2008). An Update on Substance Use and Treatment Following Traumatic Brain Injury. Annals of the New York Academy of Sciences, 1141, 148-162. http://dx.doi.org/10.1196/annals.1441.029

Graham, J. R. (2000). MMPI-2: Assessing Personality and Psychopathology (3rd ed.). New York: Oxford University Press.

Grant, D. A., \& Berg, E. A. (1948). A Behavioral Analysis of Degree of Reinforcement and Ease of Shifting to New Responses in a Weigl-Type Card-Sorting Problem. Journal of Experimental Psychology, 38, 404-411. http://dx.doi.org/10.1037/h0059831

Green, P., Allen, I. M., \& Astner, K. (1996). The Word Memory Test: A User's Guide to the Oral and Computer-Admistered Forms. Durham, NC: CogniSyst.

Green, P., Rohling, M. L., Lees Haley, P. R., \& Allen, L. M. (2001). Effort Has a Greater Effect on Test Scores Than Severe Brain Injury in Compensation Claimants. Brain Injury, 15, 1045-1060. http://dx.doi.org/10.1080/02699050110088254

Greenspan, A., Stringer, A., Phillips, V. L., Hammond, F., \& Goldstein, F. (2006). Symptoms of Post-Traumatic Stress: Intrusion and Avoidance 6 and 12 Months after TBI. Brain Injury, 20, 733-742. http://dx.doi.org/10.1080/02699050600773276

Greiffenstein, M., \& Baker, W. J. (2008). Validity Testing in Dually Diagnosed Post-Traumatic Stress Disorder and Mild Closed Head Injury. The Clinical Neuropsychologist, 22, 565-582. http://dx.doi.org/10.1080/13854040701377810

Griffin, S., van Reekum, R., \& Masanic, C. (2003). A Review of Cholinergic Agents in the Treatment of Neurobehavioral Deficits Following Traumatic Brain Injury. The Journal of Neuropsychiatry and Clinical Neurosciences, 15, 17-26. http://dx.doi.org/10.1176/jnp.15.1.17

Gronwall, D., \& Wrightson, P. (1975). Cumulative Effect of Concussion. The Lancet, 2, 995-997. http://dx.doi.org/10.1016/S0140-6736(75)90288-3

Gross, H., Kling, A., Henry, G., Herndon, C., \& Lavretsky, H. (1996). Local Cerebral Glucose Metabolism in Patients with Long-Term Behavioral and Cognitive Deficits Following Mild Traumatic Brain Injury. The Journal of Neuropsychiatry and Clinical Neurosciences, 8, 324-334. http://dx.doi.org/10.1176/jnp.8.3.324

Gualtieri, T., \& Cox, D. R. (1991). The Delayed Neurobehavioural Sequelae of Traumatic Brain Injury. Brain Injury, 5, 219232. http://dx.doi.org/10.3109/02699059109008093

Guerreiro, D. F., Navarro, R., Silva, M., Carvalho, M., \& Gois, C. (2009). Psychosis Secondary to Traumatic Brain Injury. Brain Injury, 23, 358-361. http://dx.doi.org/10.1080/02699050902800918

Guerrero, J. L., Thurman, D. J., \& Sniezek, J. E. (2000). Emergency Department Visits Associated with Traumatic Brain In- 
jury: United States, 1995-1996. Brain Injury, 14, 181-186. http://dx.doi.org/10.1080/026990500120835

Guskiewicz, K., Bruce, S., Cantu, R., Ferrara, M., Kelly, J., McCrea, M. et al. (2004). National Athletic Trainers’ Association Position Statement: Management of Sport-Related Concussion. Journal of Athletic Training, 39, 280-297.

Haacke, E. M., Duhaime, A., Gean, A., Riedy, G., Wintermark, M., Mukherjee, P. et al. (2010). Common Data Elements in Radiologic Imaging of Traumatic Brain Injury. Journal of Magnetic Resonance Imaging, 32, 516-543. http://dx.doi.org/10.1002/jmri.22259

Hadjigeorgiou, G. M., Paterakis, K., Dardiotis, E., Dardioti, M., Aggelakis, K., Tasiou, A. et al. (2005). IL-1RN and IL-1B Gene Polymorphisms and Cerebral Hemorrhagic Events after Traumatic Brain Injury. Neurology, 65, 1077-1082. http://dx.doi.org/10.1212/01.wnl.0000178890.93795.0e

Hammond, F., Hart, T., Bushnik, T., Corrigan, J., \& Sasser, H. (2004). Change and Predictors of Change in Communication, Cognition, and Social Function between 1 and 5 Years after Traumatic Brain Injury. The Journal of Head Trauma Rehabilitation, 19, 314-328. http://dx.doi.org/10.1097/00001199-200407000-00006

Hanks, R. A., Rapport, L. J., Millis, S. R., \& Deshpande, S. A. (1999). Measures of Executive Functioning as Predictors of Functional Ability and Social Integration in a Rehabilitation Sample. Archives of Physical Medicine and Rehabilitation, 80, 1030-1037. http://dx.doi.org/10.1016/S0003-9993(99)90056-4

Hanks, R., Wood, D., Millis, S., Harrison-Felix, C., Pierce, C., Rosenthal, M. et al. (2003). Violent Traumatic Brain Injury: Occurrence, Patient Characteristics, and Risk Factors from the Traumatic Brain Injury Model Systems Project. Archives of Physical Medicine and Rehabilitation, 84, 249-254. http://dx.doi.org/10.1053/apmr.2003.50096

Harris, J. K., Godfrey, H. P., Partridge, F. M., \& Knight, R. G. (2001). Caregiver Depression Following Traumatic Brain Injury (TBI): A Consequence of Adverse Effects on Family Members? Brain Injury, 15, 223-238. http://dx.doi.org/10.1080/02699050010004040

Hart, T., Seignourel, P., \& Sherer, M. (2009). A Longitudinal Study of Awareness of Deficit after Moderate to Severe Traumatic Brain Injury. Neuropsychological Rehabilitation, 19, 161-176. http://dx.doi.org/10.1080/09602010802188393

Hart, T., Whyte, J., Polansky, M., Kersey-Matusiak, G., \& Fidler-Sheppard, R. (2005). Community Outcomes Following Traumatic Brain Injury: Impact of Race and Preinjury Status. The Journal of Head Trauma Rehabilitation, 20, 158-172. http://dx.doi.org/10.1097/00001199-200503000-00004

Hartikainen, K., Waljas, M., Isoviita, T., Dastidar, P., Liimatainen, S., Solbakk, A. et al. (2010). Persistent Symptoms in Mild to Moderate Traumatic Brain Injury Associated with Executive Dysfunction. Neuropsychology, Development, and Cognition. Section A, Journal of Clinical and Experimental Neuropsychology, 32, 767-774. http://dx.doi.org/10.1080/13803390903521000

Harvey, A. G., \& Bryant, R. A. (2000). Two-Year Prospective Evaluation of the Relationship between Acute Stress Disorder and Posttraumatic Stress Disorder Following Mild Traumatic Brain Injury. The American Journal of Psychiatry, 157, 626-628. http://dx.doi.org/10.1176/appi.ajp.157.4.626

Heinrichs, R. W. (1990a). Current and Emergent Applications of Neuropsychological Assessment: Problems of Validity and Utility. Professional Psychology: Research and Practice, 21, 171-176. http://dx.doi.org/10.1037/0735-7028.21.3.171

Heinrichs, R. W. (1990b). Variables Associated with Wisconsin Card Sorting Test Performance in Neuropsychiatric Patients Referred for Assessment. Neuropsychiatry, Neuropsychology and Behavioral Neurology, 3, 107-112.

Helffenstein, D., \& Wechsler, R. (1982). The Use of Interpersonal Process Recall (IPR) in the Remediation of Interpersonal and Communication Skill Deficits in the Newly Brain Injured. Clinical Neuropsychologist, 4, 139-143.

Hibbard, M. R., Cantor, J., Charatz, H., Rosenthal, R., Ashman, T., Gundersen, N. et al. (2002). Peer Support in the Community: Initial Findings of a Mentoring Program for Individuals with Traumatic Brain Injury and Their Families. The Journal of Head Trauma Rehabilitation, 17, 112-131. http://dx.doi.org/10.1097/00001199-200204000-00004

Himanen, L., Portin, R., Isoniemi, H., Helenius, H., Kurki, T., \& Tenovuo, O. (2005). Cognitive Functions in Relation to MRI Findings 30 Years after Traumatic Brain Injury. Brain Injury, 19, 93-100. http://dx.doi.org/10.1080/02699050410001720031

Hiott, D. W., \& Labbate, L. (2002). Anxiety Disorders Associated with Traumatic Brain Injuries. NeuroRehabilitation, 17, 345-355.

Hiscock, M., \& Hiscock, C. K. (1989). Refining the Forced-Choice Method for the Detection of Malingering. Neuropsychology, Development, and Cognition. Section A, Journal of Clinical and Experimental Neuropsychology, 11, 967-974. http://dx.doi.org/10.1080/01688638908400949

Holshouser, B., Tong, K., Ashwal, S., Oyoyo, U., Ghamsary, M., Saunders, D. et al. (2006). Prospective Longitudinal Proton Magnetic Resonance Spectroscopic Imaging in Adult Traumatic Brain Injury. Journal of Magnetic Resonance Imaging, 24, 33-40. http://dx.doi.org/10.1002/jmri.20607

Hoofien, D., Gilboa, A., Vakil, E., \& Donovick, P. J. (2001). Traumatic Brain Injury (TBI) 10 - 20 Years Later: A Compre- 
hensive Outcome Study of Psychiatric Symptomatology, Cognitive Abilities and Psychosocial Functioning. Brain Injury, 15, 189-209. http://dx.doi.org/10.1080/026990501300005659

Hooper, H. E. (1983). Hooper Visual Organization Test Manual. Los Angeles, CA: Western Psychological Services.

Hornstein, A., Lennihan, L., Seliger, G., Lichtman, S., \& Schroeder, K. (1996). Amphetamine in Recovery from Brain Injury. Brain Injury, 10, 145-148. http://dx.doi.org/10.1080/026990596124647

Howieson, D. B., \& Lezak, M. D. (2002). Separating Memory from Other Cognitive Problems. In A. Baddeley (Ed.), Handbook of Memory Disorders (2nd ed., pp. 637-654). Chichester: Wiley.

Huang, M., Theilmann, R., Robb, A., Angeles, A., Nichols, S., Drake, A. et al. (2009). Integrated Imaging Approach with MEG and DTI to Detect Mild Traumatic Brain Injury in Military and Civilian Patients. Journal of Neurotrauma, 26, 12131226. http://dx.doi.org/10.1089/neu.2008.0672

Hughes, D., Jackson, A., Mason, D., Berry, E., Hollis, S., \& Yates, D. (2004). Abnormalities on Magnetic Resonance Imaging Seen Acutely Following Mild Traumatic Brain Injury: Correlation with Neuropsychological Tests and Delayed Recovery. Neuroradiology, 46, 550-558. http://dx.doi.org/10.1007/s00234-004-1227-x

Hyder, A., Wunderlich, C., Puvanachandra, P., Gururaj, G., \& Kobusingye, O. (2007). The Impact of Traumatic Brain Injuries: A Global Perspective. NeuroRehabilitation, 22, 341-353.

Isoniemi, H., Tenovuo, O., Portin, R., Himanen, L., \& Kairisto, V. (2006). Outcome of Traumatic Brain Injury after Three Decades-Relationship to ApoE Genotype. Journal of Neurotrauma, 23, 1600-1608. http://dx.doi.org/10.1089/neu.2006.23.1600

Iverson, G. (2006). Misdiagnosis of the Persistent Postconcussion Syndrome in Patients with Depression. Archives of Clinical Neuropsychology, 21, 303-310. http://dx.doi.org/10.1016/j.acn.2005.12.008

Iverson, G.L., Franzen, M.D., \& Lovell, M. (1999). Normative Comparisons for the Controlled Oral Word Association Test Following Acute Traumatic Brain Injury. Clinical Neuropsychology, 13, 437-441. http://dx.doi.org/10.1076/1385-4046(199911)13:04;1-Y;FT437

Jacobson, I., Ryan, M. A. K., Hooper, T., Smith, T., Amoroso, P., Boyko, E. et al. (2008). Alcohol Use and Alcohol-Related Problems before and after Military Combat Deployment. JAMA, 300, 663-675.

Jager, T. E., Weiss, H. B., Coben, J. H., \& Pepe, P. E. (2000). Traumatic Brain Injuries Evaluated in U.S. Emergency Departments, 1992-1994. Academic Emergency Medicine, 7, 134-140. http://dx.doi.org/10.1111/j.1553-2712.2000.tb00515.x

Jagoda, A., Bazarian, J., Bruns, J., Cantrill, S., Gean, A., Howard, P. et al. (2009). Clinical Policy: Neuroimaging and Decision Making in Adult Traumatic Brain Injury in the Acute Setting. Journal of Emergency Nursing, 35, 5-40. http://dx.doi.org/10.1016/j.jen.2008.12.010

Jellinger, K. A., Paulus, W., Wrocklage, C., \& Litvan, I. (2001). Effects of Closed Traumatic Brain Injury and Genetic Factors on the Development of Alzheimer's Disease. European Journal of Neurology, 8, 707-710. http://dx.doi.org/10.1046/j.1468-1331.2001.00322.x

Jenkins, A., Teasdale, G., Hadley, M. D., Macpherson, P., \& Rowan, J. O. (1986). Brain Lesions Detected by Magnetic Resonance Imaging in Mild and Severe Head Injuries. The Lancet, 2, 445-446.

http://dx.doi.org/10.1016/S0140-6736(86)92145-8

Jennett, B., \& Bond, M. (1975). Assessment of Outcome after Severe Brain Damage. The Lancet, 1, 480-484. http://dx.doi.org/10.1016/S0140-6736(75)92830-5

Jennings, J. S., Gerber, A. M., \& Vallano, M. L. (2008). Pharmacological Strategies for Neuroprotection in Traumatic Brain Injury. Mini Reviews in Medicinal Chemistry, 8, 689-701. http://dx.doi.org/10.2174/138955708784567377

Jentsch, J. D., \& Taylor, J. R. (1999). Impulsivity Resulting from Frontostriatal Dysfunction in Drug Abuse: Implications for the Control of Behavior by Reward-Related Stimuli. Psychopharmacology, 146, 373-390. http://dx.doi.org/10.1007/PL00005483

Johnstone, B., \& Wilhelm, K. L. (1997). The Construct Validity of the Hooper Visual Organization Test. Assessment, 4, 243248.

Johnstone, B., Mount, D., Gaines, T., Goldfader, P., Bounds, T., \& Pitts, O. (2003). Race Differences in a Sample of Vocational Rehabilitation Clients with Traumatic Brain Injury. Brain Injury, 17, 95-104. http://dx.doi.org/10.1080/0269905021000010212

Johnstone, B., Vieth, A. Z., Johnson, J. C., \& Shaw, J. A. (2000). Recall as a Function of Single versus Multiple Trials: Implications for Rehabilitation. Rehabilitation Psychology, 45, 3-15. http://dx.doi.org/10.1037/0090-5550.45.1.3

Jordan, B. D. (2007). Genetic Influences on Outcome Following Traumatic Brain Injury. Neurochemical Research, 32, 905915. http://dx.doi.org/10.1007/s11064-006-9251-3

Jorge, R. E., Robinson, R. G., Starkstein, S. E., \& Arndt, S. V. (1994). Influence of Major Depression on 1-Year Outcome in Patients with Traumatic Brain Injury. Journal of Neurosurgery, 81, 726-733. http://dx.doi.org/10.3171/jns.1994.81.5.0726 
Jorge, R., Robinson, R., Moser, D., Tateno, A., Crespo Facorro, B., \& Arndt, S. (2004). Major Depression Following Traumatic Brain Injury. Archives of General Psychiatry, 61, 42-50. http://dx.doi.org/10.1001/archpsyc.61.1.42

Judd, D., \& Wilson, S. L. (2005). Psychotherapy with Brain Injury Survivors: An Investigation of the Challenges Encountered by Clinicians and Their Modifications to Therapeutic Practice. Brain Injury, 19, 437-449. http://dx.doi.org/10.1080/02699050400010994

Kahn, J. P., Mastroianni, A. M., \& Sugarman, J. (1998). Beyond Consent: Seeking Justice in Research. New York: Oxford Univerity Press.

Kaitaro, T., Koskinen, S., \& Kaipio, M. L. (1995). Neuropsychological Problems in Everyday Life: A 5-Year Follow-Up Study of Young Severely Closed-Head-Injured Patients. Brain Injury, 9, 713-727. http://dx.doi.org/10.3109/02699059509008227

Kaschel, R., Della Sala, S., Cantagallo, A., Fahlbock, A., Laaksonen, R., \& Kazen, M. (2002). Imagery Mnemonics for the Rehabilitation of Memory: A Randomized Group Controlled Trial. Neuropsychological Rehabilitation, 12, 127-153. http://dx.doi.org/10.1080/09602010143000211

Kashluba, S., Hanks, R., Casey, J., \& Millis, S. (2008). Neuropsychologic and Functional Outcome after Complicated Mild Traumatic Brain Injury. Archives of Physical Medicine and Rehabilitation, 89, 904-911. http://dx.doi.org/10.1016/j.apmr.2007.12.029

Kazdin, A. E. (2003). Research Design in Clinical Psychology (4th ed.). London: Pearson.

Keith, R. A., Granger, C. V., Hamilton, B. B., \& Sherwin, F. S. (1987). The Functional Independence Measure: A New Tool for Rehabilitation. Advances in Clinical Rehabilitation, 1, 6-18.

Kennedy, M. R. T., Coelho, C., Turkstra, L., Ylvisaker, M., Sohlberg, M., Yorkston, K. et al. (2008). Intervention for Executive Functions after Traumatic Brain Injury: A Systematic Review, Meta-Analysis and Clinical Recommendations. Neuropsychological Rehabilitation, 18, 257-299. http://dx.doi.org/10.1080/09602010701748644

Kennepohl, S., Shore, D., Nabors, N., \& Hanks, R. (2004). African-American Acculturation and Neuropsychological Test Performance Following Traumatic Brain Injury. Journal of the International Neuropsychological Society, 10, 566-577. http://dx.doi.org/10.1017/S1355617704104128

Kesler, S. R., Adams, H. F., \& Bigler, E. D. (2000). SPECT, MR and Quantitative MR Imaging: Correlates with Neuropsychological and Psychological Outcome in Traumatic Brain Injury. Brain Injury, 14, 851-857. http://dx.doi.org/10.1080/026990500445682

Ketter, T. A., Kimbrell, T. A., George, M. S., Dunn, R. T., Speer, A. M., Benson, B. E. et al. (2001). Effects of Mood and Subtype on Cerebral Glucose Metabolism in Treatment-Resistant Bipolar Disorder. Biological Psychiatry, 49, 97-109. http://dx.doi.org/10.1016/S0006-3223(00)00975-6

Khouzam, H. R., \& Donnelly, N. J. (1998). Remission of Traumatic Brain Injury-Induced Compulsions during Venlafaxine Treatment. General Hospital Psychiatry, 20, 62-63. http://dx.doi.org/10.1016/S0163-8343(97)00097-2

Kim, E., Lauterbach, E., Reeve, A., Arciniegas, D., Coburn, K., Mendez, M. et al. (2007). Neuropsychiatric Complications of Traumatic Brain Injury: A Critical Review of the Literature (a Report by the ANPA Committee on Research). The Journal of Neuropsychiatry and Clinical Neurosciences, 19, 106-127.

Konsman, J., Drukarch, B., \& Van Dam, A. (2007). (Peri)vascular Production and Action of Pro-Inflammatory Cytokines in Brain Pathology. Clinical Science, 112, 1-25. http://dx.doi.org/10.1042/CS20060043

Koponen, S., Taiminen, T., Portin, R., Himanen, L., Isoniemi, H., Heinonen, H. et al. (2002). Axis I and II Psychiatric Disorders after Traumatic Brain Injury: A 30-Year Follow-Up Study. The American Journal of Psychiatry, 159, $1315-1321$. http://dx.doi.org/10.1176/appi.ajp.159.8.1315

Kou, Z., Wu, Z., Tong, K., Holshouser, B., Benson, R., Hu, J. et al. (2010). The Role of Advanced MR Imaging Findings as Biomarkers of Traumatic Brain Injury. The Journal of Head Trauma Rehabilitation, 25, 267-282. http://dx.doi.org/10.1097/HTR.0b013e3181e54793

Kraus, J. F., \& Chu, L. D. (2005). Epidemiology. In J. M. Silver, T. W. McAllister, \& S. C. Yudofsky (Eds.), Textbook of Traumatic Brain Injury (pp. 3-26). Washington DC: American Psychiatric Publishing.

Kraus, M. F., \& Maki, P. M. (1997). Effect of Amantadine Hydrochloride on Symptoms of Frontal Lobe Dysfunction in Brain Injury: Case Studies and Review. The Journal of Neuropsychiatry and Clinical Neurosciences, 9, 222-230. http://dx.doi.org/10.1176/jnp.9.2.222

Krefetz, D., Steer, R., Gulab, N., \& Beck, A. (2002). Convergent Validity of the Beck Depression Inventory-II with the Reynolds Adolescent Depression Scale in Psychiatric Inpatients. Journal of Personality Assessment, 78, 451-460. http://dx.doi.org/10.1207/S15327752JPA7803_05

Kreutzer, J. S., Seel, R. T., \& Gourley, E. (2001). The Prevalence and Symptom Rates of Depression after Traumatic Brain Injury: A Comprehensive Examination. Brain Injury, 15, 563-576. http://dx.doi.org/10.1080/02699050010009108 
Kreutzer, J. S., Witol, A. D., \& Marwitz, J. H. (1996). Alcohol and Drug Use among Young Persons with Traumatic Brain Injury. Journal of Learning Disabilities, 29, 643-651. http://dx.doi.org/10.1177/002221949602900608

Kreutzer, J., Marwitz, J., Walker, W., Sander, A., Sherer, M., Bogner, J. et al. (2003). Moderating Factors in Return to Work and Job Stability after Traumatic Brain Injury. The Journal of Head Trauma Rehabilitation, 18, 128-138. http://dx.doi.org/10.1097/00001199-200303000-00004

Kurca, E., Sivk, S., \& Kucera, P. (2006). Impaired Cognitive Functions in Mild Traumatic Brain Injury Patients with Normal and Pathologic Magnetic Resonance Imaging. Neuroradiology, 48, 661-669. http://dx.doi.org/10.1007/s00234-006-0109-9

Kurth, S. M., Bigler, E. D., \& Blatter, D. D. (1994). Neuropsychological Outcome and Quantitative Image Analysis of Acute Haemorrhage in Traumatic Brain Injury: Preliminary Findings. Brain Injury, 8, 489-500. http://dx.doi.org/10.3109/02699059409151001

Lajiness-O’Neill, R., Erdodi, L., \& Bigler, E. (2010). Memory and Learning in Pediatric Traumatic Brain Injury: A Review and Examination of Moderators of Outcome. Applied Neuropsychology, 17, 83-92. http://dx.doi.org/10.1080/09084281003708837

Lange, R., Iverson, G., \& Franzen, M. (2009). Neuropsychological Functioning Following Complicated vs. Uncomplicated Mild Traumatic Brain Injury. Brain Injury, 23, 83-91. http://dx.doi.org/10.1080/02699050802635281

Langfitt, T. W., Obrist, W. D., Alavi, A., Grossman, R. I., Zimmerman, R., Jaggi, J. et al. (1986). Computerized Tomography, Magnetic Resonance Imaging, and Positron Emission Tomography in the Study of Brain Trauma. Preliminary Observations. Journal of Neurosurgery, 64, 760-767. http://dx.doi.org/10.3171/jns.1986.64.5.0760

Langlois, J., Rutland-Brown, W., \& Wald, M. (2006). The Epidemiology and Impact of Traumatic Brain Injury: A Brief Overview. The Journal of Head Trauma Rehabilitation, 21, 375-378. http://dx.doi.org/10.1097/00001199-200609000-00001

Larrabee, G. J. (1997). Neuropsychological Outcome, Post Concussion Symptoms, and Forensic Considerations in Mild Closed Head Trauma. Seminars in Clinical Neuropsychiatry, 2, 196-206.

Larrabee, G. J. (2000). Association between IQ and Neuropsychological Test Performance: Commentary on Tremont, Hoffman, Scott, and Adams (1998). The Clinical Neuropsychologist, 14, 139-145. http://dx.doi.org/10.1076/1385-4046(200002)14:1;1-8;FT139

Larrabee, G., Millis, S., \& Meyers, J. (2008). Sensitivity to Brain Dysfunction of the Halstead-Reitan vs an Ability-Focused Neuropsychological Battery. The Clinical Neuropsychologist, 22, 813-825. http://dx.doi.org/10.1080/13854040701625846

Leber, W., \& Jenkins, M. R. (1996). Psychotherapy with Clients Who Have Injuries and Their Families. In R. L. Adams, O. A. Parsons, J. L. Culbertson, \& S. J. Nixon (Eds.), Neuropsychology for Clinical Practice (pp. 489-506). Washington DC: American Psychological Association.

Leininger, B. E., Gramling, S. E., Farrell, A. D., Kreutzer, J. S., \& Peck, E. A. (1990). Neuropsychological Deficits in Symptomatic Minor Head Injury Patients after Concussion and Mild Concussion. Journal of Neurology, Neurosurgery and Psychiatry, 53, 293-296. http://dx.doi.org/10.1136/jnnp.53.4.293

Leininger, B. E., Kreutzer, J. S., \& Hill, M. R. (1991). Comparison of Minor and Severe Head Injury Emotional Sequelae Using the MMPI. Brain Injury, 5, 199-205. http://dx.doi.org/10.3109/02699059109008090

Levin, H. S. (1995). Neurobehavioral Outcome of Closed Head Injury: Implications for Clinical Trials. Journal of Neurotrauma, 12, 601-610. http://dx.doi.org/10.1089/neu.1995.12.601

Levin, H. S., Amparo, E., Eisenberg, H. M., Williams, D. H., High, W. M., McArdle, C. B. et al. (1987). Magnetic Resonance Imaging and Computerized Tomography in Relation to the Neurobehavioral Sequelae of Mild and Moderate Head Injuries. Journal of Neurosurgery, 66, 706-713. http://dx.doi.org/10.3171/jns.1987.66.5.0706

Levin, H. S., Benton, A. L., \& Grossman, R. G. (1982). Neurobehavioural Consequences of Closed Head Injury. New York: Oxford University Press.

Levin, H. S., Brown, S. A., Song, J. X., McCauley, S. R., Boake, C., Contant, C. F. et al. (2001). Depression and Posttraumatic Stress Disorder at Three Months after Mild to Moderate Traumatic Brain Injury. Neuropsychology, Development, and Cognition. Section A, Journal of Clinical and Experimental Neuropsychology, 23, 754-769.

http://dx.doi.org/10.1076/jcen.23.6.754.1021

Levin, H. S., O’Donnell, V. M., \& Grossman, R. G. (1979). The Galveston Orientation and Amnesia Test. A Practical Scale to Assess Cognition after Head Injury. The Journal of Nervous and Mental Disease, 167, 675-684. http://dx.doi.org/10.1097/00005053-197911000-00004

Levine, A., Miller, E., Becker, J., Selnes, O., \& Cohen, B. (2004). Normative Data for Determining Significance of TestRetest Differences on Eight Common Neuropsychological Instruments. The Clinical Neuropsychologist, 18, 373-384. http://dx.doi.org/10.1080/1385404049052420

Levine, B., Cabeza, R., McIntosh, A. R., Black, S. E., Grady, C. L., \& Stuss, D. T. (2002). Functional Reorganisation of 
Memory after Traumatic Brain Injury: A Study with $\mathrm{H}_{2}{ }^{15} \mathrm{O}$ Positron Emission Tomography. Journal of Neurology, Neurosurgery and Psychiatry, 73, 173-181. http://dx.doi.org/10.1136/jnnp.73.2.173

Levine, B., Dawson, D., Boutet, I., Schwartz, M. L., \& Stuss, D. T. (2000). Assessment of Strategic Self-Regulation in Traumatic Brain Injury: Its Relationship to Injury Severity and Psychosocial Outcome. Neuropsychology, 14, 491-500. http://dx.doi.org/10.1037/0894-4105.14.4.491

Levine, B., Fujiwara, E., O’Connor, C., Richard, N., Kovacevic, N., Mandic, M. et al. (2006). In Vivo Characterization of Traumatic Brain Injury Neuropathology with Structural and Functional Neuroimaging. Journal of Neurotrauma, 23, 1396-1411. http://dx.doi.org/10.1089/neu.2006.23.1396

Levine, B., Robertson, I. H., Clare, L., Carter, G., Hong, J., \& Wilson, B. A. (2000). Rehabilitation of Executive Functioning: An Experimental-Clinical Validation of Goal Management Training. Journal of International Neuropsychological Society, 6, 299-312. http://dx.doi.org/10.1017/S1355617700633052

Lewine, J. D., \& Orrison, W. W. (1995). Magnetic Source Imaging: Basic Principles and Applications in Neuroradiology. Academic Radiology, 2, 436-440. http://dx.doi.org/10.1016/S1076-6332(05)80351-4

Lewis, F. D., Nelson, J., Nelson, C., \& Reusink, P. (1988). Effects of Three Feedback Contingencies on the Socially Inappropriate Talk of a Brain-Injured Adult. Behavior Therapy, 19, 203-211. http://dx.doi.org/10.1016/S0005-7894(88)80043-1

Lewis, L. (1991). A Framework for Developing a Psychotherapy Treatment Plan with Brain-Injured Patients. Journal of Head Trauma Rehabilitation, 6, 22-29. http://dx.doi.org/10.1097/00001199-199112000-00006

Lezak, M. D. (1983). Neuropsychological Assessment (2nd ed.). New York: Oxford University Press.

Lezak, M. D. (1987). Relationships between Personality Disorders, Social Disorders, Social Disturbances and Physical Disability Following Traumatic Brain Injury. Journal of Head Trauma Rehabilitation, 2, 57-69. http://dx.doi.org/10.1097/00001199-198703000-00009

Lezak, M. D., \& O’Brien, K. P. (1988). Longitudinal Study of Emotional, Social, and Physical Changes after Traumatic Brain Injury. Journal of Learning Disabilities, 21, 456-463. http://dx.doi.org/10.1177/002221948802100802

Lezak, M. D., Howieson, D. B., \& Loring, D. W. (2004). Neuropsychological Assessment (4th ed.). New York: Oxford University Press.

Li, J., Zhang, J., Yoganandan, N., Pintar, F., \& Gennarelli, T. (2007). Regional Brain Strains and Role of Falx in Lateral Impact-Induced Head Rotational Acceleration. Biomedical Sciences Instrumentation, 43, 24-29.

Lopez, M. N., Charter, R. A., \& Newman, R. J. (2000). Psychometric Properties of the Halstead Category Test. The Clinical Neuropsychologist, 14, 157-161. http://dx.doi.org/10.1076/1385-4046(200005)14:2;1-Z;FT157

Lopez, M., Lazar, M., \& Oh, S. (2003). Psychometric Properties of the Hooper Visual Organization Test. Assessment, 10, 66-70. http://dx.doi.org/10.1177/1073191102250183

Lundin, A., de Boussard, C., Edman, G., \& Borg, J. (2006). Symptoms and Disability until 3 Months after Mild TBI. Brain Injury, 20, 799-806. http://dx.doi.org/10.1080/02699050600744327

Luria, A.R. (1966). Higher Cortical Functions in Man. New York: Basic Books.

Lux, W. (2007). A Neuropsychiatric Perspective on Traumatic Brain Injury. Journal of Rehabilitation Research and Development, 44, 951-962. http://dx.doi.org/10.1682/JRRD.2007.01.0009

Lynch, W. (2004). Determination of Effort Level, Exaggeration, and Malingering in Neurocognitive Assessment. The Journal of Head Trauma Rehabilitation, 19, 277-283. http://dx.doi.org/10.1097/00001199-200405000-00008

Maas, A. I. R., Harrison Felix, C., Menon, D., Adelson, P. D., Balkin, T., Bullock, R. et al. (2011). Standardizing Data Collection in Traumatic Brain Injury. Journal of Neurotrauma, 28, 177-187. http://dx.doi.org/10.1089/neu.2010.1617

Maas, A. I. R., Hukkelhoven, C. W. P. M., Marshall, L., \& Steyerberg, E. (2005). Prediction of Outcome in Traumatic Brain Injury with Computed Tomographic Characteristics: A Comparison between the Computed Tomographic Classification and Combinations of Computed Tomographic Predictors. Neurosurgery, 57, 1173-1182. http://dx.doi.org/10.1227/01.NEU.0000186013.63046.6B

Maas, A., Harrison Felix, C., Menon, D., Adelson, P. D., Balkin, T., Bullock, R. et al. (2010). Common Data Elements for Traumatic Brain Injury: Recommendations from the Interagency Working Group on Demographics and Clinical Assessment. Archives of Physical Medicine and Rehabilitation, 91, 1641-1649. http://dx.doi.org/10.1016/j.apmr.2010.07.232

Maas, A., Menon, D., Lingsma, H., Pineda, J., Sandel, E., \& Manley, G. (2012). Re-Orientation of Clinical Research in Traumatic Brain Injury: Report of an International Workshop on Comparative Effectiveness Research. Journal of Neurotrauma, 29, 32-46. http://dx.doi.org/10.1089/neu.2010.1599

MacDonald, S. W. S., Dixon, R., Cohen, A., \& Hazlitt, J. (2004). Biological Age and 12-Year Cognitive Change in Older Adults: Findings from the Victoria Longitudinal Study. Gerontology, 50, 64-81. http://dx.doi.org/10.1159/000075557

Machamer, J., Temkin, N., Fraser, R., Doctor, J., \& Dikmen, S. (2005). Stability of Employment after Traumatic Brain In- 
jury. Journal of the International Neuropsychological Society, 11, 807-816. http://dx.doi.org/10.1017/S135561770505099X

Maller, J., Thomson, R. H. S., Lewis, P., Rose, S., Pannek, K., \& Fitzgerald, P. (2010). Traumatic Brain Injury, Major Depression, and Diffusion Tensor Imaging: Making Connections. Brain Research Reviews, 64, 213-240. http://dx.doi.org/10.1016/j.brainresrev.2010.04.003

Marsh, N., Kersel, D., Havill, J., \& Sleigh, J. (2002). Caregiver Burden during the Year Following Severe Traumatic Brain Injury. Neuropsychology, Development, and Cognition. Section A, Journal of Clinical and Experimental Neuropsychology, 24, 434-447. http://dx.doi.org/10.1076/jcen.24.4.434.1030

Marshall, L. F. (2000). Head Injury: Recent Past, Present, and Future. Neurosurgery, 47, 546-561.

Martzke, J. S., Swan, C. S., \& Varney, N. R. (1991). Posttraumatic Anosmia and Orbital Frontal Damage: Neuropsychological and Neuropsychiatric Correlates. Neuropsychology, 5, 213-225. http://dx.doi.org/10.1037/0894-4105.5.3.213

Mathias, J. L., \& Mansfield, K. M. (2005). Prospective and Declarative Memory Problems Following Moderate and Severe Traumatic Brain Injury. Brain Injury, 19, 271-282. http://dx.doi.org/10.1080/02699050400005028

Mathias, J. L., Bigler, E. D., Jones, N. R., Bowden, S. C., Barrett-Woodbridge, M., Brown, G. C. et al. (2004). Neuropsychological and Information Processing Performance and Its Relationship to White Matter Changes Following Moderate and Severe Traumatic Brain Injury: A Preliminary Study. Applied Neuropsychology, 11, 134-152. http://dx.doi.org/10.1207/s15324826an1103_2

Mathias, J., \& Wheaton, P. (2007). Changes in Attention and Information-Processing Speed Following Severe Traumatic Brain Injury: A Meta-Analytic Review. Neuropsychology, 21, 212-223. http://dx.doi.org/10.1037/0894-4105.21.2.212

Mathias, J., Beall, J., \& Bigler, E. (2004). Neuropsychological and Information Processing Deficits Following Mild Traumatic Brain Injury. Journal of the International Neuropsychological Society, 10, 286-297. http://dx.doi.org/10.1017/S1355617704102117

Matser, E. J., Kessels, A. G., Lezak, M. D., Jordan, B. D., \& Troost, J. (1999). Neuropsychological Impairment in Amateur Soccer Players. JAMA, 282, 971-973.

Matthews, C. G., \& Klove, K. (1964). Instruction Manual for the Adult Neuropsychology Test Battery. Madison, WI: University of Wisconsin Medical School.

Mazaux, J. M., \& Richer, E. (1998). Rehabilitation after Traumatic Brain Injury in Adults. Disability and Rehabilitation, 20, 435-447. http://dx.doi.org/10.3109/09638289809166108

McAllister, T. W., Sparling, M. B., Flashman, L. A., \& Saykin, A. J. (2001). Neuroimaging Findings in Mild Traumatic Brain Injury. Neuropsychology, Development, and Cognition. Section A, Journal of Clinical and Experimental Neuropsychology, 23, 775-791. http://dx.doi.org/10.1076/jcen.23.6.775.1026

McAllister, T. W., Sparling, M. B., Flashman, L. A., Guerin, S. J., Mamourian, A. C., \& Saykin, A. J. (2001). Differential Working Memory Load Effects after Mild Traumatic Brain Injury. NeuroImage, 14, 1004-1012.

http://dx.doi.org/10.1006/nimg.2001.0899

McCaffrey, R. L., O’Bryant, S. E., Ashendorf, L., \& Fisher, J. M. (2003). Correlations among the TOMM, Rey-15, and MMPI-2 Validity Scales in a Sample of TBI Litigants. Journal of Forensic Neuropsychology, 3, 45-53. http://dx.doi.org/10.1300/J151v03n03_03

McCaig, L. F., \& McLemore, T. (1994). Plan and Operation of the National Hospital Ambulatory Medical Survey. Series 1: Programs and Collection Procedures. Vital and Health Statistics. Series 1. Programs and Collection Procedures, No. 34, $1-78$.

McCauley, S. R., Boake, C., Levin, H. S., Contant, C. F., \& Song, J. X. (2001). Postconcussional Disorder Following Mild to Moderate Traumatic Brain Injury: Anxiety, Depression, and Social Support as Risk Factors and Comorbidities. Neuropsychology, Development, and Cognition. Section A, Journal of Clinical and Experimental Neuropsychology, 23, $792-808$. http://dx.doi.org/10.1076/jcen.23.6.792.1016

McCrea, M., Pliskin, N., Barth, J., Cox, D., Fink, J., French, L. et al. (2008). Official Position of the Military TBI Task Force on the Role of Neuropsychology and Rehabilitation Psychology in the Evaluation, Management, and Research of Military Veterans with Traumatic Brain Injury. The Clinical Neuropsychologist, 22, 10-26. http://dx.doi.org/10.1080/13854040701760981

McDonald, B., Flashman, L., \& Saykin, A. (2002). Executive Dysfunction Following Traumatic Brain Injury: Neural Substrates and Treatment Strategies. NeuroRehabilitation, 17, 333-344.

McDonald, S., \& Saunders, J. (2005). Differential Impairment in Recognition of Emotion across Different Media in People with Severe Traumatic Brain Injury. Journal of the International Neuropsychological Society, 11, 392-399. http://dx.doi.org/10.1017/S1355617705050447

McDowell, S., Whyte, J., \& D’Esposito, M. (1998). Differential Effect of a Dopaminergic Agonist on Prefrontal Function in Traumatic Brain Injury Patients. Brain, 121, 1155-1164. http://dx.doi.org/10.1093/brain/121.6.1155 
McIntosh, T. K., Juhler, M., \& Wieloch, T. (1998). Novel Pharmacologic Strategies in the Treatment of Experimental Traumatic Brain Injury: 1998. Journal of Neurotrauma, 15, 731-769. http://dx.doi.org/10.1089/neu.1998.15.731

Meehan, W., \& Mannix, R. (2010). Pediatric Concussions in United States Emergency Departments in the Years 2002 to 2006. The Journal of Pediatrics, 157, 889-893. http://dx.doi.org/10.1016/j.jpeds.2010.06.040

Menon, D., Schwab, K., Wright, D., \& Maas, A. (2010). Position Statement: Definition of Traumatic Brain Injury. Archives of Physical Medicine and Rehabilitation, 91, 1637-1640. http://dx.doi.org/10.1016/j.apmr.2010.05.017

Meyers, J. E., \& Meyers, K. R. (1995). Rey Complex Figure Test under Four Different Administration Procedures. The Clinicial Neuropsychologist, 9, 63-67. http://dx.doi.org/10.1080/13854049508402059

Millis, S. R., Rosenthal, M., Novack, T. A., Sherer, M., Nick, T. G., Kreutzer, J. S. et al. (2001). Long-Term Neuropsychological Outcome after Traumatic Brain Injury. The Journal of Head Trauma Rehabilitation, 16, 343-355. http://dx.doi.org/10.1097/00001199-200108000-00005

Mitrushina, M., Satz, P., Chervinsky, A., \& D’Elia, L. (1991). Performance of Four Age Groups of Normal Elderly on the Rey Auditory-Verbal Learning Test. Journal of Clinical Psychology, 47, 351-357. http://dx.doi.org/10.1002/1097-4679(199105)47:3<351::AID-JCLP2270470305>3.0.CO;2-S

Mittenberg, W., Tremont, G., Zielinski, R. E., Fichera, S., \& Rayls, K. R. (1996). Cognitive-Behavioral Prevention of Postconcussion Syndrome. Archives of Clinical Neuropsychology, 11, 139-145. http://dx.doi.org/10.1016/0887-6177(95)00006-2

Mooney, G., \& Speed, J. (2001). The Association between Mild Traumatic Brain Injury and Psychiatric Conditions. Brain Injury, 15, 865-877. http://dx.doi.org/10.1080/02699050110065286

Morey, L. C. (1991). Personality Assessment Iinventory; Professional Manual. Odessa, FL: Psychological Assessment Resources.

Murdoch, I., Perry, E. K., Court, J. A., Graham, D. I., \& Dewar, D. (1998). Cortical Cholinergic Dysfunction after Human Head Injury. Journal of Neurotrauma, 15, 295-305. http://dx.doi.org/10.1089/neu.1998.15.295

Nakai, T., Rhine, W. D., Enzmann, D. R., Stevenson, D. K., \& Spielman, D. M. (1996). A Model for Detecting Early Metabolic Changes in Neonatal Asphyxia by 1H-MRS. Journal of Magnetic Resonance Imaging, 6, 445-452. http://dx.doi.org/10.1002/jmri.1880060306

Nelson, N., Boone, K., Dueck, A., Wagener, L., Lu, P., \& Grills, C. (2003). Relationships between Eight Measures of Suspect Effort. The Clinical Neuropsychologist, 17, 263-272. http://dx.doi.org/10.1076/clin.17.2.263.16511

Newgard, C. D., Sears, G. K., Rea, T. D., Davis, D. P., Pirrallo, R. G., Callaway, C. W. et al. (2008). The Resuscitation Outcome Consortium Epistry-Trauma: Design, Development, and Implementation of a North American Epidemiologic Prehospital Trauma Registry. Resuscitation, 78, 170-178. http://dx.doi.org/10.1016/j.resuscitation.2008.01.029

Nichols, D. (2001). Essentials of the MMPI-2 Assessment. New York: John Wiley \& Sons.

Niemeier, J., Kreutzer, J., Marwitz, J., Gary, K., \& Ketchum, J. (2011). Efficacy of a Brief Acute Neurobehavioural Intervention Following Traumatic Brain Injury: A Preliminary Investigation. Brain Injury, 25, 680-690. http://dx.doi.org/10.3109/02699052.2011.573520

Niogi, S. N., Mukherjee, P., Ghajar, J., Johnson, C., Kolster, R. A., Sarkar, R. et al. (2008a). Extent of Microstructural White Matter Injury in Postconcussive Syndrome Correlates with Impaired Cognitive Reaction Time: A 3T Diffusion Tensor Imaging Study of Mild Traumatic Brain Injury. American Journal of Neuroradiology, 29, 967-973. http://dx.doi.org/10.3174/ajnr.A0970

Niogi, S. N., Mukherjee, P., Ghajar, J., Johnson, C., Kolster, R., Lee, H. et al. (2008b). Structural Dissociation of Attentional Control and Memory in Adults with and without Mild Traumatic Brain Injury. Brain, 131, 3209-3221. http://dx.doi.org/10.1093/brain/awn247

Novack, T. A., Dillon, M. C., \& Jackson, W. T. (1996). Neurochemical Mechanisms in Brain Injury and Treatment: A Review. Neuropsychology, Development, and Cognition. Section A, Journal of Clinical and Experimental Neuropsychology, 18, 685-706. http://dx.doi.org/10.1080/01688639608408292

O’Neill, J., Hibbard, M. R., Brown, M., Jaffe, M., Sliwinski, M., Vandergoot, D. et al. (1998). The Effect of Employment on Quality of Life and Community Integration after Traumatic Brain Injury. The Journal of Head Trauma Rehabilitation, 13, 68-79. http://dx.doi.org/10.1097/00001199-199808000-00007

Otis, J., McGlinchey, R., Vasterling, J., \& Kerns, R. (2011). Complicating Factors Associated with Mild Traumatic Brain Injury: Impact on Pain and Posttraumatic Stress Disorder Treatment. Journal of Clinical Psychology in Medical Settings, 18, 145-154. http://dx.doi.org/10.1007/s10880-011-9239-2

Ottens, A., Kobeissy, F., Golden, E., Zhang, Z., Haskins, W., Chen, S. et al. (2006). Neuroproteomics in Neurotrauma. Mass Spectrometry Reviews, 25, 380-408. http://dx.doi.org/10.1002/mas.20073

Ownsworth, T. L., \& McFarland, K. (1999). Memory Remediation in Long-Term Acquired Brain Injury: Two Approaches in 
Diary Training. Brain Injury, 13, 605-626. http://dx.doi.org/10.1080/026990599121340

Ownsworth, T., \& McKenna, K. (2004). Investigation of Factors Related to Employment Outcome Following Traumatic Brain Injury: A Critical Review and Conceptual Model. Disability and Rehabilitation, 26, 765-783. http://dx.doi.org/10.1080/09638280410001696700

Paolo, A. M., Axelrod, B. N., \& Troster, A. (1996). Test-Retest Stability of the Wisconsin Card Sorting Test. Assessment, 3, 137-143.

Paolo, A. M., Troster, A. I., Axelrod, B. N., \& Koller, W. C. (1995). Construct Validity of the WCST in Normal Elderly and Persons with Parkinson's Disease. Archives of Clinical Neuropsychology, 10, 463-473. http://dx.doi.org/10.1093/arclin/10.5.463

Parry-Jones, B., Vaughan, F., \& Miles Cox, W. (2006). Traumatic Brain Injury and Substance Misuse: A Systematic Review of Prevalence and Outcomes Research (1994-2004). Neuropsychological Rehabilitation, 16, 537-560. http://dx.doi.org/10.1080/09602010500231875

Pedraza, O., \& Mungas, D. (2008). Measurement in Cross-Cultural Neuropsychology. Neuropsychology Review, 18, $184-193$. http://dx.doi.org/10.1007/s11065-008-9067-9

Penn, P. R., Rose, F. D., \& Johnson, D. A. (2009). Virtual Enriched Environments in Paediatric Neuropsychological Rehabilitation Following Traumatic Brain Injury: Feasibility, Benefits and Challenges. Developmental Neurorehabilitation, 12, 32-43. http://dx.doi.org/10.1080/17518420902739365

Perlstein, W., Cole, M., Demery, J., Seignourel, P., Dixit, N., Larson, M. et al. (2004). Parametric Manipulation of Working Memory Load in Traumatic Brain Injury: Behavioral and Neural Correlates. Journal of the International Neuropsychological Society, 10, 724-741. http://dx.doi.org/10.1017/S1355617704105110

Perrine, K. (1993). Differential Aspects of Conceptual Processing in the Category Test and Wisconsin Card Sorting Test. Neuropsychology, Development, and Cognition. Section A, Journal of Clinical and Experimental Neuropsychology, 15, 461-473. http://dx.doi.org/10.1080/01688639308402571

Pierpaoli, C., Jezzard, P., Basser, P. J., Barnett, A., \& Di Chiro, G. (1996). Diffusion Tensor MR Imaging of the Human Brain. Radiology, 201, 637-648. http://dx.doi.org/10.1148/radiology.201.3.8939209

Podell, K., Gifford, K., Bougakov, D., \& Goldberg, E. (2010). Neuropsychological Assessment in Traumatic Brain Injury. Psychiatric Clinics of North America, 33, 855-876. http://dx.doi.org/10.1016/j.psc.2010.08.003

Pollack, I. W. (1994). Individual Psychotherapy. In J. M. Silver, S. C. Yudofsky, \& R. E. Hales (Eds.), Neuropsychiatry of Traumatic Brain Injury (pp. 671-702). Washington DC: American Psychiatric Press.

Pollack, I. W. (2005). Psychotherapy. In J. M. Silver, T. W. McAllister, \& S. C. Yudofsky (Eds.), Textbook of Traumatic Brain Injury (1st ed., pp. 641-654). Washington DC: American Psychiatric Press.

Ponsford, J. L., Oliver, J. H., \& Curran, C. (1995). A Profile of Outcome: 2 Years after Traumatic Brain Injury. Brain Injury, 9, 1-10. http://dx.doi.org/10.3109/02699059509004565

Ponsford, J., \& Kinsella, G. (1992). Attentional Deficits Following Closed-Head Injury. Neuropsychology, Development, and Cognition. Section A, Journal of Clinical and Experimental Neuropsychology, 14, 822-838. http://dx.doi.org/10.1080/01688639208402865

Ponsford, J., Harrington, H., Oliver, J., \& Roper, M. (2006). Evaluation of a Community-Based Model of Rehabilitation Following Traumatic Brain Injury. Neuropsychological Rehabilitation, 16, 315-328. http://dx.doi.org/10.1080/09602010500176534

Ponsford, J., Olver, J., Ponsford, M., \& Nelms, R. (2003). Long-Term Adjustment of Families Following Traumatic Brain Injury Where Comprehensive Rehabilitation Has Been Provided. Brain Injury, 17, 453-468.

http://dx.doi.org/10.1080/0269905031000070143

Ponsford, J., Willmott, C., Rothwell, A., Cameron, P., Ayton, G., Nelms, R. et al. (2001). Impact of Early Intervention on Outcome after Mild Traumatic Brain Injury in Children. Pediatrics, 108, 1297-1303.

http://dx.doi.org/10.1542/peds.108.6.1297

Ponsford, J., Willmott, C., Rothwell, A., Cameron, P., Kelly, A. M., Nelms, R. et al. (2000). Factors Influencing Outcome Following Mild Traumatic Brain Injury in Adults. Journal of the International Neuropsychological Society, 6, 568-579. http://dx.doi.org/10.1017/S1355617700655066

Powell, J., Ferraro, J., Dikmen, S., Temkin, N., \& Bell, K. (2008). Accuracy of Mild Traumatic Brain Injury Diagnosis. Archives of Physical Medicine and Rehabilitation, 89, 1550-1555. http://dx.doi.org/10.1016/j.apmr.2007.12.035

Powell, J., Heslin, J., \& Greenwood, R. (2002). Community Based Rehabilitation after Severe Traumatic Brain Injury: A Randomised Controlled Trial. Journal of Neurology, Neurosurgery and Psychiatry, 72, 193-202.

http://dx.doi.org/10.1136/jnnp.72.2.193

Prigatano, G. P. (1992). Personality Disturbances Associated with Traumatic Brain Injury. Journal of Consulting and Clini- 
cal Psychology, 60, 360-368. http://dx.doi.org/10.1037/0022-006X.60.3.360

Prigatano, G. P., Altman, I. M., \& O’Brien, K. P. (1990). Behavioral Limitations That Traumatic Brain-Injured Patients Tend to Underestimate. The Clinical Neuropsychologist, 4, 163-176. http://dx.doi.org/10.1080/13854049008401509

Prigatano, G. P., Fordyce, D. J., Zeiner, H. K., Roueche, J. R., Pepping, M., \& Wood, B. C. (1984). Neuropsychological Rehabilitation after Closed Head Injury in Young Adults. Journal of Neurology, Neurosurgery and Psychiatry, 47, 505-513. http://dx.doi.org/10.1136/jnnp.47.5.505

Prigatano, G. P., Klonoff, P. S., O’Brien, K. P., Altman, I. M., Amin, K., Chiapello, D. et al. (1994). Productivity after Neuropsychologically Oriented Milieu Rehabilitation. The Journal of Head Trauma Rehabilitation, 9, 91-102. http://dx.doi.org/10.1097/00001199-199403000-00011

Randolph, C., McCrea, M., \& Barr, W. (2005). Is neuropsychological Testing Useful in the Management of Sport-Related Concussion? Journal of Athletic Training, 40, 139-152.

Rao, V., \& Lyketsos, C. (2002). Psychiatric Aspects of Traumatic Brain Injury. Psychiatric Clinics of North America, 25, 43-69. http://dx.doi.org/10.1016/S0193-953X(03)00052-2

Rao, V., Munro, C. A., Rosenberg, P., Ward, J., Bertrand, M., Degoankar, M. et al. (2010). Neuroanatomical Correlates of Depression in Post Traumatic Brain Injury: Preliminary Results of a Pilot Study. Journal of Neuropsychiatry and Clinical Neuroscience, 22, 231-235. http://dx.doi.org/10.1176/jnp.2010.22.2.231

Rappaport, M., Hall, K. M., Hopkins, K., Belleza, T., \& Cope, D. N. (1982). Disability Rating Scale for Severe Head Trauma: Coma to Community. Archives of Physical Medicine and Rehabilitation, 63, 118-123.

Rees, L. M., Tombaugh, T. N., \& Gansler, D. A. Moczynski, N. P. (1998). Five Validation Experiments of the Test of Memory Malingering (TOMM). Psychological Assessment, 10, 10-20. http://dx.doi.org/10.1037/1040-3590.10.1.10

Reitan, R. M. (1955). The Relation of the Trail Making Test to Organic Brain Damage. Journal of Consulting Psychology, 19, 393-394. http://dx.doi.org/10.1037/h0044509

Reitan, R. M. (1969). Manual for Administration of Neuropsychological Test Batteries for Adults and Children. Indianapolis, IN: Publishing House.

Reitan, R. M., \& Wolfson, D. (1985). The Halstead-Reitan Neuropsychological Test Battery: Theory and Interpretattion. Tucson, AZ: Neuropsychology Press.

Reitan, R. M., \& Wolfson, D. (1993). The Halstead-Reitan Neuropsychological Test Battery: Theory and Clinical Applications (2nd ed.). Tucson, AZ: Neuropsychology Press.

Rey, A. (1964). L'Examen Clinique en Psychologie. Paris: Presses Universitaires de France.

Richards, M. S., Goldberg, J., Rodin, M. B., \& Anderson, R. J. (1989). Alcohol Consumption and Problem Drinking in White Male Veterans and Nonveterans. American Journal of Public Health, 79, 1011-1015. http://dx.doi.org/10.2105/AJPH.79.8.1011

Ricker, J. H., Hillary, F. G., \& DeLuca, J. (2001). Functionally Activated Brain Imaging (O-15 PET and fMRI) in the Study of Learning and Memory after Traumatic Brain Injury. The Journal of Head Trauma Rehabilitation, 16, $191-205$. http://dx.doi.org/10.1097/00001199-200104000-00007

Risdall, J. E., \& Menon, D. K. (2011). Traumatic Brain Injury. Philosophical Transactions of the Royal Society, 366, 241250. http://dx.doi.org/10.1098/rstb.2010.0230

Rivara, F., Koepsell, T., Wang, J., Durbin, D., Jaffe, K., Vavilala, M. et al. (2011). Comparison of Telephone with World Wide Web-Based Responses by Parents and Teens to a Follow-Up Survey after Injury. Health Services Research, 46, 964-981. http://dx.doi.org/10.1111/j.1475-6773.2010.01236.x

Robinson, R., \& Jorge, R. (2002). Longitudinal Course of Mood Disorders Following Traumatic Brain Injury. Archives of General Psychiatry, 59, 23-24. http://dx.doi.org/10.1001/archpsyc.59.1.23

Rochat, L., Beni, C., Billieux, J., Azouvi, P., Annoni, J., \& Van der Linden, M. (2010). Assessment of Impulsivity after Moderate to Severe Traumatic Brain Injury. Neuropsychological Rehabilitation, 20, 778-797. http://dx.doi.org/10.1080/09602011.2010.495245

Rogers, J., \& Read, C. (2007). Psychiatric Comorbidity Following Traumatic Brain Injury. Brain Injury, 21, 1321-1333. http://dx.doi.org/10.1080/02699050701765700

Romesser, J., Shen, S., Reblin, M., Kircher, J., Allen, S., Roberts, T. et al. (2011). A Preliminary Study of the Effect of a Diagnosis of Concussion on PTSD Symptoms and Other Psychiatric Variables at the Time of Treatment Seeking among Veterans. Military Medicine, 176, 246-252. http://dx.doi.org/10.7205/MILMED-D-10-00056

Rosen, V. M., \& Engle, R. W. (1997). The Role of Working Memory Capacity in Retrieval. Journal of Experimental Psychology.General, 126, 211-227. http://dx.doi.org/10.1037/0096-3445.126.3.211

Royan, J., Tombaugh, T. N., Rees, L., \& Francis, M. (2004). The Adjusting-Paced Serial Addition Test (Adjusting-PSAT): 
Thresholds for Speed of Information Processing as a Function of Stimulus Modality and Problem Complexity. Archives of Clinical Neuropsychology, 19, 131-143. http://dx.doi.org/10.1093/arclin/19.1.131

Ruff, R. M., \& Niemann, H. (1990). Cognitive Rehabilitation versus Day Treatment in Head-Injured Adults: Is There an Impact on Emotional and Psychosocial Adjustment? Brain Injury, 4, 339-347. http://dx.doi.org/10.3109/02699059009026187

Ruff, R. M., Crouch, J. A., Trster, A. I., Marshall, L. F., Buchsbaum, M. S., Lottenberg, S. et al. (1994). Selected Cases of Poor Outcome Following a Minor Brain Trauma: Comparing Neuropsychological and Positron Emission Tomography Assessment. Brain Injury, 8, 297-308. http://dx.doi.org/10.3109/02699059409150981

Ruff, R. M., Evans, R., \& Marshall, L. F. (1986). Impaired Verbal and Figural Fluency after Head Injury. Archives of Clinical Neuropsychology, 1, 87-101. http://dx.doi.org/10.1093/arclin/1.2.87

Ruff, R. M., Light, R. H., Parker, S. B., \& Levin, H. S. (1996). Benton Controlled Oral Word Association Test: Reliability and Updated Norms. Archives of Clinical Neuropsychology, 11, 329-338. http://dx.doi.org/10.1093/arclin/11.4.329

Rutland-Brown, W., Langlois, J., Thomas, K., \& Lily, Y. (2006). Incidence of Traumatic Brain Injury in the United States, 2003. The Journal of Head Trauma Rehabilitation, 21, 544-548. http://dx.doi.org/10.1097/00001199-200611000-00009

Saatman, K., Duhaime, A., Bullock, R., Maas, A. I. R., Valadka, A., \& Manley, G. (2008). Classification of Traumatic Brain Injury for Targeted Therapies. Journal of Neurotrauma, 25, 719-738. http://dx.doi.org/10.1089/neu.2008.0586

Saint-Cyr, J. A., \& Taylor, A. E. (1992). The Mobilization of Procedural Learning: The "Key Signature” of the Basal Ganglia. In L. R. Squire, \& N. Butters (Eds.), Neuropsychology of Memory (2nd ed., pp. 91-102). New York: Guilford Press.

Salcido, R., \& Costich, J. F. (1992). Recurrent Traumatic Brain Injury. Brain Injury, 6, 293-298. http://dx.doi.org/10.3109/02699059209029671

Sander, A., Pappadis, M., Davis, L., Clark, A., Evans, G., Struchen, M. et al. (2009). Relationship of Race/Ethnicity and Income to Community Integration Following Traumatic Brain Injury: Investigation in a Non-Rehabilitation Trauma Sample. NeuroRehabilitation, 24, 15-27.

Sanders, J. A. (1995). Magnetic Resonance Spectroscopy. In W. W. Orrison, J. D. Lewine, J. A. Sanders, \& M. F. Harthshorne (Eds.), Functional Brain Imaging (pp. 419-467). St. Louis, MO: Mosby.

Sattler, J. M., \& Ryan, J. J. (2009). Assessment with the WAIS-IV. San Diego, CA: Jerome M. Sattler, Publisher, Inc.

Savola, O., \& Hillbom, M. (2003). Early Predictors of Post-Concussion Symptoms in Patients with Mild Head Injury. European Journal of Neurology, 10, 175-181. http://dx.doi.org/10.1046/j.1468-1331.2003.00552.x

Schatz, P., Pardini, J., Lovell, M., Collins, M., \& Podell, K. (2006). Sensitivity and Specificity of the ImPACT Test Battery for Concussion in Athletes. Archives of Clinical Neuropsychology, 21, 91-99. http://dx.doi.org/10.1016/j.acn.2005.08.001

Scheibel, R., Newsome, M., Troyanskaya, M., Steinberg, J., Goldstein, F., Mao, H. et al. (2009). Effects of Severity of Traumatic Brain Injury and Brain Reserve on Cognitive-Control Related Brain Activation. Journal of Neurotrauma, 26, 1447-1461. http://dx.doi.org/10.1089/neu.2008.0736

Schneiderman, A., Braver, E., \& Kang, H. (2008). Understanding Sequelae of Injury Mechanisms and Mild Traumatic Brain Injury Incurred during the Conflicts in Iraq and Afghanistan: Persistent Postconcussive Symptoms and Posttraumatic Stress Disorder. American Journal of Epidemiology, 167, 1446-1452. http://dx.doi.org/10.1093/aje/kwn068

Schönberger, M., Ponsford, J., Olver, J., \& Ponsford, M. (2010). A Longitudinal Study of Family Functioning after TBI and Relatives’ Emotional Status. Neuropsychological Rehabilitation, 20, 813-829.

http://dx.doi.org/10.1080/09602011003620077

Schretlen, D. J. (2000). Do Neurocognitive Ability and Personality Traits Account for Different Aspects of Psychosocial Outcome after Traumatic Brain Injury? Rehabilitation Psychology, 45, 260-273. http://dx.doi.org/10.1037/0090-5550.45.3.260

Schretlen, D., \& Shapiro, A. (2003). A Quantitative Review of the Effects of Traumatic Brain Injury on Cognitive Functioning. International Review of Psychiatry, 15, 341-349. http://dx.doi.org/10.1080/09540260310001606728

Schulenberg, S. E., \& Yutrzenka, B. A. (2001). Equivalence of Computerized and Conventional Versions of the Beck Depression Inventory-II (BDI-II). Current Psychology, 20, 216-230. http://dx.doi.org/10.1007/s12144-001-1008-1

Seel, R., Kreutzer, J., Rosenthal, M., Hammond, F., Corrigan, J., \& Black, K. (2003). Depression after Traumatic Brain Injury: A National Institute on Disability and Rehabilitation Research Model Systems Multicenter Investigation. Archives of Physical Medicine and Rehabilitation, 84, 177-184. http://dx.doi.org/10.1053/apmr.2003.50106

Segalowitz, S. J., Unsal, A., \& Dywan, J. (1992). CNV Evidence for the Distinctiveness of Frontal and Posterior Neural Processes in a Traumatic Brain-Injured Population. Neuropsychology, Development, and Cognition. Section A, Journal of Clinical and Experimental Neuropsychology, 14, 545-565. http://dx.doi.org/10.1080/01688639208402844

Selassie, A., Pickelsimer, E., Frazier, L., \& Ferguson, P. (2004). The Effect of Insurance Status, Race, and Gender on ED Disposition of Persons with Traumatic Brain Injury. The American Journal of Emergency Medicine, 22, 465-473. 
http://dx.doi.org/10.1016/j.ajem.2004.07.024

Shafi, S., \& Gentilello, L. (2008). Ethnic Disparities in Initial Management of Trauma Patients in a Nationwide Sample of Emergency Department Visits. Archives of Surgery, 143, 1057-1061. http://dx.doi.org/10.1001/archsurg.143.11.1057

Shafi, S., de la Plata, C., Diaz-Arrastia, R., Bransky, A., Frankel, H., Elliott, A. et al. (2007a). Ethnic Disparities Exist in Trauma Care. The Journal of Trauma, 63, 1138-1142. http://dx.doi.org/10.1097/TA.0b013e3181568cd4

Shafi, S., de la Plata, C., Diaz-Arrastia, R., Shipman, K., Carlile, M., Frankel, H. et al. (2007b). Racial Disparities in Long-Term Functional Outcome after Traumatic Brain Injury. The Journal of Trauma, 63, 1263-1268.

http://dx.doi.org/10.1097/TA.0b013e31815b8f00

Shallice, T. (1982). Specific Impairments of Planning. Philosophical Transactions of the Royal Society B: Biological Sciences, 298, 199-209. http://dx.doi.org/10.1098/rstb.1982.0082

Sharpe, S., Kool, B., Shepherd, M., Dalziel, S., \& Ameratunga, S. (2012). Mild Traumatic Brain Injury: Improving Quality of Care in the Paediatric Emergency Department Setting. Journal of Paediatrics and Child Health, 48, 170-176. http://dx.doi.org/10.1111/j.1440-1754.2011.02068.x

Sherer, M., \& Novack, T. A. (2003). Neuropsychological Assessment after Brain Injury. In G. P. Prigatano, \& N. H. Pilskin (Eds.), Clinical Neuropsychology and Cost outcome Research: A Beginning (pp. 39-60). New York: Psychology Press.

Sherer, M., Nick, T., Sander, A., Hart, T., Hanks, R., Rosenthal, M. et al. (2003). Race and Productivity Outcome after Traumatic Brain Injury: Influence of Confounding Factors. The Journal of Head Trauma Rehabilitation, 18, 408-424. http://dx.doi.org/10.1097/00001199-200309000-00003

Sherer, M., Novack, T., Sander, A., Struchen, M., Alderson, A., \& Thompson, R. (2002). Neuropsychological Assessment and Employment Outcome after Traumatic Brain Injury: A Review. The Clinical Neuropsychologist, 16, 157-178. http://dx.doi.org/10.1076/clin.16.2.157.13238

Shiel, A., Burn, J. P., Henry, D., Clark, J., Wilson, B. A., Burnett, M. E. et al. (2001). The Effects of Increased Rehabilitation Therapy after Brain Injury: Results of a Prospective Controlled Trial. Clinical Rehabilitation, 15, 501-514. http://dx.doi.org/10.1191/026921501680425225

Shute, G. E., \& Huertas, V. (1990). Developmental Variability of Frontal Lobe Function. Developmental Neuropsychology, 6 , 1-11. http://dx.doi.org/10.1080/87565649009540445

Shutter, L., Tong, K., Lee, A., \& Holshouser, B. (2006). Prognostic Role of Proton Magnetic Resonance Spectroscopy in Acute Traumatic Brain Injury. The Journal of Head Trauma Rehabilitation, 21, 334-349.

http://dx.doi.org/10.1097/00001199-200607000-00005

Sidaros, A., Engberg, A., Sidaros, K., Liptrot, M., Herning, M., Petersen, P. et al. (2008). Diffusion Tensor Imaging during Recovery from Severe Traumatic Brain Injury and Relation to Clinical Outcome: A Longitudinal Study. Brain, 131, 559572. http://dx.doi.org/10.1093/brain/awm294

Siesj, B. K. (1993). Basic Mechanisms of Traumatic Brain Damage. Annals of Emergency Medicine, 22, 959-969. http://dx.doi.org/10.1016/S0196-0644(05)82736-2

Simpson, G., \& Tate, R. (2007). Suicidality in People Surviving a Traumatic Brain Injury: Prevalence, Risk Factors and Implications for Clinical Management. Brain Injury, 21, 1335-1351. http://dx.doi.org/10.1080/02699050701785542

Sinnakaruppan, I., Downey, B., \& Morrison, S. (2005). Head Injury and Family Carers: A Pilot Study to Investigate an Innovative Community-Based Educational Programme for Family Carers and Patients. Brain Injury, 19, 283-308. http://dx.doi.org/10.1080/02699050400003924

Slick, D. J., Hopp, G., Strauss, E., \& Spellacy, F. J. (1996). Victoria Symptom Validity Test: Efficiency for Detecting Feigned Memory Impairment and Relationship to Neuropsychological Tests and MMPI-2 Validity Scales. Neuropsychology, Development, and Cognition. Section A, Journal of Clinical and Experimental Neuropsychology, 18, 911-922. http://dx.doi.org/10.1080/01688639608408313

Smith, A. (1991). Symbol Digit Modalities Test. Los Angeles, CA: Western Psychological Services.

Smith, G. S., \& Kraus, J. F. (1988). Alcohol and Residential, Recreational, and Occupational Injuries: A Review of the Epidemiologic Evidence. Annual Review of Public Health, 9, 99-121. http://dx.doi.org/10.1146/annurev.pu.09.050188.000531

Smith, M.J., Vaughan, F.L., Cox, L.J., McConvelle, H., Roberts, M., Stoddart, S. et al. (2006). The Impact of Community Rehabilitation for Acquired Brain Injury on Carer Burden: An Exploratory Study. Journal of Head Trauma Rehabilitation, 21, 76-81. http://dx.doi.org/10.1097/00001199-200601000-00008

Snow, P., Douglas, J., \& Ponsford, J. (1998). Conversational Discourse Abilities Following Severe Traumatic Brain Injury: A Follow-Up Study. Brain Injury, 12, 911-935. http://dx.doi.org/10.1080/026990598121981

Sosin, D. M., Sniezek, J. E., \& Thurman, D. J. (1996). Incidence of Mild and Moderate Brain Injury in the United States, 1991. Brain Injury, 10, 47-54. http://dx.doi.org/10.1080/026990596124719

Sprinkle, S. D., Lurie, D., Insko, S. L., Atkinson, G., Jones, G. L., Logan, A. R. et al. (2002). Criterion Validity, Severity Cut 
Scores, and Test Retest Reliability of the Beck Depression Inventory-II in a University Counseling Center Sample. Jouranl of Counselling Psychology, 49, 381-385. http://dx.doi.org/10.1037/0022-0167.49.3.381

Staudenmayer, K., Diaz-Arrastia, R., de Oliveira, A., Gentilello, L., \& Shafi, S. (2007). Ethnic Disparities in Long-Term Functional Outcomes after Traumatic Brain Injury. The Journal of Trauma, 63, 1364-1369. http://dx.doi.org/10.1097/TA.0b013e31815b897b

Stein, S., Burnett, M., \& Glick, H. (2006). Indications for CT Scanning in Mild Traumatic Brain Injury: A Cost-Effectiveness Study. The Journal of Trauma, 61, 558-566. http://dx.doi.org/10.1097/01.ta.0000233766.60315.5e

Stranjalis, G., Korfias, S., Papapetrou, C., Kouyialis, A., Boviatsis, E., Psachoulia, C. et al. (2004). Elevated Serum S-100B Protein as a Predictor of Failure to Short-Term Return to Work or Activities after Mild Head Injury. Journal of Neurotrauma, 21, 1070-1075. http://dx.doi.org/10.1089/0897715041651088

Strauss, E., Sherman, E. M. S., \& Spreen, O. (2006). A Compendium of Neuropsychological Tests. New York: Oxford University Press.

Stroop, J. R. (1935). Studies of Interference in Serial Verbal Reaction. Journal of Experimental Psychology, 18, 643-662. http://dx.doi.org/10.1037/h0054651

Stuss, D. T., Levine, B., Alexander, M. P., Hong, J., Palumbo, C., Hamer, L. et al. (2000). Wisconsin Card Sorting Test Performance in Patients with Focal Frontal and Posterior Brain Damage: Effects of Lesion Location and Test Structure on Separable Cognitive Processes. Neuropsychologia, 38, 388-402. http://dx.doi.org/10.1016/S0028-3932(99)00093-7

Tagliaferri, F., Compagnone, C., Korsic, M., Servadei, F., \& Kraus, J. (2006). A Systematic Review of Brain Injury Epidemiology in Europe. Acta Neurochirurgica, 148, 255-268. http://dx.doi.org/10.1007/s00701-005-0651-y

Tate, P. S., Freed, D. M., Bombardier, C. H., Harter, S. L., \& Brinkman, S. (1999). Traumatic Brain Injury: Influence of Blood Alcohol Level on Post-Acute Cognitive Function. Brain Injury, 13, 767-784. http://dx.doi.org/10.1080/026990599121160

Taverni, J. P., Seliger, G., \& Lichtman, S. W. (1998). Donepezil Medicated Memory Improvement in Traumatic Brain Injury during Post Acute Rehabilitation. Brain Injury, 12, 77-80. http://dx.doi.org/10.1080/026990598122881

Teasdale, G. M., Nicoll, J. A., Murray, G., \& Fiddes, M. (1997). Association of Apolipoprotein E Polymorphism with Outcome after Head Injury. The Lancet, 350, 1069-1071. http://dx.doi.org/10.1016/S0140-6736(97)04318-3

Teasdale, G., \& Jennett, B. (1974). Assessment of Coma and Impaired Consciousness. A Practical Scale. The Lancet, 2, 81-84. http://dx.doi.org/10.1016/S0140-6736(74)91639-0

Teasdale, T. W., \& Engberg, A. W. (2001). Suicide after Traumatic Brain Injury: A Population Study. Journal of Neurology, Neurosurgery and Psychiatry, 71, 436-440. http://dx.doi.org/10.1136/jnnp.71.4.436

Temkin, N., Corrigan, J., Dikmen, S., \& Machamer, J. (2009). Social Functioning after Traumatic Brain Injury. The Journal of Head Trauma Rehabilitation, 24, 460-467. http://dx.doi.org/10.1097/HTR.0b013e3181c13413

Terrio, H., Brenner, L., Ivins, B., Cho, J., Helmick, K., Schwab, K. et al. (2009). Traumatic Brain Injury Screening: Preliminary Findings in a US Army Brigade Combat Team. The Journal of Head Trauma Rehabilitation, 24, 14-23. http://dx.doi.org/10.1097/HTR.0b013e31819581d8

Thomas, M. (2004). The Potential Unlimited Programme: An Outdoor Experiential Education and Group Work Approach That Facilitates Adjustment to Brain Injury. Brain Injury, 18, 1271-1286. http://dx.doi.org/10.1080/02699050410001698776

Thurman, D. J., Branche, C. M., \& Sniezek, J. E. (1998). The Epidemiology of Sports-Related Traumatic Brain Injuries in the United States: Recent Developments. The Journal of Head Trauma Rehabilitation, 13, 1-8. http://dx.doi.org/10.1097/00001199-199804000-00003

Thurmond, V., Hicks, R., Gleason, T., Miller, A. C., Szuflita, N., Orman, J. et al. (2010). Advancing Integrated Research in Psychological Health and Traumatic Brain Injury: Common Data Elements. Archives of Physical Medicine and Rehabilitation, 91, 1633-1636. http://dx.doi.org/10.1016/j.apmr.2010.06.034

Tiffin, J. (1968). Purdue Pegboard Examiner's Manual. Rosemont, IL: London House.

Timofeev, I., Carpenter, K. L. H., Nortje, J., Al Rawi, P., O’Connell, M., Czosnyka, M. et al. (2011). Cerebral Extracellular Chemistry and Outcome Following Traumatic Brain Injury: A Microdialysis Study of 223 Patients. Brain, 134, 484-494. http://dx.doi.org/10.1093/brain/awq353

Tomaiuolo, F., Worsley, K., Lerch, J., Di Paola, M., Carlesimo, G., Bonanni, R. et al. (2005). Changes in White Matter in Long-Term Survivors of Severe Non-Missile Traumatic Brain Injury: A Computational Analysis of Magnetic Resonance Images. Journal of Neurotrauma, 22, 76-82. http://dx.doi.org/10.1089/neu.2005.22.76

Tombaugh, T. N. (1996). Test of Memory Malingering. Los Angeles, CA: Western Psychological Services.

Triggs, W. J., Calvanio, R., Levine, M., Heaton, R. K., \& Heilman, K. M. (2000). Predicting Hand Preference with Performance on Motor Tasks. Cortex, 36, 679-689. http://dx.doi.org/10.1016/S0010-9452(08)70545-8 
Udekwu, P., Kromhout-Schiro, S., Vaslef, S., Baker, C., \& Oller, D. (2004). Glasgow Coma Scale Score, Mortality, and Functional Outcome in Head-Injured Patients. The Journal of Trauma, 56, 1084-1089.

http://dx.doi.org/10.1097/01.TA.0000124283.02605.A5

Umansky, R., \& Geller, V. (2000). Olanzapine Treatment in an Organic Hallucinosis Patient. International Journal of Neuropsychopharmacology, 3, 81-82. http://dx.doi.org/10.1017/S1461145700001723

Umile, E., Sandel, M. E., Alavi, A., Terry, C., \& Plotkin, R. (2002). Dynamic Imaging in Mild Traumatic Brain Injury: Support for the Theory of Medial Temporal Vulnerability. Archives of Physical Medicine and Rehabilitation, 83, 15061513. http://dx.doi.org/10.1053/apmr.2002.35092

Vagnozzi, R., Signoretti, S., Tavazzi, B., Floris, R., Ludovici, A., Marziali, S. et al. (2008). Temporal Window of Metabolic Brain Vulnerability to Concussion: A Pilot 1H-Magnetic Resonance Spectroscopic Study in Concussed Athletes-Part III. Neurosurgery, 62, 1286-1295. http://dx.doi.org/10.1227/01.neu.0000333300.34189.74

Van Boven, R., Harrington, G., Hackney, D., Ebel, A., Gauger, G., Bremner, J. D. et al. (2009). Advances in Neuroimaging of Traumatic Brain Injury and Posttraumatic Stress Disorder. Journal of Rehabilitation Research and Development, 46, 717-757. http://dx.doi.org/10.1682/JRRD.2008.12.0161

van den Burg, W., \& Kingma, A. (1999). Performance of 225 Dutch School Children on Rey’s Auditory Verbal Learning test (AVLT): Parallel Test-Retest Reliabilities with an Interval of 3 Months and Normative Data. Archives of Clinical Neuropsychology, 14, 545-559.

van Reekum, R., Cohen, T., \& Wong, J. (2000). Can Traumatic Brain Injury Cause Psychiatric Disorders? The Journal of Neuropsychiatry and Clinical Neurosciences, 12, 316-327. http://dx.doi.org/10.1176/appi.neuropsych.12.3.316

Varney, N. R., Roberts, R. J., Struchen, M. A., Hanson, T. V., Franzen, K. M., \& Connell, S. K. (1996). Design Fluency among Normals and Patients with Closed Head Injury. Archives of Clinical Neuropsychology, 11, 345-353. http://dx.doi.org/10.1093/arclin/11.4.345

Vickery, C. D., Berry, D. T., Inman, T. H., Harris, M. J., \& Orey, S. A. (2001). Detection of Inadequate Effort on Neuropsychological Testing: A Meta-Analytic Review of Selected Procedures. Archives of Clinical Neuropsychology, 16, 45-73.

Vilkki, J., Holst, P., Ohman, J., Servo, A., \& Heiskanen, O. (1990). Social Outcome Related to Cognitive Performance and Computed Tomographic Findings after Surgery for a Ruptured Intracranial Aneurysm. Neurosurgery, 26, 579-584. http://dx.doi.org/10.1227/00006123-199004000-00004

von Cramon, D. Y., Matthes-von Cramon, G., \& Mai, N. (1991). Problem-Solving Deficits in Brain Injured Patients. A Therapeutic Approach. Neuropsychological Rehabilitation: An International Journal, 1, 45-64. http://dx.doi.org/10.1080/09602019108401379

Vos, P. E., Battistin, L., Birbamer, G., Gerstenbrand, F., Potapov, A., Prevec, T. et al. (2002). EFNS Guideline on Mild Traumatic Brain Injury: Report of an EFNS Task Force. European Journal of Neurology, 9, 207-219. http://dx.doi.org/10.1046/j.1468-1331.2002.00407.x

Wagner, A. K., Hammond, F. M., Sasser, H. C., Wiercisiewski, D., \& Norton, H. J. (2000). Use of Injury Severity Variables in Determining Disability and Community Integration after Traumatic Brain Injury. The Journal of Trauma, 49, 411-419. http://dx.doi.org/10.1097/00005373-200009000-00005

Walker, A.J., Onus, M., Doyle, M., Clare, J., \& McCarthy, K. (2005). Cognitive Rehabilitation after Severe Traumatic Brain Injury: A Pilot Programme of Goal Planning and Outdoor Adventure Course Participation. Brain Injury, 19, 1237-1241. http://dx.doi.org/10.1080/02699050500309411

Warden, D., Gordon, B., McAllister, T., Silver, J., Barth, J., Bruns, J. et al. (2006). Guidelines for the Pharmacologic Treatment of Neurobehavioral Sequelae of Traumatic Brain Injury. Journal of Neurotrauma, 23, 1468-1501. http://dx.doi.org/10.1089/neu.2006.23.1468

Warriner, E., \& Velikonja, D. (2006). Psychiatric Disturbances after Traumatic Brain Injury: Neurobehavioral and Personality Changes. Current Psychiatry Reports, 8, 73-80. http://dx.doi.org/10.1007/s11920-006-0083-2

Watt, S., Shores, E. A., Baguley, I., Dorsch, N., \& Fearnside, M. (2006). Protein S-100 and Neuropsychological Functioning Following Severe Traumatic Brain Injury. Brain Injury, 20, 1007-1017. http://dx.doi.org/10.1080/02699050600909698

Webb, P. M., \& Glueckauf, R. L. (1994). The Effects of Direct Involvement in Goal Setting on Rehabilitation Outcome for Person with Traumatic Brain Injuries. Rehabilitation Psychology, 39, 179-188.

Wechsler, D. (2008). Wechsler Adult Intelligence Scale (4th ed.). San Antonio, TX: Pearson.

Wechsler, D. (2009). Wechsler Memory Scale (4th ed.). San Antonio, TX: Pearson.

Weinstein, M., Silverstein, M. L., Nader, T., \& Turnbull, A. (1999). Sustained Attention and Related Perceptuomotor Functions. Perceptual and Motor Skills, 89, 387-388. http://dx.doi.org/10.2466/pms.1999.89.2.387

Wheaton, P., Mathias, J. L., \& Vink, R. (2009). Impact of Early Pharmacological Treatment on Cognitive and Behavioral Outcome after Traumatic Brain Injury in Adults: A Meta-Analysis. Journal of Clinical Psychopharmacology, 29, $468-477$. 
http://dx.doi.org/10.1097/JCP.0b013e3181b66f04

Whisman, M. A., Perez, J. E., \& Ramel, W. (2000). Factor Structure of the Beck Depression Inventory-Second Edition (BDI-II) in a Student Sample. Journal of Clinical Psychology, 56, 545-551. http://dx.doi.org/10.1002/(SICI)1097-4679(200004)56:4<545::AID-JCLP7>3.0.CO;2-U

Whiteneck, G., Gerhart, K., \& Cusick, C. (2004). Identifying Environmental Factors That Influence the Outcomes of People with Traumatic Brain Injury. The Journal of Head Trauma Rehabilitation, 19, 191-204. http://dx.doi.org/10.1097/00001199-200405000-00001

Whyte, J., Hart, T., Schuster, K., Fleming, M., Polansky, M., \& Coslett, H. B. (1997). Effects of Methylphenidate on Attentional Function after Traumatic Brain Injury. A Randomized, Placebo-Controlled Trial. American Journal of Physical Medicine Rehabilitation, 76, 440-450. http://dx.doi.org/10.1097/00002060-199711000-00002

Whyte, J., Hart, T., Vaccaro, M., Grieb Neff, P., Risser, A., Polansky, M. et al. (2004). Effects of Methylphenidate on Attention Deficits after Traumatic Brain Injury: A Multidimensional, Randomized, Controlled Trial. American Journal of Physical Medicine Rehabilitation, 83, 401-420. http://dx.doi.org/10.1097/01.PHM.0000128789.75375.D3

Wilde, E. A., McCauley, S. R., Hunter, J. V., Bigler, E. D., Chu, Z., Wang, Z. J. et al. (2008). Diffusion Tensor Imaging of Acute Mild Traumatic Brain Injury in Adolescents. Neurology, 70, 948-955. http://dx.doi.org/10.1212/01.wnl.0000305961.68029.54

Wilde, E., Whiteneck, G., Bogner, J., Bushnik, T., Cifu, D., Dikmen, S. et al. (2010). Recommendations for the Use of Common Outcome Measures in Traumatic Brain Injury Research. Archives of Physical Medicine and Rehabilitation, 91, 1650-1660.e17. http://dx.doi.org/10.1016/j.apmr.2010.06.033

Wilkie, F., Goodkin, K., Khamis, I., van Zuilen, M., Lee, D., Lecusay, R. et al. (2003). Cognitive Functioning in Younger and Older HIV-1-Infected Adults. Journal of Acquired Immune Deficiency Syndromes, 33, S93-S105. http://dx.doi.org/10.1097/00126334-200306012-00006

Willer, B., Ottenbacher, K. J., \& Coad, M. L. (1994). The Community Integration Questionnaire. A Comparative Examination. American Journal of Physical Medicine Rehabilitation, 73, 103-111. http://dx.doi.org/10.1097/00002060-199404000-00006

Woischneck, D., \& Firsching, R. (1998). The Efficiency of the Glasgow Outcome Scale (GOS)-Score for the Long-Term Follow-Up after Severe Brain Injuries. Acta Neurochir Supplement, 71, 138-141.

Writer, B.W., \& Schillerstrom, J.E. (2009). Psychopharmacological Treatment for Cognitive Impairment in Survivors of Traumatic Brain Injury: A Critical Review. Journal of Neuropsychiatry and Clinical Neuroscience, 21, 362-370. http://dx.doi.org/10.1176/jnp.2009.21.4.362

Yamamoto, Y. L., Thompson, C. J., Meyer, E., Robertson, J. S., \& Feindel, W. (1977). Dynamic Positron Emission Tomography for Study of Cerebral Hemodynamics in A Cross Section of the Head Using Positron-Emitting 68Ga-EDTA and 77Kr. Journal of Computer Assisted Tomography, 1, 43-56. http://dx.doi.org/10.1097/00004728-197701000-00007

Ylvisaker, M., Turkstra, L., Coehlo, C., Yorkston, K., Kennedy, M., Sohlberg, M. et al. (2007). Behavioural Interventions for Children and Adults with Behaviour Disorders after TBI: A Systematic Review of the Evidence. Brain Injury, 21, 769-805. http://dx.doi.org/10.1080/02699050701482470

Zafonte, R. D., Hammond, F. M., Mann, N. R., Wood, D. L., Black, K. L., \& Millis, S. R. (1996). Relationship between Glasgow Coma Scale and Functional Outcome. American Journal of Physical Medicine Rehabilitation, 75, 364-369. http://dx.doi.org/10.1097/00002060-199609000-00012

Zatzick, D., Rivara, F., Jurkovich, G., Hoge, C., Wang, J., Fan, M. et al. (2010). Multisite Investigation of Traumatic Brain Injuries, Posttraumatic Stress Disorder, and Self-Reported Health and Cognitive Impairments. Archives of General Psychiatry, 67, 1291-1300. http://dx.doi.org/10.1001/archgenpsychiatry.2010.158

Zhang, J., Yoganandan, N., Pintar, F., \& Gennarelli, T. (2006). Role of Translational and Rotational Accelerations on Brain Strain in Lateral Head Impact. Biomedical Sciences Instrumentation, 42, 501-506.

Zhang, L., Plotkin, R., Wang, G., Sandel, M. E., \& Lee, S. (2004). Cholinergic Augmentation with Donepezil Enhances Recovery in Short-Term Memory and Sustained Attention after Traumatic Brain Injury. Archives of Physical Medicine and Rehabilitation, 85, 1050-1055. http://dx.doi.org/10.1016/j.apmr.2003.10.014

Zhang, Q., \& Sachdev, P. (2003). Psychotic Disorder and Traumatic Brain Injury. Current Psychiatry Reports, 5, $197-201$. http://dx.doi.org/10.1007/s11920-003-0042-0

Zink, B. J. (1996). Traumatic Brain Injury. Emergency Medicine Clinics of North America, 14, 115-150. http://dx.doi.org/10.1016/S0733-8627(05)70241-8 